Universidade de São Paulo

Instituto de Física de São Carlos

Isabela Almeida Silva

\title{
Medida da dinâmica de correlações quânticas em ressonância magnética nuclear
}



Isabela Almeida Silva

\section{Medida da dinâmica de correlações quânticas em ressonância magnética nuclear}

Dissertação apresentada ao Programa de PósGraduação em Física do Instituto de Física de São Carlos da Universidade de São Paulo, para obtenção do título de mestre em Ciências.

Área de Concentração: Física Básica

Orientador: Prof. Dr. Eduardo Ribeiro de Azevedo

Versão Corrigida

(versão original disponível na Unidade que aloja o Programa)

São Carlos 
AUTORIZO A REPRODUÇÃO E DIVULGAÇÃO TOTAL OU PARCIAL DESTE TRABALHO, POR QUALQUER MEIO CONVENCIONAL OU ELETRÔNICO, PARA FINS DE ESTUDO E PESQUISA, DESDE QUE CITADA A FONTE.

Ficha catalográfica elaborada pelo Serviço de Biblioteca e Informação do IFSC, com os dados fornecidos pelo(a) autor(a)

Silva, Isabela Almeida

Medida da dinâmica de correlações quânticas em ressonância magnética nuclear / Isabela Almeida Silva; orientador Eduardo Ribeiro de Azevedo - versão corrigida -- São Carlos, 2013.

$114 \mathrm{p}$.

Dissertação (Mestrado - Programa de Pós-Graduação em Física Básica) -- Instituto de Física de São Carlos, Universidade de São Paulo, 2013.

1. Informação quântica. 2. Ressonância magnética nuclear. 3. Mecanismos de decoerência. 4. Discórdia quântica. I. deAzevedo, Eduardo Ribeiro, orient. II. Título. 


\section{AGRADECIMENTOS}

Sonho que se sonha só, é só um sonho que se sonha só. Mas sonho que se sonha junto é realidade.

Raul Seixas

Em primeiro lugar agradeço a Deus por seu amor e misericórdia que sempre estiveram presentes em minha vida e dirigiram meus passos até aqui.

Agradeço aos meus pais, Dário e Vera, por sempre terem me apoiado e ajudado. Obrigada pelos conselhos, o amor, a dedicação com que sempre cuidaram de mim e o investimento. Também agradeço à minha irmã Rebeca pelo carinho e apoio. E a todos os meus familiares (avós, tios e primos) que sempre estiveram presentes na minha vida.

Ao meu orientador Prof. Dr. Eduardo Ribeiro de Azevêdo, agradeço pela confiança de me aceitar como aluna, pela dedicação ao trabalho, cuidado e pela paciência para ensinar e discutir os problemas. E ao Prof. Dr. Diogo Soares Pinto que também me orientou neste trabalho, obrigada pelo empenho e motivação que sempre me animaram a prosseguir.

Aos colegas de sala, Márcio, Oigres, Tião, Vô e Jaciara, minha gratidão pela companhia, ajuda, brincadeiras, músicas e piadas. Aos colegas Rodrigo e Arthur por me cederem a amostra de SDS utilizada nos experimentos de spin 3/2. Ao Prof. Dr. Ruben Auccaise pela colaboração na realização dos experimentos de spin $1 / 2$, bem como ao grupo de Informação Quântica do Centro Brasileiro de Pesquisas Físicas - CBPF, local onde estes experimentos foram realizados. E aos demais amigos e colegas que tive o prazer de conhecer no Instituto de Física de São Carlos, obrigada por tornaram esta jornada mais divertida e tranquila. Agradeço também ao colega Thiago Mosqueiro pela ajuda com o template de latex desta dissertação.

Aos amigos da Igreja Presbiteriana de São Carlos pelo acolhimento e por se tornarem a minha família em São Carlos. E à todos os amigos de longe, em especial às minhas irmãs de coração Natália e Rayssa com quem sempre pude contar.

Agradeço ainda ao Instituto de Física de São Carlos pela estrutura e apoio financeiro que permitiram a realização desta pesquisa e à CAPES por me conceder a bolsa de estudos. 



\section{RESUMO}

SILVA, I.A. Medida da dinâmica de correlações quânticas em ressonância magnética nuclear. 2013. 115 p. Dissertação (Mestrado em Ciências) - Instituto de Física de São Carlos, Universidade de São Paulo, São Carlos, 2013.

Nesta dissertação apresentamos um estudo dos mecanismos de decoerência de sistemas quânticos de Ressonância Magnética Nuclear (RMN) e os seus efeitos sobre a evolução temporal das medidas de correlação não-clássica. Para tal, apresentaremos inicialmente uma revisão bibliográfica sobre alguns dos diversos quantificadores de discórdia quântica, tais como discórdia entrópica, geométrica e negatividade do caráter quântico. Para descrever os canais de atenuação de fase e de amplitude generalizada, que descrevem a relaxação de sistemas de RMN, utilizamos o formalismo de operações quânticas, através da descrição dos operadores de Kraus. As implementações experimentais foram realizadas a partir de sistemas de $2 \mathrm{q}$-bits descritos por sistemas de RMN de 2 spins $1 / 2$ acoplados via acoplamento $\mathrm{J}$ e sistemas de spins $3 / 2$ sujeitos ao acoplamento quadrupolar. Experimentalmente, observamos o surgimento do fenômeno de congelamento (freezing) da discórdia quântica para o sistema de 2 spins $1 / 2$ e o fenômeno de duplo sudden-change em um sistema de spin $3 / 2$. Além disso, propuzemos um método de medida direta para os elementos da matriz densidade de um sistema de 2 spins $1 / 2$ acoplados via acoplamento J, que permite obter toda a informação necessária para o cálculo dos quantificadores de discórdia sem que seja preciso reconstruir completamente a matriz densidade, ou seja, sem empregar o dispendioso método de tomografia de estado quântico (TEQ).

PALAVRAS-ChAVE: Informação quântica. Ressonância magnética nuclear. Mecanismos de decoerência. Discórdia quântica. 



\section{ABSTRACT}

SILVA, I.A. Measurement of quantum correlations dynamics in nuclear magnetic resonance. 2013. 115 p. Dissertação (Mestrado em Ciências) - Instituto de Física de São Carlos, Universidade de São Paulo, São Carlos, 2013.

We present a study of the decoherence processes in Nuclear Magnetic Resonance (NMR) quantum systems and their effects on the temporal evolution of non-classical correlations. For that, we review some quantum discord quantifiers, such as entropic and geometric discord as well as negativity of quantumness. To describe the relaxation of NMR systems, we use Kraus operators phase and generalized amplitude damping channels. The experimental demonstrations were achieved in 2 qubits systems implemented by $\mathrm{J}$ coupled spins $1 / 2$ as well as spins $3 / 2$ subject to quadrupolar interaction. We demonstrate the freezing phenomenon of quantum discord in a 2 spins $1 / 2$ system, subject to phase and amplitude damping channel, and the phenomenon of double sudden-change in a spin $3 / 2$ system, subject to amplitude damping channel. Furthermore, for spin $1 / 2$ system, we introduce a method to selectively measure density matrix elements, that provide the necessary information to calculate discord quantifiers, without needing the full reconstruction provided by usual quantum state tomography.

KEYWORDS: Quantum information. Nuclear magnetic resonance. Decoherence. Quantum discord. 



\section{LISTA DE FIGURAS}

2.1 Diagrama de transformação de coordenadas.

2.2 Esquema dos níveis de energia de um sistema sujeito ao acoplamento J]. .

2.3 Esquema dos níveis de energia de um sistema sujeito à interação quadrupolar

2.4 Representação esquemática de um espectrômetro de RMN de alta resolução.

2.5 Esquema para a sonda de um espectrômetro de RMN.

2.6 Correspondência entre a fase da radiofrequência $\left(\phi_{n}\right)$ e o eixo de rotação da magnetização no plano $x y$ após a aplicação deste pulso. . . . . . . . . . p. 35

2.7 Esfera de Bloch

3.1 Fluxograma descrevendo o programa de otimização de SMPs.

3.2 Ilustração da técnica de tomografia de estado quântico para spin $1 / 2$

3.3 Ilustração da técnica de tomografia de estado quântico para spin $3 / 2$. . .

4.1 Diagrama de Venn representando a informação mútua total de um sistema

4.2 Representação esquemática para as medidas de entropia relativa.

5.1 Dinâmica das correlações de um estado sujeito ao canal de atenuação de fase

5.2 Previsão teórica para a discórdia geométrica de um estado sujeito aos canais de atenuação de fase e de amplitude generalizada

5.3 Previsão teórica para os efeitos do canal de atenuação de fase sobre a medida de negatividade do caráter quântco.

5.4 Previsão teórica para os efeitos do canal de atenuacão de amplitude generalizada sobre a medida de negatividade do caráter quântico. . . . . . . . . . . p.84

6.1 Representacão esquemática dos experimentos de RMN voltados para o estudo da relaxação de sistema quânticos. . . . . . . . . . . . . . . . . . p. 88

6.2 Seqüência de pulsos para realização do método de medida direta . . . . . . . p. 89

6.3 Representação esquemática da molécula de $\mathrm{CHCl}_{3} \ldots \ldots$. . . . . . . . . . p. 92 
6.4 Matrizes densidade de desvio implementadas experimentalmente para medidas de freezing . . . . . . . . . . . . . . . . . . . . . . . p.93

6.5 Resultados experimentais para a discórdia geométrica $\ldots \ldots$. . . . . . . . p. 94

6.6 Resultados experimentais para a negatividade de um estado em um sistema de 2 spins $1 / 2$ acoplados. . . . . . . . . . . . . . . . . . . . p. p 96

6.7 Resultados experimentais para a discórdia entrópica $\quad \ldots \quad \ldots \quad \ldots \quad \ldots \quad$. . . . 97

6.8 Matrizes densidade de desvio implementadas experimentalmente para medidas de double sudden-change . . . . . . . . . . . . . . . . . . . . . . . . p.99

6.9 Resultados experimentais para a negatividade de um estado em um sistema de spins $3 / 2 \ldots \ldots \ldots$. . . . . . . . . . . . . . . . . . . . . . . . . . p. 100 


\section{LISTA DE TABELAS}

2.1 Operadores de Kraus . . . . . . . . . . . . . . . . . . . . . . p. 42

4.1 Classificacão de Estados em termos da presença ou ausência de emaranhamento e discórdia . . . . . . . . . . . . . . . . . . . . . p. 63

6.1 Ângulos de rotação para medida direta das correlações quânticas $\quad$. . . . . p. p. 89 



\section{SUMÁRIO}

1 Introdução

2 Elementos de Ressonância Magnética Nuclear

2.1 Interação com Campos Magnéticos Externos

2.2 Interação

2.3 Interação Quadrupolar

2.4 Operadores de Rotação

2.5 Operador Densidade

2.6 Relaxação de Sistemas de RMN

2.7 Detecção do Sinal de RMN

2.8 RMN no contexto de Informação Quântica

3 Ferramentas para o Processamento de Informação Quântica via RMN

3.1 Estados Pseudo-Puros

3.2 Pulsos Fortemente Modulados (SMP).

3.3 Tomografia de Estado Quântico (TEQ)

4 Medidas de Correlação Quântica

4.1 Correlação Clássica x Correlação Quântica

4.2 Discórdia Geométrica

4.3 Negatividade 
5.2 Sistema de 2 q-bits representados por Spins $1 / 2$ Acoplados . . . . . . . p. 79

5.3 Sistema de $\operatorname{Spin} 3 / 2 \ldots \ldots \ldots \ldots \ldots$ p. 83

6 Medida de Observável de Correlações Quânticas $\quad$ p. 87

6.1 Método de Medida Direta . . . . . . . . . . . . . . . . p. 87

6.2 Comprovação experimental para o fenômeno de Freezing das correlações quânticas . . . . . . . . . . . . . . . . . . . p. 91

6.3 Fenômeno de Duplo Sudden-Change . . . . . . . . . . . . . . . . . . . p. 99

7 Conclusões e Perspectivas $\quad$ p. 103

$\begin{array}{lr}\text { REFERÊNCIAS } & \text { p. } 107\end{array}$ 


\section{Capítulo 1}

\section{Introdução}

As propriedades quânticas de sistemas físicos, como elétrons, núcleos e pacotes de luz, podem ser exploradas para fornecer grandes desenvolvimentos do ponto de vista da tecnologia de informação e comunicação. No entanto, a pesquisa por trás da tecnologia quântica ainda está pouco desenvolvida. O emaranhamento certamente desempenha um papel importante neste campo, tendo sido por muito tempo considerado fundamental para que a exploração das características quânticas resultassem em avanços tecnológicos. No entanto, a obtenção de resultados incompatíveis com descrições puramente clássicas a partir de estados separáveis (não emaranhados), mostrou que o emaranhamento é apenas a ponta do iceberg. Assim, abriu-se um novo caminho para o estudo de correlações quânticas mais gerais.

Neste contexto, vale à pena ressaltar a importância do trabalho de Knill e Laflamme sobre o modelo de computação DQC1 (1), no qual um algoritmo quântico utilizando estados mistos para a determinação do traço normalizado de uma matriz poderia fornecer um ganho exponencial de eficiência em relação aos algoritmos clássicos. A partir daí iniciou-se uma corrida para estudar e descrever os outros tipos de correlações quânticas, diferentes do emaranhamento. Em 2001, Henderson e Vedral (2) e Ollivier e Zurek (3) introduziram, a partir de medidas de entropia, um dos mais importantes quantificadores destas correlações, denominado de Discórdia Quântica Entrópica. No entanto, o cálculo da discórdia quântica definida por estes autores torna-se complicado por envolver processos de extremização sobre os conjuntos de projetores de medida. Por esta razão, muitos outros quantificadores tem sido propostos. De forma geral, estes quantificadores estão relacionados à medidas da entropia do sistema, medidas geométricas e medidas do emaranhamento criado entre o sistema e o instrumento de medida $(3-5)$.

Devido à grande facilidade de controle sobre os estados de spins nucleares, uma das técnicas amplamente utilizadas no estudo de informação quântica é a técnica de Ressonância Magnética Nuclear (RMN). Porém, sistemas de RMN não constituem estados puros mas misturas estatísticas e por esta razão não é possível construir estados emaranhados a partir de sistemas de RMN à temperatura ambiente (utilizando-se técnicas convencionais). Contudo, estes sistemas podem ser usados para estudar a existência das outras formas de correlação quântica nos estados separáveis. 
No entanto, apenas preparar estados que inicialmente apresentem correlações não-clássicas não é suficiente para a implementação bem sucedida de protocolos quânticos. Como os sistemas não estão isolados do restante do universo, com o passar do tempo essas correlações serão destruídas, o que ocorre de diversas formas dependendo do sistema que está sendo tratado.

Assim, o objetivo deste trabalho é estudar as correlações não-clássicas de sistemas de 2 q-bits e a forma como estas correlações são afetadas pelos processos de relaxação. Em RMN, é possível descrever sistemas de 2 q-bits através de um sistema de 2 spins $1 / 2$ acoplados via acoplamento J e também através de um sistema de spins $3 / 2$ afetado pelo acoplamento quadrupolar. Em cada um desses casos observa-se a presença de um banho de fase distinto, por esta razão estudaremos separadamente cada um destes sistemas observando as diferentes propriedades que cada um destes banhos induz nas correlações quânticas de algumas classes de estados.

Em geral, implementações experimentais na área de informação quântica envolvem o emprego do método de Tomografia de Estado Quântico (TEQ), o que permite reconstruir completamente a matriz densidade do sistema e com isto ter acesso a toda a informação contida nele. No entanto, apesar de eficiente este método pode se tornar dispendioso em termos do tempo de experimento necessário para se obter a completa relaxação de um sistema e também o fato de envolver certos tratamentos matemáticos no processo de reconstrução da matriz a partir dos dados coletados. Porém, em certos casos de interesse, não é necessário conhecer toda a matriz densidade do sistema para se calcular certos quantificadores de correlação quântica, mas apenas algumas de suas correlações. Com isto, desenvolvemos o método de medida direta que, a partir de uma sequência de pulsos específica, nos permite medir estas correlações e calcular diretamente o quantificadores de discórdia. Nosso segundo objetivo é, então, apresentar e validar a utilização deste método.

Assim, esta dissertação encontra-se dividida em 7 capítulos, onde o primeiro corresponde à esta introdução. No capítulo 2 apresentaremos uma rápida exposição a cerca dos tipos de interação encontrados em sistemas de RMN e relevantes para este trabalho, a saber a interação J, interação quadrupolar e a interação com campo de rádio frequência. Também apresentaremos os formalismos de operadores de rotação e operador densidade. Em seguida, descreveremos a relaxação dos sistema de RMN de forma fenomenológica, apresentando com isso as equações de Bloch. Uma breve exposição a cerca da detecção do sinal de RMN será feita para introduzir alguns conceitos importantes que serão utilizados no decorrer do trabalho. Por fim, apresentaremos alguns conceitos de RMN no contexto de informação quântica e introduziremos o formalismo de operações quânticas via operadores de Kraus para descrever 
os processos de relaxação.

No capítulo 3 discutiremos algumas das ferramentas utilizadas nos experimentos de RMN no campo de informação quântica. Para isso apresentaremos o conceito de estados pseudopuros, a técnica de Pulsos Fortemente Modulados (SMP), que utilizaremos como parte da preparação de estados iniciais, e a técnica de Tomografia de Estado Quântico (TEQ).

Uma revisão bibliográfica a cerca dos quantificadores da discórdia quântica será apresentada no capítulo 4, onde discutiremos com detalhes as discórdias entrópia e geométrica e o quantificador da negatividade do caráter quântico. No capítulo 5 serão discutidos os efeitos dos processos de decoerência sobre estes quantificadores de discórdia, onde nosso foco estará nos processos de relaxação encontrados em sistemas de RMN. Com isso, apresentaremos as condições teóricas para o surgimento de fenômenos interessantes como de congelamento (freezing) e mudança súbita (double sudden-change) no comportamento da discórdia.

No capítulo 6 estão colocados os resultados experimentais. Em primeiro lugar, para alguns estados de interesse, faremos a comparação entre a relaxação dos quantificadores de discórdia obtida através da medida direta com os resultados para a tomografia. E em seguida, apresentaremos algumas propriedades interessantes como os fenômenos de freezing e sudden-change. Por fim, no capítulo 7 apontaremos nossas conclusões e perspectivas. 


\section{Elementos de Ressonância Magnética Nuclear}

O fenômeno de ressonância magnética nuclear (RMN) consiste basicamente da interação dos spins nucleares com campos magnéticos que podem ser inerentes do sistema físico (interações internas), ou aplicados externamente (interações externas) (6-8). As principais interações internas são:

- Interação Zeeman nuclear: interação entre o momento de dipolo magnético do núcleo e os campos magnéticos que existirem ao seu redor. Em RMN dita de alto campo, o campo magnético aplicado é da ordem de Tesla, o que implica em uma interação da ordem de $\mathrm{MHz}$ e amplitude da ordem de alguns Gauss.

- Interação com campo de Rádio Frequência: interação entre o momento de dipolo magnético do núcleo e um campo magnético oscilante da ordem de $\mathrm{MHz}$.

Dependendo de suas aracterísticas físicas, o sistema será afetado por diferentes formas de interações internas. As principais delas são:

- Deslocamento Químico: está relacionado ao ambiente eletrônico, ou seja, a forma como o movimento orbital dos elétrons próximos induz um campo magnético local ao redor do núcleo. Para substâncias diamagnéticas, os valores de deslocamento químico, em geral, são da ordem de partes por milhão (ppm) da frequência Zeeman.

- Acoplamento Dipolar: interação direta através do espaço entre dois momentos de dipolo magnético criado pelo campo magnético de um deles na posição do outro. Em líquidos isotrópicos, os movimentos moleculares tornam esta interação desprezível. No entanto, em sólidos, o acoplamento é da ordem de dezenas de $\mathrm{kHz}$.

- Acoplamento Escalar J: interação indireta entre os momentos de dipolo magnético de núcleos vizinhos, mediada pelas nuvens eletrônicas em torno das espécies nucleares. A magnitude desta interação é da ordem de $0-10^{2} \mathrm{~Hz}$, e ocorre tanto no estado sólido como em líquidos. 
- Acoplamento Quadrupolar: interação entre o momento de quadrupolo elétrico do núcleo e o gradiente de campo elétrico existente devido à distribuição de cargas ao redor dele. Esta interação pode alcançar valores de magnitude de $10^{9} \mathrm{~Hz}$, ocorrendo apenas para núcleos com $I>1 / 2$.

Para o restante deste trabalho serão relevantes as interações externas: Zeeman Nuclear e a Interação com Campos de Rádio Freqüência, que apresentaremos com mais detalhe na seção 2.1 e as interações internas de Acoplamento J e Quadrupolar, seções 2.2 e 2.3, respectivamente. As seções 2.4, 2.5 e 2.6 são destinadas aos operadores de rotação, ao formalismo de operador densidade e à descrição da relaxação dos sistemas de RMN via equações de Bloch, respectivamente. Na seção 2.7 apresentaremos o processo experimental de detecção do sinal de RMN. Por fim, na seção 2.8 introduziremos alguns conceitos relativos ao estudo de informação quântica no contexto da RMN e o formalismo de operações quânticas, 2.8.1.

\subsection{Interação com Campos Magnéticos Externos}

O principal fenômeno que permite a existência da técnica de RMN é a interação Zeeman nuclear. A interação entre o momento de dipolo magnético nuclear e um campo magnético externo estático $\vec{B}_{0}$ faz com que os estados do núcleo assumam diferentes valores de energia dependendo da interação do spin nuclear com respeito à direção de $\vec{B}_{0}$.

A Hamiltoniana de interação Zeeman é descrita matematicamente por $H_{Z}=-\vec{\mu} \cdot \vec{B}_{0}=$ $-\hbar \gamma B_{0} I_{z}$, onde define-se a frequência de Larmor como sendo $\omega_{L}=\gamma B_{0}$, que corresponde à frequência de precessão do momento magnético quando este é submetido à um campo estático $\left(B_{0}\right)$. $\gamma$ é o fator giromagnético (característico de cada espécie nuclear) e $I_{z}$ o operador quântico definido a partir do campo principal $\vec{B}_{0}$. Assim, os autovalores da Hamiltoniana Zeeman são proporcionais aos autovalores do operador $I_{z}$,

$$
E_{m}=-m \hbar \omega_{L}
$$

Portanto, a interação Zeeman é responsável pela quebra da desgenerescência dos níveis de energia nucleares de forma que para um spin nuclear $I$ existem $2 I+1$ níveis de energia.

A excitação entre esses níveis de energia pode ser induzida através da aplicação de campos 
magnéticos oscilantes (em ressonância com a frequência de Larmor apropriada, $\omega_{L}=\gamma B_{0}$ ). No caso de spins nucleares, na presença de um campo externo estático da ordem de alguns Tesla, a frequência Larmor é da ordem de $\mathrm{MHz}$, portanto a excitação pode ser feita através de campos de rádio-frequência (RF) (6).

A descrição do comportamento de um spin na presença de um campo magnético estático é dada pela Hamiltoniana independente do tempo $H_{Z}=-\hbar \gamma B_{0} I_{z}$, logo a solução geral da equação de Schrödinger dependente do tempo será dada por (9),

$$
\psi(r, t)=\sum_{m=-I}^{I} c_{m} u_{I, m}(\vec{r}) e^{-i E_{m} t / \hbar}
$$

onde $c_{m}$ são constantes complexas e $u_{I, m}(\vec{r})$ são as soluções da equação independente do tempo. Então, a magnetização média, por exemplo na direção- $x$, corresponde à

$$
\left\langle\mu_{x}(t)\right\rangle=\int \psi^{*}(\vec{r}, t) \mu_{x} \psi(\vec{r}, t) d^{3} r .
$$

Se a este campo estático $\vec{B}_{0}$ adicionarmos um campo de RF alternado $\vec{B}_{1}(t)$, tal que

$$
\vec{B}_{1}(t)=B_{1}\left[\cos (\Omega t) \hat{x}_{\phi}+\sin (\Omega t) \hat{y}_{\phi}\right]
$$

onde $\Omega$ é a frequêcia do campo de RF e os versores $\hat{x}_{\phi}$ e $\hat{y}_{\phi}$ indicam a direção do campo $B_{1}$ em relação ao referencial do laboratório, de forma que

$$
\begin{aligned}
& \hat{x}_{\phi}=\cos \phi \hat{x}_{l a b}+\sin \phi \hat{y}_{l a b} \\
& \hat{y}_{\phi}=-\sin \phi \hat{x}_{l a b}+\cos \phi \hat{y}_{l a b},
\end{aligned}
$$

como ilustrado na Figura 2.1.

Então, substituindo estes resultados na equação de Schrödinger para $\vec{B}_{0}+\vec{B}_{1}(t)$,

$$
\begin{aligned}
-\frac{\hbar}{i} \frac{\partial \psi}{\partial t} & =-(\vec{\mu} \cdot \vec{B}) \psi \\
& =-\gamma \hbar\left\{B_{0} I_{z}+B_{1} I_{x_{\phi}^{\prime}}\right\} \psi,
\end{aligned}
$$

onde $I_{x_{\phi}^{\prime}}=I_{x_{\phi}} \cos (\Omega t)+I_{y_{\phi}} \sin (\Omega t)$ é o operador de spin escrito em termos do referencial da fase $\phi$ do campo. Como esta hamiltoniana apresenta dependência temporal, esta equação não é de fácil resolução. No entanto, sendo $e^{-i \Omega I_{z} t}$ um operador de rotação, então podemos escrever $I_{x_{\phi}^{\prime}}=e^{-i \Omega I_{z} t} I_{x_{\phi}} e^{i \Omega I_{z} t}$. Substituindo-se este resultado na Eq. (2.1.6) segue que

$$
-\frac{\hbar}{i} \frac{\partial \psi}{\partial t}=-\gamma \hbar\left\{B_{0} I_{z}+B_{1} e^{-i \Omega I_{z} t} I_{x_{\phi}} e^{-i \Omega I_{z} t}\right\} \psi
$$




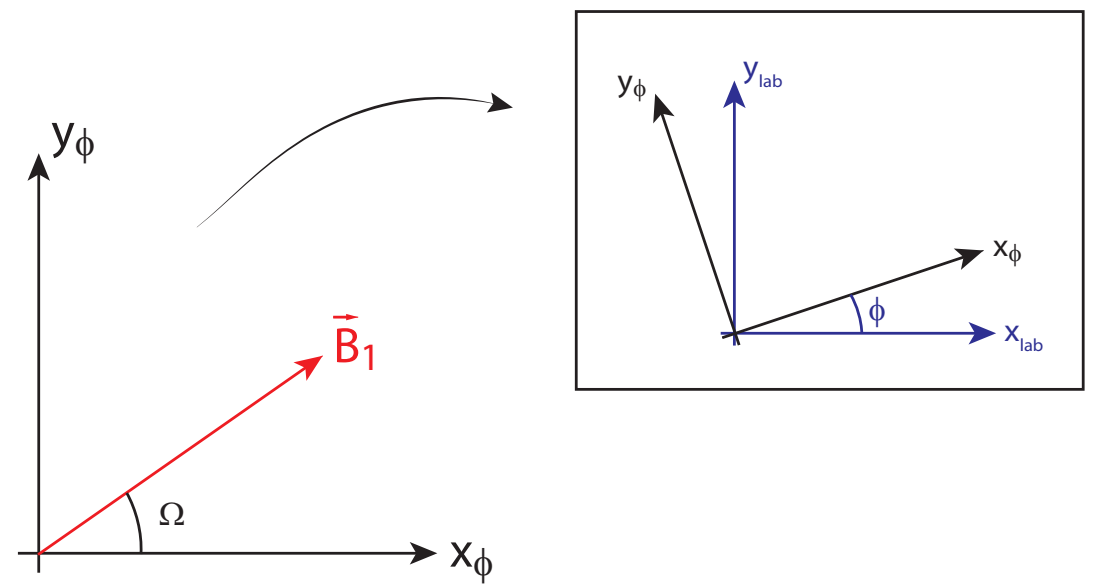

Figura 2.1 - Diagrama representando as transformações de coordenadas realizadas no tratamento de um sistema de RMN sujeito à um campo de RF qualquer, na presença de um campo magnético estático.

Para eliminarmos a dependência temporal da Hamiltoniana, definimos $\psi^{\prime}=e^{i \Omega I_{z} t} \psi$, o que implica em $\psi=e^{-i \Omega I_{z} t} \psi^{\prime}$. Com isto, a Eq. (2.1.7) pode ser reescrita como

$$
-\frac{\hbar}{i}\left[-i \Omega I_{z} e^{-i \Omega I_{z} t} \psi^{\prime}+e^{-i \Omega I_{z} t} \frac{\partial \psi^{\prime}}{\partial t}\right]=-\gamma \hbar\left[B_{0} I_{z}+B_{1} e^{-i \Omega I_{z} t} I_{x} e^{i \Omega I_{z} t}\right] e^{-i \Omega I_{z} t} \psi^{\prime}
$$

Multiplicando-se esta equação pela esquerda por $e^{i \Omega I_{z} t}$ e rearranjando-se os termos, encontramos que

$$
-\frac{\hbar}{i} \frac{\partial \psi^{\prime}}{\partial t}=-\left[\hbar\left(\Omega+\gamma B_{0}\right) I_{z}+\gamma \hbar B_{1} I_{x_{\phi}}\right] \psi^{\prime}
$$

onde usamos que $I_{z}=e^{-i \Omega I_{z} t} I_{z} e^{i \Omega I_{z} t}$.

Reescrevendo esta expressão em termos da fase inicial do campo $B_{1}$,

$$
I_{x_{\phi}}=I_{x} \cos \phi+I_{y} \sin \phi
$$

definimos o sistema de coordenadas girante no qual o campo efetivo experimentado pelo spin é descrito por (8)

$$
\vec{B}_{\text {efetivo }}=\hat{z}\left(B_{0}+\frac{\Omega}{\gamma}\right)+(\hat{x} \cos \phi+\hat{y} \sin \phi) B_{1},
$$

ou seja, para uma fase $\phi=0$ o campo $B_{1}$ encontra-se na direção $x$ e para $\phi=\pi / 2$ a direção será y. E a Hamiltoniana efetiva corresponde à

$$
H^{\prime}=-\left[\left(\hbar \Omega+\gamma \hbar B_{0}\right) I_{z}+\gamma \hbar B_{1} I_{x_{\phi}}\right] .
$$


Assim, se $\Omega=-\gamma B_{0}$ então o campo $\vec{B}_{1}$ está em ressonância com o sistema e, portanto, apesar de possuir intensidade muito menor que o campo estático $\left(B_{1} \ll B_{0}\right)$, apenas o seu efeito é sentido pelo spin.

Como, neste referencial, $H^{\prime}$ é independente do tempo, então a solução da equação de Schrödinger pode ser escrita como

$$
\psi^{\prime}(t)=e^{-i H^{\prime} t / \hbar} \psi^{\prime}(0)
$$

ou seja, a solução para o referencial inicial seria $\psi(t)=e^{-i \Omega I_{z} t} e^{-i H^{\prime} t / \hbar} \psi(0)$.

Assim, supondo que o campo foi aplicado em ressonância com o sistema, então $H^{\prime}=$ $-\gamma \hbar B_{1} I_{x_{\phi}}$ e a magnetização média na direção- $z$ será dada por

$$
\begin{aligned}
\left\langle\mu_{z}(t)\right\rangle & =\int \psi^{*}(t) \mu_{z} \psi(t) d^{3} r \\
& =\gamma \hbar \int \psi^{*}(0) e^{-i \gamma B_{1} I_{x} t} e^{i \Omega I_{z} t} I_{z} e^{-i \Omega I_{z} t} e^{i \gamma B_{1} I_{x} t} \psi(0) .
\end{aligned}
$$

Mas como

$$
\left\{\begin{array}{l}
e^{i \Omega I_{z} t} I_{z} e^{-i \Omega I_{z} t}=I_{z} \\
e^{-i \gamma B_{1} I_{x} t} I_{z} e^{i \gamma B_{1} I_{x} t}=-I_{y} \sin \left(\omega_{1} t\right)+I_{z} \cos \left(\omega_{1} t\right),
\end{array}\right.
$$

onde $\omega_{1}=\gamma B_{1}$, então

$$
\left\langle\mu_{z}(t)\right\rangle=\left\langle\mu_{z}(0)\right\rangle \cos \left(\omega_{1} t\right)-\left\langle\mu_{y}(0)\right\rangle \sin \left(\omega_{1} t\right)
$$

Logo, se em $t=0$ a magnetização está ao longo do eixo- $z$, então $\left\langle\mu_{y}(0)\right\rangle=0$ e, portanto

$$
\left\langle\mu_{z}(t)\right\rangle=\left\langle\mu_{z}(0)\right\rangle \cos \left(\omega_{1} t\right)
$$

Ou seja, no referencial girante, observamos o momento magnético rodando em torno do eixo- $x$ com frequência angular $\omega_{1}=\gamma B_{1}$. O ângulo $\theta$ que o momento magnético fará com o eixo- $z$ quando o campo alternado for desligado, dependerá do tempo $t_{\omega_{1}}$ durante o qual este campo esteve ligado $\left(\theta=\omega_{1} t_{\omega_{1}}\right)$.

No caso de um sistema heteronuclear, cada spin possui o seu próprio referencial girante, com sua respectiva frequência de rotação. 


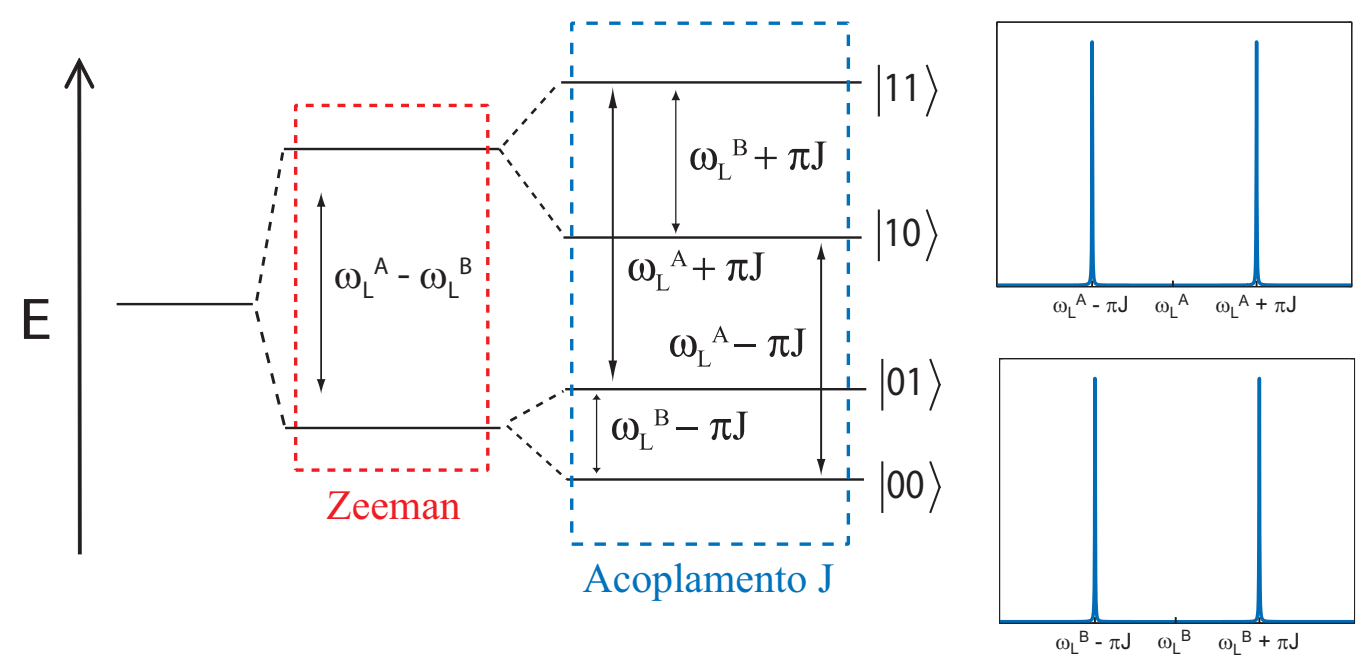

Figura 2.2 - Esquema dos quatro níveis de energia para um sistema de dois spins, $I$ e $S$, sujeitos à um campo externo (Efeito Zeeman) e ao acoplamento J. Observa-se o desdobramento das linhas devido apenas ao Efeito Zeeman e devido aos dois efeitos conjuntamente. Destaca-se também a associação entre cada nível de energia e a base binária de dois q-bits.

\subsection{Interação J}

Para o estudo de informação quântica em sistema de 2 qu-bits, a existência de interação entre eles é essencial. No contexto da técnica de RMN, uma das interações que nos permite estudar este tipo de sistema é a interação escalar J. Denotaremos por $I$ e $S$ os operadores de spin de cada uma das espécies nucleares, $I=S=1 / 2$, envolvidas nesta interação. Neste caso, estes operadores de spin comutam e agem em espaços vetoriais distintos (9) e a Hamiltoniana secular que descreve este acoplamento em sistemas líquidos heteronucleares pode ser escrita como o produto direto entre $I_{z}$ e $S_{z}$,

$$
H_{J}=2 \pi \hbar J I_{z} S_{z}
$$

onde, neste caso, $I_{z}=\frac{1}{2}\left(\sigma_{z} \otimes \mathbb{I}\right)$ e $S_{z}=\frac{1}{2}\left(\mathbb{I} \otimes \sigma_{z}\right)$ para $\sigma_{z}$ o operador de Pauli usual.

Assim, a hamiltoniana do sistema considerando-se as interações Zeeman e J, $H_{z}+H_{J}$, será

$$
H=-\hbar \omega_{I} I_{z}-\hbar \omega_{S} S_{z}+2 \pi \hbar J I_{z} S_{z}
$$

E os seus autoestados serão o produto direto dos autoestados dos operadores $I_{z}$ e $S_{z}$, que denotaremos por $\left|m_{I}, m_{S}\right\rangle$, com autovalores $m_{I}= \pm 1 / 2$ e $m_{S}= \pm 1 / 2$, respectivamente. 
Observa-se, então, a formação de quatro níveis de energia distintos, com autoenergias dadas por,

$$
\begin{gathered}
E_{+1 / 2,+1 / 2}=\hbar\left(-\frac{\omega_{I}}{2}-\frac{\omega_{S}}{2}+\frac{\pi J}{2}\right) \\
E_{+1 / 2,-1 / 2}=\hbar\left(-\frac{\omega_{I}}{2}+\frac{\omega_{S}}{2}-\frac{\pi J}{2}\right) \\
E_{-1 / 2,+1 / 2}=\hbar\left(\frac{\omega_{I}}{2}-\frac{\omega_{S}}{2}-\frac{\pi J}{2}\right) \\
E_{-1 / 2,-1 / 2}=\hbar\left(\frac{\omega_{I}}{2}+\frac{\omega_{S}}{2}+\frac{\pi J}{2}\right)
\end{gathered}
$$

A Figura 2.2 apresenta um esquema dos níveis destes níveis de energia e uma representação para os espectros dos observáveis diretos de RMN neste caso.

\subsection{Interação Quadrupolar}

Em sistemas de RMN de spin quadrupolar, $S>1 / 2$, os núcleos possuem momento de quadrupolo elétrico que interage com o gradiente de campo elétrico produzido pela distribuição de cargas ao seu redor, o que é conhecido como interação quadrupolar. A forma geral da Hamiltoniana desta interação, no caso da molécula estar arbitrariamente orientada (6)), é dada por

$$
H_{Q}=\frac{e Q}{2 I(2 I-1) \hbar} \vec{I} \cdot \overleftrightarrow{V} \cdot \vec{I}
$$

onde $Q$ é o momento de quadrupolo nuclear, $I$ é o número quântico de spin e $\overleftrightarrow{V}$ é o tensor que descreve o gradiente de campo elétrico. No referencial PAS*, este tensor é diagonal e seus elementos satisfazem,

$$
V_{x x}+V_{y y}+V_{z z}=0
$$

Nos casos em que a interação quadrupolar é muito menor que a interação Zeeman, $\left|\omega_{Q}\right| \ll$

\footnotetext{
* Sistema de eixos principais (principal axis system), no qual o operador é diagonal.
} 


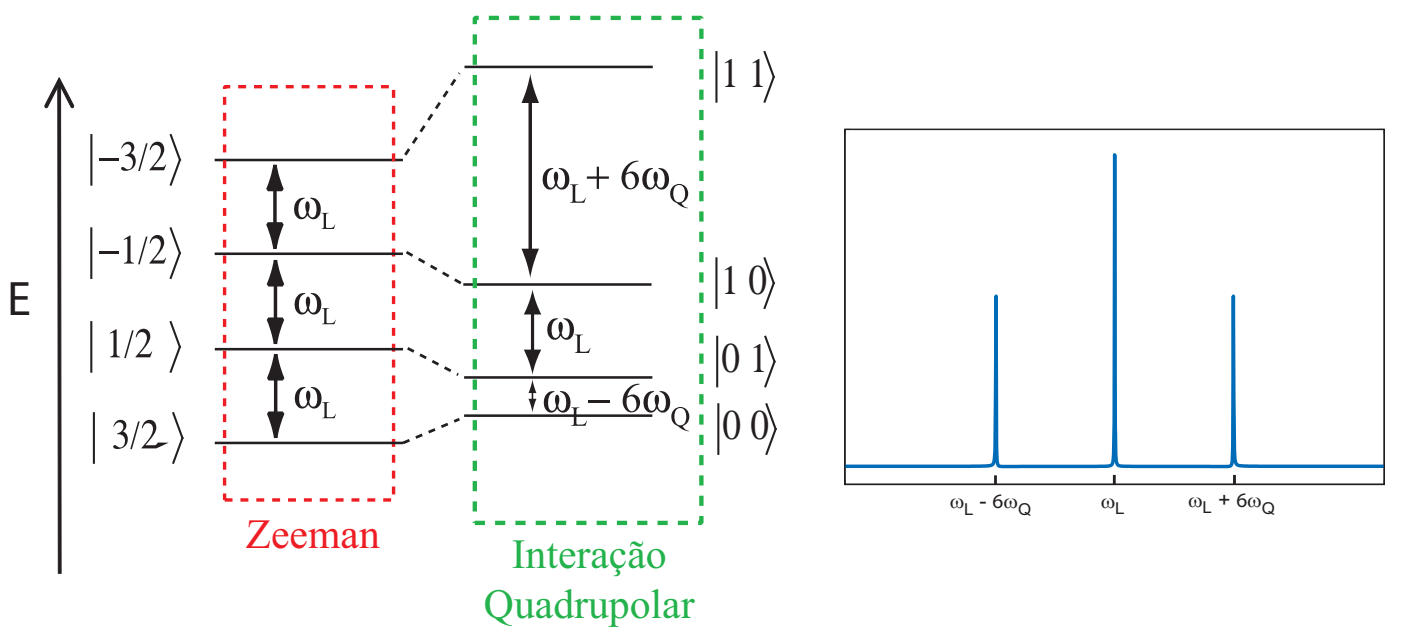

Figura 2.3 - Esquema dos quatro níveis de energia para um sistema de spin $\mathrm{I}=\frac{3}{2}$ considerando-se as interações Zeeman e quadrupolar. Também apresenta-se a associação entre os níveis de energia e a base lógica de dois q-bits.

$\left|\omega_{0}\right|$, esta Hamiltoniana pode ser aproximada, em primeira ordem de perturbação, por

$$
H_{Q}=\frac{e^{2} q Q}{4 I(2 I-1)}\left[3 I_{z}^{2}-I(I+1) \mathbb{I}+\frac{\eta_{Q}}{2}\left(I_{+}^{2}+I_{-}^{2}\right)\right]
$$

onde $e q=V_{z z}$ e $\eta_{Q}=\frac{V_{x x}-V_{y y}}{V_{z z}}$ é o parâmetro de assimetria do acoplamento quadrupolar. No entanto, a simetria dos cristais líquidos que serão utilizados neste trabalho permite considerar $\eta_{Q}=0$. Assim, segue que, a Hamiltoniana do sistema é dada por

$$
H=H_{Z}+H_{Q}=-\hbar \omega_{L} I_{z}+\hbar \frac{\omega_{Q}}{6}\left[3 I_{z}^{2}-I(I+1) \mathbb{I}\right]
$$

onde $\omega_{Q}=\frac{3 e^{2} q Q}{2 I(2 I-1) \hbar}$ e os autovalores do sistema serão dados por,

$$
E_{m}=-m \hbar \omega_{L}+\hbar \omega_{Q}\left[3 m^{2}-I(I+1)\right]
$$

o que implica em $2 I$ transições com frequências distintas. Para $I=\frac{3}{2}$, os níveis de energia correspondentes à $m= \pm \frac{3}{2}$ sofrem deslocamentos idênticos, enquanto que os níveis $m= \pm \frac{1}{2}$ não são afetados pelo acoplamento quadrupolar (em $1^{a}$ ordem), como ilustrado pela Figura 2.3 . 


\subsection{Operadores de Rotação}

Através da interação dos spins com campos de RF é possível produzir quaisquer rotações desejadas no momento magnético médio da amostra. Estas rotações são descritas pelos operadores de rotação,

$$
R_{\mathbf{n}}(\theta)=e^{-i \theta \mathbf{n} \cdot I}
$$

onde $\mathbf{n}$ é o vetor unitário que define o eixo de rotação e $\theta$ é o ângulo de rotação.

Sistemas de spin $1 / 2$ não interagentes podem ser descritos em termos das matrizes de Pauli, cuja representação matricial é dada por

$$
\sigma_{x}=\left[\begin{array}{ll}
0 & 1 \\
1 & 0
\end{array}\right] \quad \sigma_{y}=\left[\begin{array}{cc}
0 & -i \\
i & 0
\end{array}\right] \quad \sigma_{z}=\left[\begin{array}{cc}
1 & 0 \\
0 & -1
\end{array}\right]
$$

e que se relacionam com os operadores de spin $I$ de forma que $I=\frac{1}{2} \sigma$. Assim, para estes sistemas, os operadores de rotação em torno dos três eixos cartesianos tem a seguinte forma matricial (10),

$$
\begin{aligned}
& R_{x}(\theta) \equiv e^{-i \theta I_{x} / 2}=\cos \left(\frac{\theta}{2}\right) \mathbb{I}-i \sin \left(\frac{\theta}{2}\right) I_{x}=\left[\begin{array}{cc}
\cos \left(\frac{\theta}{2}\right) & -i \sin \left(\frac{\theta}{2}\right) \\
-i \sin \left(\frac{\theta}{2}\right) & \cos \left(\frac{\theta}{2}\right)
\end{array}\right] \\
& R_{y}(\theta) \equiv e^{-i \theta I_{y} / 2}=\cos \left(\frac{\theta}{2}\right) \mathbb{I}-i \sin \left(\frac{\theta}{2}\right) I_{y}=\left[\begin{array}{cc}
\cos \left(\frac{\theta}{2}\right) & -\sin \left(\frac{\theta}{2}\right) \\
\sin \left(\frac{\theta}{2}\right) & \cos \left(\frac{\theta}{2}\right)
\end{array}\right] \\
& R_{z}(\theta) \equiv e^{-i \theta I_{z} / 2}=\cos \left(\frac{\theta}{2}\right) \mathbb{I}-i \sin \left(\frac{\theta}{2}\right) I_{z}=\left[\begin{array}{cc}
e^{-i \theta / 2} & 0 \\
0 & e^{i \theta / 2}
\end{array}\right]
\end{aligned}
$$

onde $\mathbb{I}$ é o operador identidade.

Já no caso de spins $1 / 2$ interagentes, quando um campo de RF na direção $I_{x}$ é aplicado no spin $I$, a Hamiltoniana do sistema descrita pela Eq. (2.2.2) pode ser reescrita, no referencial duplo girante, na forma

$$
H=-\hbar\left(\omega_{I}-\Omega_{I}\right) I_{z}-\hbar\left(\omega_{S}-\Omega_{S}\right) S_{z}+2 \pi \hbar J I_{z} S_{z}-\gamma_{I} \hbar B_{1} I_{x}
$$

São definidos pulsos hard os pulsos de RF de alta potência capazes de excitar indistintamente todas as transições permitidas pelas regras de seleção $\left(\Delta m_{I}= \pm 1\right.$ e $\left.\Delta m_{S}= \pm 1\right)$. Para esta categoria de pulsos de RF, a duração do pulso é tal que a banda de excitação é 
muito superior ao acoplamento $\mathrm{J}$ e aos offsets ${ }^{\dagger}$ de frequência $\left(\omega_{I}-\Omega_{I}\right)$. Assim, quando estes pulsos são aplicados próximos à ressonância, o termo de acoplamento J bem como os termos de offset de frequência são desprezíveis comparados ao termo da RF. Portanto, para este caso, a Hamiltoniana efetiva será $H_{\text {efetivo }}=-\gamma_{I} \hbar B_{1} I_{x}$. Então, considerando-se sistemas heteronucleares onde as frequências de ressonância de cada núcleo são bastante distantes, a RF aplicada à uma espécie não terá influência sobre a outra (7). Consequentemente, da mesma forma que no caso não interagente, as rotações podem ser escritas em termos de operadores exponenciais, sendo necessário realizar apenas a expansão do espaço de operadores através do produto tensorial. Por exemplo, no caso em que desejamos produzir uma rotação em $I_{x}$ apenas no $1^{\circ}$ q-bit,

$$
R_{x}(\theta) \otimes 1=\left[\begin{array}{cccc}
\cos \left(\frac{\theta}{2}\right) & 0 & -i \sin \left(\frac{\theta}{2}\right) & 0 \\
0 & \cos \left(\frac{\theta}{2}\right) & 0 & -i \sin \left(\frac{\theta}{2}\right) \\
-i \sin \left(\frac{\theta}{2}\right) & 0 & \cos \left(\frac{\theta}{2}\right) & 0 \\
0 & -i \sin \left(\frac{\theta}{2}\right) & 0 & \cos \left(\frac{\theta}{2}\right)
\end{array}\right]
$$

Experimentalmente, isto pode ser implementado utilizando-se uma sonda de dupla ressonância, capaz de excitar duas frequências distintas de forma independente (7).

Já no caso quadrupolar, a Hamiltoniana do sistema, Eq. (2.3.4), se reescreve na forma

$$
H_{\text {efetivo }}=-\hbar\left(\omega_{L}-\Omega\right) I_{z}+\hbar \omega_{Q}\left(3 I_{z}^{2}-I^{2}\right)-\hbar \omega_{1} I_{x}
$$

Na situação em que são aplicados pulsos hard com frequência $\omega_{1} \gg \omega_{Q}$, apenas o termo referente à RF é relevante, logo a Hamiltoniana efetiva é dada por $H_{\text {efetivo }}=\hbar \omega_{1} I_{x}$. Neste caso, todas as transições permitidas pelas regras de seleção $(\Delta m= \pm 1)$ são excitadas. Para a excitação de uma única transição, utiliza-se o regime de pulsos seletivos (ou pulsos soft), $\omega_{1} \ll$ $\omega_{Q}$, onde pulsos de longa duração e baixa potência são aplicados, de forma que a frequência do pulso de RF relaciona a energia dos estados que deseja conectar, $\omega_{R F}=\left(E_{f}-E_{i}\right) / \hbar$, $(11,12)$. Portanto, a aplicação de pulsos hard implica na rotação de todo o sistema, ou seja, na rotação de todos os "q-bits" envolvidos. Enquanto que pulsos seletivos permitem excitar transições entre níveis específicos, o que pode ser usado para realizar rotações em apenas um dos q-bits.

†Diferença entre a frequência de Larmor e a frequência do referencial girante. 
Sistemas quadrupolares de spin $3 / 2$ podem ser descritos na base,

$$
\begin{gathered}
I_{x}=\frac{1}{2}\left[\begin{array}{cccc}
0 & \sqrt{3} & 0 & 0 \\
\sqrt{3} & 0 & 2 & 0 \\
0 & 2 & 0 & \sqrt{3} \\
0 & 0 & \sqrt{3} & 0
\end{array}\right] I_{y}=\frac{i}{2}\left[\begin{array}{cccc}
0 & -\sqrt{3} & 0 & 0 \\
\sqrt{3} & 0 & -2 & 0 \\
0 & 2 & 0 & -\sqrt{3} \\
0 & 0 & \sqrt{3} & 0
\end{array}\right] \\
I_{z}=\frac{1}{2}\left[\begin{array}{cccc}
3 & 0 & 0 & 0 \\
0 & 1 & 0 & 0 \\
0 & 0 & -1 & 0 \\
0 & 0 & 0 & -3
\end{array}\right]
\end{gathered}
$$

a partir da qual podemos contruir os operadores de rotação, de forma análoga ao que foi feito para o sistema de spin 1/2, (7). Ou seja, para um pulso hard aplicado em torno do eixo-x, por exemplo, temos $R_{x}(\theta)=e^{-i \theta I_{x}}$. Assim, para $\theta=\pi / 2$ temos o operador de rotação

$$
R_{x}(\pi / 2)=\frac{1}{2 \sqrt{2}}\left[\begin{array}{cccc}
1 & -i \sqrt{3} & -\sqrt{3} & i \\
-i \sqrt{3} & -1 & -i & -\sqrt{3} \\
-\sqrt{3} & -i & -1 & -i \sqrt{3} \\
i & -\sqrt{3} & -i \sqrt{3} & 1
\end{array}\right]
$$

No caso de pulsos soft, reescrevemos a Hamiltoniana da Eq. (2.4.8) utilizando-se o fato de que para pulsos de RF com o campo $B_{1}$ aplicado ao longo da direção $n$, os operadores $I_{n}$ $(n=x, y, z)$ podem ser escritos na forma

$$
\begin{aligned}
I_{n} & =\sum_{r s} \sqrt{c^{r s}} I_{n}^{r s}, \text { para } n=x, y \\
I_{z} & =\sum_{r s} c^{r s} I_{z}^{r s}
\end{aligned}
$$

onde $c^{r s}=I(I+1)-m_{r} m_{s}$, rs define a transição que se deseja excitar e os operadores de transição única são dados dados por (12)

$$
\begin{gathered}
\left\langle\psi_{i}\left|I_{x}^{(r s)}\right| \psi_{f}\right\rangle=1 / 2\left(\delta_{i r} \delta_{f s}+\delta_{i s} \delta_{f r}\right), \\
\left\langle\psi_{i}\left|I_{y}^{(r s)}\right| \psi_{f}\right\rangle=i / 2\left(-\delta_{i r} \delta_{f s}+\delta_{i s} \delta_{f r}\right), \\
\left\langle\psi_{i}\left|I_{z}^{(r s)}\right| \psi_{f}\right\rangle=1 / 2\left(\delta_{i r} \delta_{f s}-\delta_{i s} \delta_{f r}\right),
\end{gathered}
$$


Com isto, o operador de rotação pode ser escrito como (11)

$$
R_{n}^{r s}(\theta)=\exp \left(\frac{-i \theta \omega_{Q}}{2 \omega_{1}}\left[\frac{\Delta \omega}{\omega_{Q}}\left(\sum_{r s} c^{r s} I_{z}^{r s}\right)-\frac{\omega_{1}}{\omega_{Q}} \sqrt{c^{r s}} I_{n}^{r s}+\left(\sum_{i j} c^{i j} I_{z}^{i j}\right)^{2}-\frac{3}{4}\right]\right)(2
$$

E assim, por exemplo, o operador de rotação da transição $01(|3 / 2\rangle \rightarrow|1 / 2\rangle)$ é dado por

$$
R_{n}^{01}(\theta)=\left[\begin{array}{cccc}
\cos \left(\frac{\theta \sqrt{3}}{2}\right) e^{2 i \omega_{Q} t_{p}} & i \sin \left(\frac{\theta \sqrt{3}}{2}\right) e^{i\left(2 \omega_{Q} t_{p}-\frac{\pi}{2} n\right)} & 0 & 0 \\
i \sin \left(\frac{\theta \sqrt{3}}{2}\right) e^{i\left(2 \omega_{Q} t_{p}+\frac{\pi}{2} n\right)} & \cos \left(\frac{\theta \sqrt{3}}{2}\right) e^{2 i \omega_{Q} t_{p}} & 0 & 0 \\
0 & 0 & 1 & 0 \\
0 & 0 & 0 & e^{-4 i \omega_{Q} t_{p}}
\end{array}\right]
$$

Apesar deste método permitir selecionar cada uma das transições e aplicar rotações de forma independente em cada uma delas, o fato de serem usados pulsos de longa duração pode ser um fator limitante para a sua utilização.

\subsection{Operador Densidade}

Sistemas de RMN não constituem estados puros, onde é possível assegurar que cada microestado encontra-se em um determinado estado quântico. Ao contrário, sistemas de RMN são misturas estatísticas, onde a magnetização observada corresponde, na verdade, a uma média sobre o ensemble de momentos magnéticos dos núcleos da amostra (microestados que constituem o sistema global). Por esta razão, o formalismo de Operador Densidade tornase uma ferramenta essencial na descrição deste tipo de sistema (13).

Utilizando o exemplo da magnetização, sabemos, pela Mecânica Quântica, que esta quantidade é proporcional ao valor esperado do operador de spin $I$. Matematicamente isto significa que

$$
\mathbf{M}=\langle\mathbf{I}\rangle=\sum_{i} q_{i}\left\langle\psi_{i}|\mathbf{I}| \psi_{i}\right\rangle
$$

onde a soma sobre $i$ corresponde a soma sobre todos os microestados do sistema $\left|\psi_{i}\right\rangle$ com peso $q_{i}$, que representa, por sua vez, a probabilidade deste estado ser encontrado. Com isto, 
definimos o operador densidade do sistema,

$$
\rho=\sum_{i} q_{i}\left|\psi_{i}\right\rangle\left\langle\psi_{i}\right|
$$

de modo que,

$$
M=\operatorname{Tr}\{\rho I\} .
$$

Assim, toda a informação sobre o sistema está guardada no operador densidade e a obtenção de quaisquer resultados de medidas sobre o sistema envolvem apenas este operador.

O operador densidade pode ser escrito na forma matricial onde os elementos da diagonal, denominados de populações, correspondem às probabilidades de encontrar um membro do ensemble em um certo estado. Já os elementos fora da diagonal são chamados de coerências e podem ser interpretados como a existência de superposição de estados.

No equilíbrio térmico, o operador densidade do sistema pode ser escrito em termos da Hamiltoniana e da função de partição $Z=\operatorname{Tr}\left\{e^{-\frac{H}{k_{B} T}}\right\}$ deste sistema (7),

$$
\rho_{0}=\frac{e^{\frac{-H}{k_{B} T}}}{Z}
$$

neste caso, as populações satisfazem a distribuição de Boltzmann e as coerências são identicamente nulas.

No caso de um ensemble de núcleos idênticos, com número quântico $I$, e na presença de um campo $B_{0}$ aplicado na direção $z$, a Hamiltoniana Zeeman será $H_{z}=-\hbar \omega_{L} I_{z}$. Assim, na aproximação de altas temperaturas $\left(k_{B} T \gg \hbar \omega_{L}\right)$, a matriz densidade de equilíbrio pode ser escrita como

$$
\rho_{0}=\left(\frac{1}{2 I+1}\right) \mathbb{I}+\left(\frac{\alpha}{2 I+1}\right) I_{z},
$$

onde II é a matriz identidade e $\alpha=\hbar \omega_{L} / k_{B} T$. O primeiro termo da equação 2.5 .5 não contribui para o sinal de RMN e nem é sensível a ação dos pulsos de RF (rotação), por isso o segundo termo é denominado como Matriz Densidade de Desvio - $\Delta \rho$ - e é a única parte que efetivamente contribui nas análises por RMN. Por esta razão, podemos dizer que esta parte da mariz densidade contém toda a informação relevante do sistema. Esta propriedade é fundamental para o estudo de informação quântica via RMN e é a base para o conceito de estados pseudo-puros, que introduziremos na seção 3.1 . 


\subsection{Relaxação de Sistemas de RMN}

Como apresentado anteriormente, a aplicação de um pulso $\pi / 2$ em um sistema de spins nucleares na presença de um campo estático $B_{0}$ leva a magnetização resultante para o plano perpendicular à direção de $B_{0}$. Quando o campo de RF referente ao pulso é desligado, a magnetização média permanece, inicialmente, perpendicular à $B_{0}$, no entanto esta não é a situação de equilíbrio do sistema, devido a presença do campo $B_{0}$. Assim, o sistema tende a retornar ao equilíbrio. Na situação em que podemos considerar o sistema de spins como spins não interagentes, imersos em campos magnéticos oscilantes aleatórios devidos às flutuações dos campos magnéticos individuais dos outros spins do sistema, este processo de relaxação pode ser descrito em termos de dois efeitos distintos que ocorrem simultaneamente (7):

- Relaxação Transversal: processo que leva ao desaparecimento das componentes da magnetização nuclear perpendiculares ao campo $B_{0}$. Esta relaxação ocorre devido à criação de um campo pelo próprio spin nuclear no sítio de outros núcleos, o que gera uma heterogeneidade instantânea no campo magnético acarretando na perda de coerência de fase macroscópica. Por esta razão, denomina-se este processo de relaxação transversal ou relaxação spin-spin. Neste processo não há dissipação de energia do sistema e, portanto, as populações da matriz densidade permanecem constantes. Fenomenologicamente, este processo pode ser matematicamente descrito através da equação $(7,8)$,

$$
\frac{d M_{\alpha}}{d t}=-\frac{M_{\alpha}}{T_{2}}
$$

onde $\alpha=x, y$. É fácil ver que a solução desta equação é na forma

$$
M_{\alpha}=M_{0} e^{-t / T_{2}}
$$

onde $T_{2}$ é conhecido como o tempo de relaxação transversal.

- Relaxação Longitudinal: processo pelo qual a componente longitudinal da magnetização tende a atingir ou recuperar seu valor de equilíbrio. Ao contrário do que ocorre na relaxação transversal, a recuperação da componente da magnetização $M_{z}$, paralela à $B_{0}$, está relacionada a transições entre os níveis de energia do spin nuclear. Isto deve ao fato de que após a aplicação do pulso $\pi / 2$ temos $M_{z}=0$, o que corresponte às populações dos níveis serem igualadas. Ou seja, o sistema não se encontra mais no equilíbrio térmico, onde a distribuição de Boltzmann é satisfeita. Portanto, a tendência 
do sistema é liberar o excesso de energia através das transições entre os níveis de energia, o que corresponde a uma troca de energia com o ambiente magnético ao redor (rede). Por esta razão, o processo é conhecido como relaxação spin-rede (7, 14).

De forma similar ao caso da relaxação transversal, a relaxação longitudinal pode também ser descrita por uma equação fenomenológica na forma

$$
\frac{d M_{z}}{d t}=\frac{M_{0}-M_{z}}{T_{1}}
$$

onde T1 é o tempo característico do processo de relaxação longitudinal. A solução desta equação dada por

$$
M_{z}=M_{0}\left(1-e^{-t / T_{1}}\right)
$$

onde $M_{0}$ é a magnetização no equilíbrio térmico.

As equações (2.6.1) e (2.6.3) são denominadas equações de Bloch e os tempo de relaxação $T_{1}$ e $T_{2}$ são parâmetros característicos de cada sistema e suas magnitudes dependem de fatores como a temperatura, natureza da amostra (líquida ou sólida), magnitude do campo magnético externo, etc $(6,8)$.

\subsection{Detecção do Sinal de RMN}

Para uma melhor compreensão das ferramentas que utilizaremos no estudo de informação quântica, apresentaremos uma breve exposição sobre a instrumentação da técnica de RMN, em particular, sobre a detecção do sinal da amostra (6, 15).

A Figura 2.4 apresenta um esquema geral de um espectrômetro de RMN. O campo magnético estático, responsável pelo Efeito Zeeman, é criado através do magneto principal. Para experimentos de alta resolução (alto campo) são utilizados eletromagnetos capazes de produzir campos magnéticos de até algumas dezenas de Tesla, através da circulação de uma corrente da ordem de centenas de Ampères em uma espira supercondutora. Para que esta característica supercondutora seja mantida é necessário que a espira esteja à baixíssima temperatura, portanto faz-se necessário a sua imersão em Hélio líquido. Com o intuito de conter a evaporação desta substância utiliza-se uma camada de revestimento de Nitrogêlio líquido, 


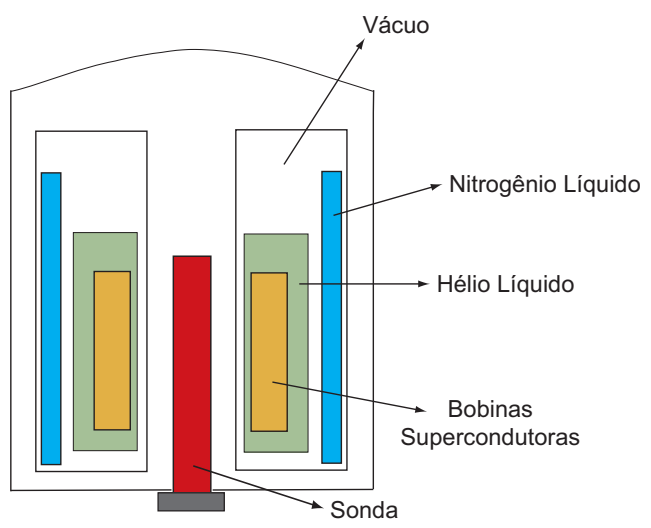

Figura 2.4- Representação esquemática de um espectrômetro de RMN de alta resolução.

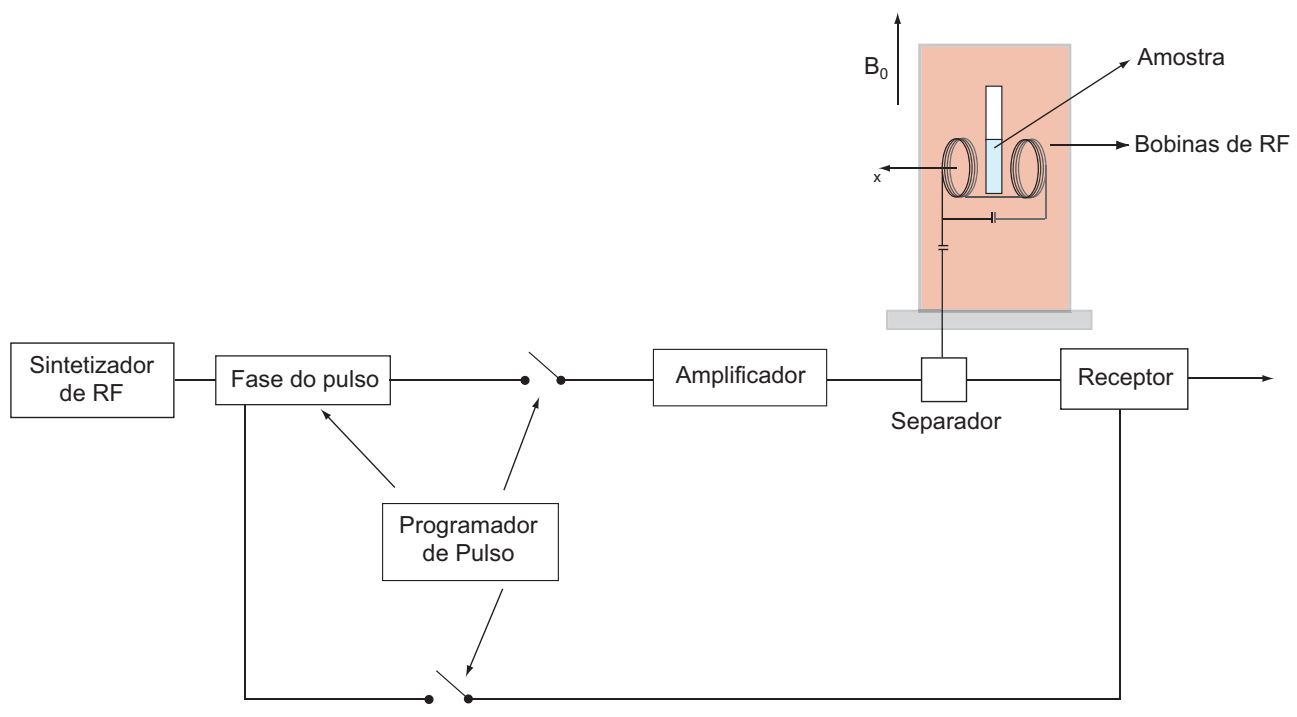

Figura 2.5 - Reresentação esquemática do circuito de transmissão do pulso e da sonda de RMN.

seguida por uma camada de vácuo. Para que uma boa resolução seja obtida nos experimentos, é necessário que este campo magnético seja o mais homogêneo possível. Para isto, utiliza-se um conjunto adicional de bobinas (bobinas de shimming), cujas correntes podem ser ajustadas pelo usuário de forma que a homogeneidade desejada seja alcançada.

No interior do magneto posiciona-se a sonda, onde a amostra é colocada. Uma das funções da sonda é posicionar a amostra na região onde o campo magnético é mais homogêneo. A sonda também inclui os circuitos eletrônicos responsáveis por irradiar a amostra com os campos de RF desejados e, em seguida, detectar os sinais de RF emitidos por ela. A Figura 2.5 apresenta um esquema para este aparato, onde também apresentamos um esquema para a transmissão do pulso de RF. O sinal elétrico é produzido no sintetizador, cuja frequência de 


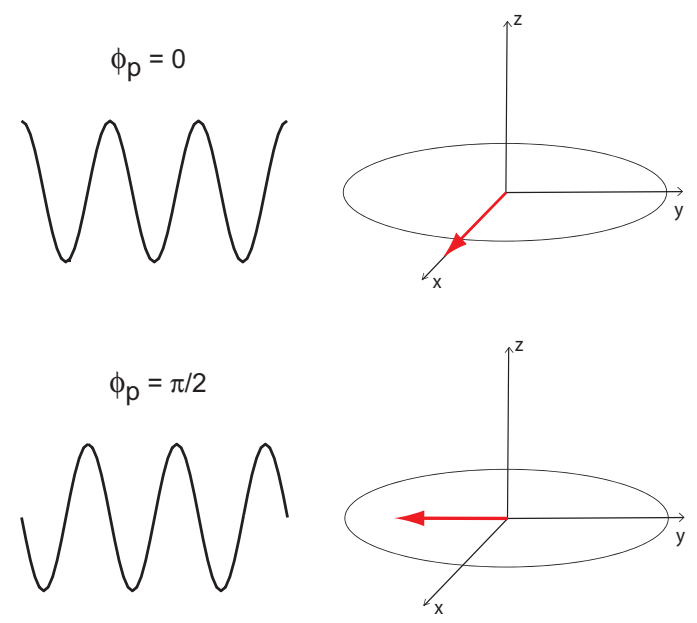

Figura 2.6 - Correspondência entre a fase da radiofrequência $\left(\phi_{p}\right)$ e o eixo de rotação da magnetização no plano $x y$ após a aplicação deste pulso.

oscilação é muito próxima da frequência Larmor do núcleo em estudo $\left(\omega_{0}\right)$. Matematicamente,

$$
s_{\text {sint }} \sim \cos \left(\omega_{0} t+\phi_{p}\right)
$$

onde $\phi_{p}$ define a fase do pulso de RF, a direção do pulso no plano $x y$, de forma semelhante ao definido pela Eq. (2.1.4), a Figura 2.6 fornece uma interpretação geométrica desta definição.

Em experimentos de RMN, é comum a fase $\phi_{p}(t)$ variar de forma brusca, o que é controlado pelo programador de pulso. Assim, após o pulso ser sintetizado ele atravessará uma chave de transmissão, responsável por definir o momento exato em que a RF será transmitida bem como a duração (comprimento) do pulso. Assim, combinando-se o efeito do programador de pulso com a chave de transmissão, é possível obter formas de onda com controle de fase e duração. Em seguida, o pulso de RF passará por um amplificador, responsável por amplificar o sinal de alguns $\mathrm{mV}$ para alguns volts, de modo que a amplitude correta para a onda seja obtida. Do amplificador a onde é transmitida à um separador, do qual sairão dois cabos: um em direção à sonda (situada dentro do magneto) e o outro em direção à parte de recepção do sinal gerado pelos spins nucleares. O separador tem a importante missão de impedir que o sinal proveniente do transmissor de RF (da ordem de algumas centenas de Watts) chegue ao receptor e que o sinal proveniente da sonda (da ordem de nano Watts) seja enviado ao transmissor.

Após a excitação dos spins nucleares e do campo de RF ser desligado, o sistema tende a retornar para o equilíbrio com o campo $B_{0}$. Neste caso, podemos escrever o movimento das coerências no referencial girante em termos das coordenadas do laboratório, como na Eq. 
$(? ?)$

$$
\rho_{i j}=\rho_{i j}^{l a b} e^{i \Omega t}
$$

onde $\Omega$ é a frequência do referencial girante. Assim, supondo que a bobina de RF esteja localizada ao longo do eixo- $x$ do sistema do laboratório, então matematicamente, a magnetização média nesta direção é proporcional ao operador $I_{x}$, de forma que vale

$$
\begin{aligned}
M_{x} & \sim\left\langle I_{x}\right\rangle \\
& =\operatorname{Tr}\left\{\rho^{l a b} I_{x}\right\} \\
& \sim \rho_{13}^{l a b}+\rho_{24}^{l a b}
\end{aligned}
$$

Como durante o processo de retorno do sistema ao equilíbrio com o campo $B_{0}$, a $M_{x}$ varia no tempo, uma corrente é induzida na bobina de detecção. Esta corrente é, portanto, proporcional à derivada temporal da magnetização na direção da bobina, à menos de uma constante proveniente de irregularidades experimentais, ou seja o sinal de RMN $\left(s_{F I D}\right)$ pode ser escrito como

$$
\begin{aligned}
s_{F I D}(t) & \sim \frac{d}{d t} M_{x} \\
& \sim \frac{d}{d t}\left(\rho_{13}^{l a b}+\rho_{24}^{l a b}\right), \\
& =-i \Omega\left(\rho_{13}+\rho_{24}\right) e^{-i \Omega t} .
\end{aligned}
$$

Devido à baixa voltagem do sinal oriundo dos spins nucleares, após deixar a sonda, este sinal é pré-amplificado à uma escala mais conveniente (faixa de áudio, por exemplo). O receptor de sinais recebe, então, este sinal pré-amplificado $\left(s_{F I D}\right)$ e o sinal de referência $\left(s_{\text {ref }}\right)$ proveniente diretamente do sintetizador, com frequência $\omega_{0}$ e fase $\phi_{\text {recep }}$, definida pelo programador de pulso,

$$
s_{r e f} \sim \cos \left(\omega_{0} t+\phi_{\text {recep }}\right)
$$

O $s_{F I D}$ é dividido por um divisor em dois sinais de mesma fase, enquanto que o $s_{\text {ref }}$ é divido em duas componentes com diferença de fase de $\pi / 2$. Cada um dos $s_{\text {ref }}$ é combinado à um dos $s_{F I D}$, o que resultará em dois sinais com frequência relativa ao offset $\Omega=\omega_{0}-\Omega$, mas com uma defasagem de $\pi / 2$. A combinação destes dois sinais permite distinguir entre valores positivos e negativos de $\Omega$ e eliminar as constantes acumuladas devido às irregularidades experimentais, o que é denominado processo de detecção em fase e quadratura.

Na prática, a direção para a qual o eixo da bobina de RF aponta é apenas uma questão 
de nomenclatura. Quem de fato determina a direção de detecção do sinal, ou seja, qual será a componente em fase, parte real, e em quadratura, parte imaginária do sinal, será a fase do detector $\phi_{\text {recep }}$.

Para as aplicações de RMN que faremos em Informação Quântica, é interessante destacar os conceitos de fase do pulso $\left(\phi_{p}\right)$ e do receptor $\left(\phi_{\text {recep }}\right)$. Assim, a fase do pulso corresponde à "direção" em que o pulso de excitação será aplicado. E a fase do receptor corresponde à fase que define qual a componente do sinal está em fase e em quadratura em relação a fase do transmissor (pulso). Por exemplo, partindo do equilíbrio térmico, um pulso com fase $y$ produzirá uma magnetização transversal na direção $x$, que executará um movimento de precessão em torno de $z$ tal que

$$
\vec{M}(t)=M_{0} \cos (\omega t) \hat{x}+M_{0} \sin (\omega t) \hat{y}
$$

Neste caso, se a fase do receptor for escolhida como $x$, então o sinal adquirido será $S(t)=$ $M_{0} \cos (\omega t)+i \sin (\omega t)$. No entanto, se escolhermos a fase do receptor como sendo $y$, então o mesmo sinal seria adquirido como $S(t)=M_{0} \sin (\omega t)-i M_{0} \cos (\omega t)$.

\subsection{RMN no contexto de Informação Quântica}

Nos processos de armazenamento e transmissão de informações, dados são criptografados em números a partir de uma base binária. Qualquer sistema físico com dois níveis de energia pode ser associado a um dígito binário (bit). Em processos clássicos isto é feito, por exemplo, através da presença ou ausência de correntes elétricas em circuitos eletrônicos, o que pode ser associado aos estados 0 e 1 , respectivamente. Um sistema quântico de dois níveis também pode ser utilizado para representar um bit, o que neste contexto é denominado "q-bit"e os seus autoestado são representados por $|0\rangle$ e $|1\rangle$ e definidos pelos vetores

$$
|0\rangle=\left[\begin{array}{l}
1 \\
0
\end{array}\right],|1\rangle=\left[\begin{array}{l}
0 \\
1
\end{array}\right] .
$$

Onde o conjunto $\{|0\rangle,|1\rangle\}$ forma uma base bidimensional no espaço de Hilbert de 1 q-bit, e é chamada de base computacional. Para uma partícula de spin $1 / 2$, o estado lógico 0 pode ser representado pelo estado de spin para cima $(|0\rangle \equiv|\uparrow\rangle)$ e o estado lógico 1 pelo estado de 


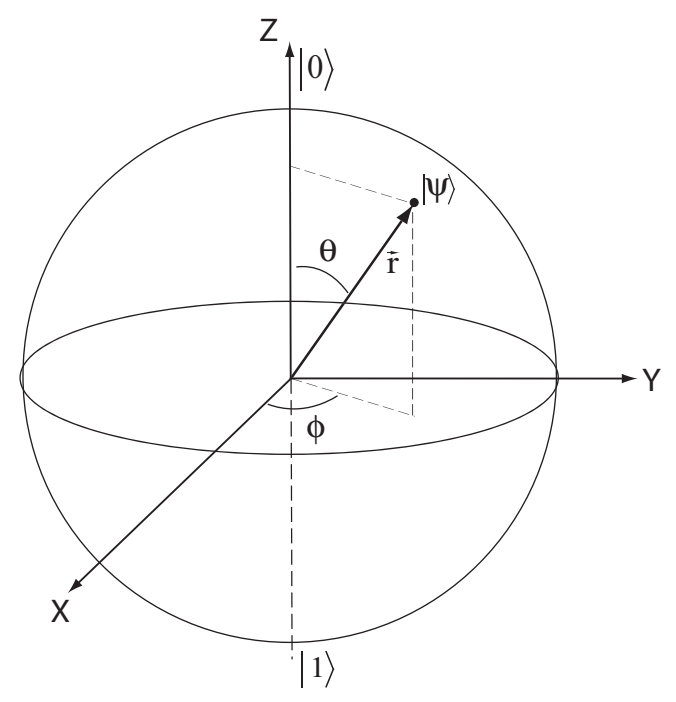

Figura 2.7- Representação da esfera de Bloch.

spin para baixo $(|1\rangle \equiv|\downarrow\rangle)$.

A grande vantagem em se utilizar estados quânticos reside no fato de que os estados 0 e 1 não são mais mutuamente exclusivos, como no caso clássico, mas uma mesma partícula pode se encontrar em uma superposição destes estados, o que é representado por

$$
|\psi\rangle=\alpha|0\rangle+\beta|1\rangle
$$

onde os coeficientes $\alpha$ e $\beta$ são números complexos tais que $|\alpha|^{2}+|\beta|^{2}=1$. Este estado pode ser parametrizado em termos de ângulos $\theta$ e $\phi$ e reescrito como,

$$
|\psi\rangle=\cos \frac{\theta}{2}|0\rangle+e^{i \phi} \sin \frac{\theta}{2}|1\rangle .
$$

Os ângulos $\theta$ e $\phi$ definem um ponto sobre a superfície de uma esfera de raio unitário, conhecida como esfera de Bloch, como ilustrado na Figura 2.7. Assim, a matriz densidade de um sistema,

$$
\begin{aligned}
\rho & =|\psi\rangle\langle\psi| \\
& =\left[\begin{array}{cc}
\cos ^{2}(\theta / 2) & e^{-i \phi} \sin (\theta / 2) \cos (\theta / 2) \\
e^{i \phi} \sin (\theta / 2) \cos (\theta / 2) & \sin ^{2}(\theta / 2)
\end{array}\right],
\end{aligned}
$$

pode ser escrita em termos do vetor $\vec{r}$ de Bloch,

$$
\rho=\frac{1}{2}(\mathbb{I}+\vec{\sigma} \cdot \vec{r})
$$

onde $\vec{\sigma}$ é o vetor cujas componente correspondem às matrizes de Pauli, dadas na Eq. (2.4.2). Com esta notação, é possível fazer uma associação direção direta com a matriz densidade e a matriz de desvio definidas na Eq. (2.5.5). Assim, estados puros possuem $\|r\|=1$ e estão 
localizados na superfície da esfera de Bloch e os estados mistos no seu interior, com $\|r\|<1$.

Sistemas de RMN são um dos tipos de sistema quântico utilizados no estudo de informação quântica. E uma das grandes vantagens de sua utilização é a facilidade de controle sobre os estados de spins nucleares que a técnica permite. Neste contexto, sistemas de 2 q-bits, que serão o foco deste trabalho, podem ser representados através de um sistema de 2 spins $1 / 2$ acoplados via acoplamento $\mathrm{J}$ e de um sistema de spins $3 / 2$. Para esta classe de sistemas a base computacional é dada pelos autoestados,

$$
|00\rangle=\left[\begin{array}{l}
1 \\
0 \\
0 \\
0
\end{array}\right],|01\rangle=\left[\begin{array}{l}
0 \\
1 \\
0 \\
0
\end{array}\right],|10\rangle=\left[\begin{array}{l}
0 \\
0 \\
1 \\
0
\end{array}\right],|11\rangle=\left[\begin{array}{l}
0 \\
0 \\
0 \\
1
\end{array}\right],
$$

que se originam dos produtos tensoriais entre autoestados de 1 q-bit $|0\rangle$ e $|1\rangle$, por exemplo $|00\rangle=|0\rangle \otimes|0\rangle$. Nas Figuras 2.2 e 2.3 observa-se a associação entre estes estados lógicos e os níveis de energia dos sistemas de RMN citados a cima.

É possível generalizar a expressão da Eq. (2.8.5) para sistema com um maior número de q-bits, o que apesar de não fornece um análogo geométrico com visualização simples, em alguns casos, como veremos nos próximos capítulos, facilita os cálculos matemáticos. Assim, para um sistema de dois q-bits escrevemos,

$$
\rho=\frac{1}{4}\left(\mathbb{I} \otimes \mathbb{I}+\sum_{i=1}^{3} x_{i} \sigma_{i} \otimes \mathbb{I}+\sum_{i=1}^{3} y_{i} \mathbb{I} \otimes \sigma_{i}+\sum_{i, j=1}^{3} C_{i j} \sigma_{i} \otimes \sigma_{j}\right),
$$

onde $x_{i}=\operatorname{Tr}\left[\rho\left(\sigma_{i} \otimes \mathbb{I}\right)\right], y_{i}=\operatorname{Tr}\left[\rho\left(\mathbb{I} \otimes \sigma_{i}\right)\right]$ são as componentes do vetor de Bloch local e $C_{i j}=\operatorname{Tr}\left[\rho\left(\sigma_{i} \otimes \sigma_{j}\right)\right]$ são as componentes do tensor de correlação. Vale ressaltar aqui, que de acordo com o exposto na seção 2.7, $x_{i}$ e $y_{i}$ são observáveis diretos de RMN, ou seja, podem ser lidos diretamente a partir de uma medida simples de RMN.

Um outro ponto que torna a técnica de RMN interessante para o estude de informação quântica é a capacidade de aplicar operações unitárias (portas lógicas) sobre os estados utilizando-se os operadores de rotação, discutidos na seção 2.4. Um exemplo de porta lógica essencial para estes estudos é a porta lógica Não-Controlado (CNOT), que atua em um dos q-bits do sistema (alvo), alterando o seu estado, apenas se o outro q-bit (controle) está no 
estado $|1\rangle$. Matricialmente, para um sistema de 2 q-bits, esta porta lógica é dada por (10)

$$
\mathrm{CNOT}_{a}=\left[\begin{array}{cccc}
1 & 0 & 0 & 0 \\
0 & 1 & 0 & 0 \\
0 & 0 & 0 & 1 \\
0 & 0 & 1 & 0
\end{array}\right], \mathrm{CNOT}_{b}=\left[\begin{array}{llll}
1 & 0 & 0 & 0 \\
0 & 0 & 0 & 1 \\
0 & 0 & 1 & 0 \\
0 & 1 & 0 & 0
\end{array}\right],
$$

onde os subindices $a$ e $b$ definem o q-bit de controle. Experimentalmente, estas portas lógicas podem ser implementadas, para um sistema de 2 spins $1 / 2$ acoplados via acoplamento J, através da seguinte sequência de pulsos (7)),

$$
\begin{aligned}
\mathrm{CNOT}_{a} & =\left(\frac{\pi}{2}\right)_{z}^{a}\left(-\frac{\pi}{2}\right)_{z}^{b}\left(\frac{\pi}{2}\right)_{x}^{b} U_{j}\left(\frac{1}{2 J}\right)\left(\frac{\pi}{2}\right)_{y}^{b} \\
\mathrm{CNOT}_{b} & =\left(\frac{\pi}{2}\right)_{z}^{b}\left(-\frac{\pi}{2}\right)_{z}^{a}\left(\frac{\pi}{2}\right)_{x}^{a} U_{j}\left(\frac{1}{2 J}\right)\left(\frac{\pi}{2}\right)_{y}^{a},
\end{aligned}
$$

onde os superindices estão relacionados ao q-bit sobre o qual o pulso será aplicado, os subindices correspondem à fase do pulso e $U_{j}(1 / 2 J)$ à um período de evolução sob o acoplamento.

Vale ressaltar que nem sempre é simples encontrar o conjunto de rotações que levam à uma porta lógica, por esta razão métodos númericos tem sido desenvolvidos com este objetivo, o que trataremos na seção 3.2 .

\subsubsection{Descrição da Relaxação via Operações Quânticas}

Neste contexto, a introdução do formalismo de operações quânticas (10) para a descrição da relaxação dos sistemas de RMN é bastante interessante. Como discutido na seção 2.6 estes processos de relaxação podem ser descritos fenomenologicamente utilizando-se as equações de Bloch (2.6.3 2.6.1). No entanto, quando se trata de sistemas de spins interagentes, como empregaremos em nossas análises, esta descrição nem sempre é suficiente. Além das operações quânticas, outras ferramentas utilizadas para descrever os mecanismos de dissipação e decoerência (relaxação), de forma mais detalhada, são os Formalismos de Redfield e de Equação Mestra (8, 16).

Em seu trabalho, Soares-Pinto, D.O. and et al. (17) mostraram que todos esses formalismos são completamente equivalentes e que para o caso de um sistema de spins não 
interagentes se reduzem às equações de Bloch. Como neste trabalho estaremos interessados apenas na evolução temporal do sistema principal, sem considerarmos explicitamente as propriedades do ambiente, utilizaremos o formalismo de operações quânticas, que descreveremos com mais detalhes a seguir.

Em sistemas quânticos fechados, a evolução temporal de um sistema é descrita através de operadores unitários,

$$
\rho \rightarrow \varepsilon(\rho)=U \rho U^{\dagger}
$$

onde $U=e^{-i H t / \hbar}$. No entanto, para sistemas quânticos abertos a evolução temporal do sistema implica em,

$$
\rho \rightarrow \varepsilon(\rho)=\operatorname{Tr}_{a m b}\left[U\left(\rho \otimes \rho_{a m b}\right) U^{\dagger}\right]
$$

Ou seja, considerando $\rho \otimes \rho_{a m b}$ como um sistema fechado, então $U$ será um operador unitário. Como o que nos interessa é a evolução do sistema principal, então define-se

$$
\varepsilon(\rho)=\sum_{i} E_{i} \rho E_{i}^{\dagger}
$$

onde $E_{i}=\left\langle a_{i}|U| a_{0}\right\rangle$ para os estados do ambiente $\left|a_{i}\right\rangle$, com $i=0$ como estado inicial. Assim, fica claro que os operadores de Kraus $E_{k}$ descrevem a dinâmica do sistema principal sem considerar explicitamente as propriedades do ambiente. Vale então ressaltar que o processo de relaxação de diferentes sistemas (e.g. $S=1 / 2$ e $S>1 / 2$ ) pode ser descrita pelo mesmo conjunto de operadores, visto que o foco deste formalismo está somente na descrição do sistema principal e não na maneira como a interação com o banho térmico ocorre (10).

Em sistemas de RMN, os principais canais que atuam no processo de decoerência são: o canal de atenuação de fase, que descreve a perda de coerência ou de informação armazenada no sistema, e o canal de amplitude generalizada, relacionado à perda de energia para o ambiente, à temperaturas finitas.

No caso de um sistema de 2 spins $1 / 2$ não interagentes, estes canais são descritos pelos operadores de Kraus apresentados na Tabela 2.1, onde $\lambda, p$ e $\gamma$ são obtidos a partir das equações de Bloch $(10,17)$. Assim, o canal de atenuação de fase se relaciona à relaxação transversal do sistema (perda de coerência sem perda de energia). Sendo $T_{2}$ o tempo característico deste processo, então

$$
\lambda=\frac{1}{2}\left(1-e^{-t / 2 T_{2}}\right) .
$$


Tabela 2.1 - Operadores de Kraus que descrevem os canais de atenuação de fase e de amplitude generalizada para um sistema de 1 q-bit.

\begin{tabular}{cc}
\hline Atenuação de Fase & Atenuação de Amplitude Generalizada \\
\hline$E_{1}=\sqrt{p}\left[\begin{array}{cc}1 & 0 \\
0 & \sqrt{1-\gamma}\end{array}\right]$ \\
$E_{1}=\sqrt{\lambda}\left[\begin{array}{cc}1 & 0 \\
0 & 1\end{array}\right]$ \\
$E_{2}=\sqrt{p}\left[\begin{array}{cc}0 & \sqrt{\gamma} \\
0 & 0\end{array}\right]$ \\
$E_{2}=\sqrt{1-\lambda}\left[\begin{array}{cc}1 & 0 \\
0 & -1\end{array}\right]$ & $E_{3}=\sqrt{1-p}\left[\begin{array}{cc}\sqrt{1-\gamma} & 0 \\
0 & 1\end{array}\right]$ \\
$E_{4}=\sqrt{1-p}\left[\begin{array}{cc}0 & 0 \\
\sqrt{\gamma} & 0\end{array}\right]$
\end{tabular}

O canal de amplitude generalizada corresponde à relaxação longitudinal, que caracteriza a perda de energia do sistema. $T_{1}$ é o tempo característico deste processo e $p \approx 1 / 2-\alpha / 2$, para $\alpha$ como definido na Eq. 2.5.5. Assim, segue que

$$
\gamma=1-e^{-t / T_{1}}
$$

Para um sistema de 2 q-bits, a Eq. (2.8.13) pode ser diretamente generalizada. Se considerarmos, por exemplo, que cada parte do sistema (cada um dos q-bits) interage de forma local e independente com o ambiente, então a evolução temporal será descrita por $(18,19)$,

$$
\varepsilon\left(\rho_{A B}\right)=\sum_{i j}\left(E_{i}^{A} \otimes 1_{B}\right)\left(1_{A} \otimes E_{j}^{B}\right) \rho_{A B}\left(1_{A} \otimes E_{j}^{B}\right)^{\dagger}\left(E_{i}^{A} \otimes 1_{B}\right)^{\dagger}
$$

onde $E_{n}^{k}(k=A, B)$ são os operadores de Kraus relativos aos canais de decoerência que agem sobre o subsistema do spin $k$ e $\rho_{A B}$ é matriz densidade total do sistema.

Para sistemas de 2 spins $1 / 2$ acoplados via um acoplamento J fraco, o processo de decoerência de um q-bit é independente do outro e por esta razão o conjunto de operadores de Kraus $E_{n}^{k}$ é o mesmo descrito na Tabela 2.1, para cada um dos canais.

No entanto, para sistemas quadrupolares a perda de coerência não é independente para cada um dos q-bits e por isso o canal de atenuação de fase local, como apresentado na Tabela 2.1] não é capaz de destruir todas as coerências que podem existir entre os dois q-bits. 
Auccaise, R. and et al. (20), utilizando o formalismo de Redfield, mostraram que o decaimento dos elementos da matriz densidade de um sistema quadrupolar, é descrito por

$$
\begin{aligned}
& \rho_{12}(t)=\frac{1}{2}\left[\rho_{12}\left(t_{0}\right)+\rho_{34}\left(t_{0}\right)+\left(\rho_{12}\left(t_{0}\right)-\rho_{34}\left(t_{0}\right)\right) e^{-2 C J_{2}\left(t-t_{0}\right)}\right] e^{-C\left(J_{0}+J_{1}\right)\left(t-t_{0}\right)}, \\
& \rho_{34}(t)=\frac{1}{2}\left[\rho_{12}\left(t_{0}\right)+\rho_{34}\left(t_{0}\right)-\left(\rho_{12}\left(t_{0}\right)-\rho_{34}\left(t_{0}\right)\right) e^{-2 C J_{2}\left(t-t_{0}\right)}\right] e^{-C\left(J_{0}+J_{1}\right)\left(t-t_{0}\right)}, \\
& \rho_{13}(t)=\frac{1}{2}\left[\rho_{13}\left(t_{0}\right)+\rho_{24}\left(t_{0}\right)+\left(\rho_{13}\left(t_{0}\right)-\rho_{24}\left(t_{0}\right)\right) e^{-2 C J_{1}\left(t-t_{0}\right)}\right] e^{-C\left(J_{0}+J_{2}\right)\left(t-t_{0}\right)}, \\
& \rho_{24}(t)=\frac{1}{2}\left[\rho_{13}\left(t_{0}\right)+\rho_{24}\left(t_{0}\right)-\left(\rho_{13}\left(t_{0}\right)-\rho_{24}\left(t_{0}\right)\right) e^{-2 C J_{1}\left(t-t_{0}\right)}\right] e^{-C\left(J_{0}+J_{2}\right)\left(t-t_{0}\right)}, \\
& \rho_{23}(t)=\rho_{23}\left(t_{0}\right) e^{-C\left(J_{1}+J_{2}\right)\left(t-t_{0}\right)}, \\
& \rho_{14}(t)=\rho_{14}\left(t_{0}\right) e^{-C\left(J_{1}+J_{2}\right)\left(t-t_{0}\right)}, \\
& \rho_{11}(t)=3 p-\frac{1}{4}\left[R_{2}^{1} e^{-2 C\left(J_{1}+J_{2}\right)\left(t-t_{0}\right)}-R_{3}^{1} e^{-2 C J_{2}\left(t-t_{0}\right)}-R_{4}^{1} e^{-2 C J_{1}\left(t-t_{0}\right)}\right], \\
& \rho_{22}(t)=p+\frac{1}{4}\left[R_{2}^{1} e^{-2 C\left(J_{1}+J_{2}\right)\left(t-t_{0}\right)}+R_{3}^{1} e^{-2 C J_{2}\left(t-t_{0}\right)}-R_{4}^{1} e^{-2 C J_{1}\left(t-t_{0}\right)}\right], \\
& \rho_{33}(t)=-p+\frac{1}{4}\left[R_{2}^{1} e^{-2 C\left(J_{1}+J_{2}\right)\left(t-t_{0}\right)}-R_{3}^{1} e^{-2 C J_{2}\left(t-t_{0}\right)}+R_{4}^{1} e^{-2 C J_{1}\left(t-t_{0}\right)}\right], \\
& \rho_{44}(t)=-3 p-\frac{1}{4}\left[R_{2}^{1} e^{-2 C\left(J_{1}+J_{2}\right)\left(t-t_{0}\right)}+R_{3}^{1} e^{-2 C J_{2}\left(t-t_{0}\right)}+R_{4}^{1} e^{-2 C J_{1}\left(t-t_{0}\right)}\right],
\end{aligned}
$$

onde $J_{0}, J_{1}$ e $J_{2}$ correspondem às densidades espectrais reduzidas (21), responsáveis por caracterizar as flutuações nos campos eletromagnéticos ao redor dos q-bits causadas pelos movimentos moleculares e atômicos. A constante $C$ é um parâmetro relacionado ao acoplamento quadrupolar. Com isto, observa-se que as coerências da diagonal secundária não dependem da densidade espectral reduzida $J_{0}$, mas apenas de $J_{1}$ e $J_{2}$, enquanto que as demais coerências dependem destes três fatores. A partir disto, Souza, A. M. and et al. (22) demonstraram que estas coerências (correspondentes às correlações entre os estados $|00\rangle$ e $|11\rangle$ e entre $|01\rangle$ e $|10\rangle)$ não são afetadas pelo canal de atenuação de fase. Para que fosse possível descrever a decoerência de um sistema de spin 3/2 a partir do formalismo de operadores de Kraus, foi definido o Canal Global de Atenuação de Fase, para o qual

$$
E_{0}=\sqrt{1-\lambda}\left[\begin{array}{cccc}
1 & 0 & 0 & 0 \\
0 & -1 & 0 & 0 \\
0 & 0 & -1 & 0 \\
0 & 0 & 0 & 1
\end{array}\right], E_{1}=\sqrt{\lambda}\left[\begin{array}{cccc}
1 & 0 & 0 & 0 \\
0 & 1 & 0 & 0 \\
0 & 0 & 1 & 0 \\
0 & 0 & 0 & 1
\end{array}\right]
$$

onde, neste caso, $\lambda=\frac{1}{2}\left(1+e^{-C J_{0} t}\right)$. Assim, em sistemas quadrupolares, o processo de decoerência pode ser descrito por um canal global de atenuação de fase (que age conjuntamente nos dois q-bits) juntamente com dois canais locais de atenuação de amplitude generalizada 
(cada um atuando sobre um dos q-bits). Os canais de amplitude generalizada são exatamente os mesmo apresentados na Tabela 2.1, mas por comparação com as equações obtidas do formalismo de Redfield, os parâmetros $\left(p_{a}, \gamma_{a}\right)$ e $\left(p_{b}, \gamma_{b}\right)$, relativos aos operadores de Kraus para cada spin, são definidos como

$$
\begin{aligned}
p_{a} & =\frac{1}{2}\left(1-\alpha_{a}\right), \quad \gamma_{a}=1-e^{-2 C J_{2} t} \\
p_{b} & =\frac{1}{2}\left(1-\alpha_{b}\right), \quad \gamma_{b}=1-e^{-2 C J_{1} t}
\end{aligned} .
$$

Vale ressaltar que, ao contrário do que ocorre para o sistema de 2 spins 1/2 acoplados, no caso quadrupolar o decaimento dos elementos da matriz de correlação é multi-exponencial e por esta razão não é possível fazer uma analogia direta com os tempos de decaimento $T_{1}$ e $T_{2}$, definidos pelas equações de Bloch. 


\section{Ferramentas para o Processamento de Informação Quântica via RMN}

Como discutido na seção 2.5, os sistemas de RMN são sistemas de mistura estatística. À princípio, este tipo de sistema não é desejável no processamento de informação quântica $(23,24)$ visto que, em geral, neste tipo de processamento faz-se necessário preparar o sistema em estados bem definidos e a partir daí realizar ou processar operações ou algoritmos quânticos, por exemplo. No entanto, tem havido um crescente interesse no entendimento de sistemas mistos, principalmente devido às novas ferramentas teóricas desenvolvidas para o entendimento quântico de sistemas abertos. Neste sentido, sistemas de RMN são excelentes, pois o ambiente pode ser bem caracterizado e o sistema quântico (spins nucleares) pode ser manipulado de forma única pelos pulsos de RF, de modo a preparar estados mistos de interesse no estudo de propriedades quânticas de sistemas abertos. Para isto, faz-se necessário compreender os fundamentos e ferramentas utilizadas na preparação e manipulação de estados.

Por essa razão, neste capítulo apresentaremos o conceito e método de preparação de Estados Pseudo Puros, na seção 3.1. Na seção 3.2. trataremos do método de Pulsos Fortemente Modulados, utilizado para a preparação de estados iniciais e o emprego de portas lógicas. E na seção 3.3, apresentaremos a técnica de Tomografia de Estado Quântico (TEQ), uma ferramenta importante no processo de reconstrução de matrizes densidade.

\subsection{Estados Pseudo-Puros}

A Eq. (2.5.5) apresenta que a matriz densidade de um sistema possui uma parte proporcional à matriz identidade e uma parte denominada de matriz de desvio. Como em experimentos de RMN apenas a matriz de desvio contribui para o sinal detectável, é possível produzir rotações 
no estado de equilíbrio térmico em conjunto com processos de medida que gerem matrizes de desvio que podem ser relacionados à estados puros. Estes estados são denominados, Estados Puro Efetivos ou Pseudo-Puros (25, 26). No entanto, a matriz densidade de desvio no equilíbrio é proporcional à $I_{z}$, o que corresponde à um estado misto e, infelizmente, estados puros não podem ser produzidos a partir de transformações unitárias em estados mistos (7), visto que, se $\rho$ é uma mistura estatística então $\operatorname{Tr}\left(\rho^{2}\right)<1$. E se $\rho^{\prime}=U \rho U^{\dagger}$, onde $U$ é uma transformação unitária, logo

$$
\begin{aligned}
\operatorname{Tr}\left(\rho^{\prime 2}\right) & =\operatorname{Tr}\left(\left[U \rho U^{\dagger}\right]^{2}\right)=\operatorname{Tr}\left(U \rho U^{\dagger} U \rho U^{\dagger}\right) \\
& =\operatorname{Tr}\left(U \rho^{2} U^{\dagger}\right)=\operatorname{Tr}\left(\rho^{2}\right)<1
\end{aligned}
$$

Assim, para a produção de estados pseudo-puros também são necessárias rotações nãounitárias ou a realização de médias sobre diferentes estados mistos. Duas das técnicas empregadas neste processo são $(7,14,27)$ :

- Média Temporal: são criados alguns estados mistos através de transformações unitárias de forma que a soma destes estados corresponda a uma matriz que pode ser escrita em termos de uma parte proporcional à matriz identidade e uma parte correspondente ao estado puro desejado (28). Por exemplo (7), dada uma matriz densidade diagonal de dois q-bits, de um estado misto, dada por

$$
\rho_{i n i}=\left[\begin{array}{cccc}
a & 0 & 0 & 0 \\
0 & b & 0 & 0 \\
0 & 0 & c & 0 \\
0 & 0 & 0 & d
\end{array}\right]
$$

se um certo conjunto de transformações unitárias for aplicado neste estado inicial, tais como

$$
U_{0}=\left[\begin{array}{llll}
1 & 0 & 0 & 0 \\
0 & 1 & 0 & 0 \\
0 & 0 & 1 & 0 \\
0 & 0 & 0 & 1
\end{array}\right], U_{1}=\left[\begin{array}{llll}
1 & 0 & 0 & 0 \\
0 & 0 & 1 & 0 \\
0 & 0 & 0 & 1 \\
0 & 1 & 0 & 0
\end{array}\right], U_{2}=\left[\begin{array}{llll}
1 & 0 & 0 & 0 \\
0 & 0 & 0 & 1 \\
0 & 1 & 0 & 0 \\
0 & 0 & 1 & 0
\end{array}\right],
$$

onde $U_{0}$ é a matriz identidade, o que corresponde a aplicação de nenhuma porta lógica, 
e $U_{1}$ e $U_{2}$ são rotações correspondentes às seguintes sequências de pulsos,

$$
\begin{aligned}
U_{1} & =\left(\frac{\pi}{2}\right)_{x}^{I_{1}} U_{J}\left(\frac{1}{2 J}\right)\left(\frac{\pi}{2}\right)_{y}^{I_{1}}\left(\frac{\pi}{2}\right)_{x}^{I_{2}} U_{J}\left(\frac{1}{2 J}\right)\left(\frac{\pi}{2}\right)_{y}^{I_{2}} \\
U_{2} & =\left(\frac{\pi}{2}\right)_{y}^{I_{2}} U_{J}\left(\frac{1}{2 J}\right)\left(\frac{\pi}{2}\right)_{x}^{I_{2}}\left(\frac{\pi}{2}\right)_{y}^{I_{1}} U_{J}\left(\frac{1}{2 J}\right)\left(\frac{\pi}{2}\right)_{x}^{I_{1}} .
\end{aligned}
$$

Com isto, obtemos

$$
\rho=U_{0} \rho_{i n i} U_{0}^{\dagger}+U_{1} \rho_{i n i} U_{1}^{\dagger}+U_{2} \rho_{i n i} U_{2}^{\dagger}=\left[\begin{array}{cccc}
3 a & 0 & 0 & 0 \\
0 & b+c+d & 0 & 0 \\
0 & 0 & b+c+d & 0 \\
0 & 0 & 0 & b+c+d
\end{array}\right],
$$

mas sendo $\rho_{\text {ini }}$ uma matriz densidade, então $a+b+c+d=1$. Consequentemente

$$
\rho=\left[\begin{array}{cccc}
1-a & 0 & 0 & 0 \\
0 & 1-a & 0 & 0 \\
0 & 0 & 1-a & 0 \\
0 & 0 & 0 & 1-a
\end{array}\right]+\left[\begin{array}{cccc}
4 a-1 & 0 & 0 & 0 \\
0 & 0 & 0 & 0 \\
0 & 0 & 0 & 0 \\
0 & 0 & 0 & 0
\end{array}\right]
$$

ou seja, $\rho=(1-a) \mathbb{I}+(4 a-1)|00\rangle\langle 00|$. Como o primeiro termo desta soma é proporcional à identidade, então não é afetado pela ação dos pulsos de RF e nem contribui para o sinal detectável. Assim, esta matriz densidade pode ser usada como uma representação de um estado puro.

- Média Espacial: esta técnica combina o uso de pulsos de RF com gradientes de campo magnético. Desta forma, o sistema é espacialmente dividido em vários sub-ensembles e cada um deles adquiri uma evolução distinta pela ação do gradiente de campo. estado pseudo-puro desejado corresponderá à média sobre todos os sub-ensembles. A grande vantagem deste método é que neste caso não é necessário combinar diferentes estados finais, mas o estado é obtido após uma única aplicação da sequência de pulsos. Por exemplo (7), se uma operação na forma

$$
U=\frac{1}{\sqrt{2}}\left[\begin{array}{cccc}
\sqrt{2} & 0 & 0 & 0 \\
0 & 0 & i \sqrt{2} & 0 \\
0 & i & 0 & i \\
0 & -1 & 0 & 1
\end{array}\right]
$$

for aplicada à matriz de equilíbrio térmico de um sistema de spins $3 / 2$, então a matriz 
densidade resultante será,

$$
\rho=\frac{1}{4}\left[\begin{array}{cccc}
1 & 0 & 0 & 0 \\
0 & 1 & 0 & 0 \\
0 & 0 & 1 & 0 \\
0 & 0 & 0 & 1
\end{array}\right]+\frac{\hbar \omega_{0}}{4 k_{B} T}\left[\begin{array}{cccc}
3 / 2 & 0 & 0 & 0 \\
0 & -1 / 2 & 0 & 0 \\
0 & 0 & -1 / 2 & -i \\
0 & 0 & i & -1 / 2
\end{array}\right] .
$$

Observa-se, então, que o segundo termo desta matriz pode ser reescrito na forma,

$$
\left[\begin{array}{cccc}
3 / 2 & 0 & 0 & 0 \\
0 & -1 / 2 & 0 & 0 \\
0 & 0 & -1 / 2 & -i \\
0 & 0 & i & -1 / 2
\end{array}\right]=-\frac{1}{2}\left[\begin{array}{cccc}
1 & 0 & 0 & 0 \\
0 & 1 & 0 & 0 \\
0 & 0 & 1 & 0 \\
0 & 0 & 0 & 1
\end{array}\right]+2\left[\begin{array}{cccc}
1 & 0 & 0 & 0 \\
0 & 0 & 0 & 0 \\
0 & 0 & 0 & -i \\
0 & 0 & i & 0
\end{array}\right]
$$

ou seja, em termos de uma parte proporcional à identidade e uma parte que possui a mesma forma do estado pseudo-puro $|00\rangle$ exceto pela presença dos termos fora da diagonal. Neste caso, aplica-se um pulso de gradiente de campo que introduz uma defasagem nas coerências em função de sua localização espacial ao longo da amostra. Assim, pode-se considerar que a amostra está dividida em vários sub-ensembles, todos com a mesma distribuição de população mas com uma defasagem nas coerências que varia, ao longo de toda a amostra, de 0 a $2 \pi$. Assim, a matriz densidade média sobre um número razoável de sub-ensembles passa a ser exatamente equivalente ao estado pseudo-puro $|00\rangle$.

\subsection{Pulsos Fortemente Modulados (SMP)}

Pulsos de RF são ditos modulados em amplitude ou fase quando as curvas de amplitude $B_{1}(t)$ ou de fase $\phi(t)$ possuem uma certa dependência temporal de maneira que o sistema de spins sofre uma evolução temporal específica. O caso em que os parâmetros $B_{1}$ e $\phi$ são mantidos constantes ao longo de toda a duração do pulso, denomina-se de Pulsos Retângulares. Partindo destas idéias, Fortunato, E. et al. (29) propuseram a utilização de uma sequência de transições discretas nos parâmetros do pulso de RF, ou seja cada pulso é dividido em um número $k$ de segmentos (pulsos retangulares) de forma que durante cada segmento os três 
parâmetros do pulso: amplitude $\left(\omega_{k}\right)$, fase $\left(\phi_{k}\right)$, duração $\left(t_{k}\right)$ são mantidos constantes,

$$
U_{\mathrm{SMP}}=\sum_{n=1}^{k} U\left(\omega_{n}, \phi_{n}, t_{n}\right) .
$$

Esses parâmetros são, então, escolhidos (utilizando um método de otimização numérica) de modo que o pulso como um todo execute uma certa operação unitária. Pode-se também otimizar um conjunto finito desses pulsos de modo que quando aplicados independentemente no estado de equilíbrio térmico gerem estados que quando somados produzam um estado pseudo-puro, de forma semelhante ao que é feito no método de média temporal. Em ambos os casos, o ponto chave é a otimização para produzir a rotação ou o estado desejado. Este método ficou conhecido como Strong Modulated Pulses (SMP).

O método de otimização numérica por trás dos pulsos SMP se baseia no fato de que com um número suficiente de parâmetros de controle qualquer tipo de evolução temporal pode, a princípio, ser representada. Assim, para cada segmento de um pulso SMP, o método busca a combinação ideal de fase, freqüência e amplitude que modulem o pulso de RF correspondente à evolução desejada. Na realidade, não existe um método analítico simples que a partir de uma evolução temporal forneça os parâmetros de pulso correspondentes, no entanto o cálculo inverso é bastante simples. Ou seja, dado um conjunto de parâmetros, é possível obter a transformação gerada por ele. Portanto, para um dado grupo de parâmetros, se soubermos medir o quão próximo esta evolução está do objetivo poderemos ajustar os parâmetros para que a transformação desejada seja encontrada.

A avaliação da proximidade entre a transformação obtida e a desejada é feita através do cálculo da fidelidade (29), o que nada mais é do que a projeção de um estado sobre o outro. Assim, se $\rho_{\text {alvo }}$ corresponde à matriz densidade desejada e $\rho_{s m p}$ à matriz obtida pelo método de SMP, então

$$
F\left(\rho_{\text {alvo }}, \rho_{\text {smp }}\right)=\frac{\operatorname{Tr}\left(\rho_{\text {alvo }} \rho_{\text {smp }}\right)}{\sqrt{\operatorname{Tr}\left(\rho_{\text {alvo }}^{2}\right) \operatorname{Tr}\left(\rho_{\text {alvo }}^{2}\right)}}
$$

onde, a função fidelidade varia de -1 , para estados antiparalelos, até 1 , para estados paralelos, passando por 0 no caso de estados ortogonais. Como, em geral, os algoritmos de otimização são construídos de forma a minimizar uma função, definimos $F_{-}=1-F$ de forma que $F_{-}=0(F=1)$ corresponde à uma otimização perfeita.

Para se determinar os parâmetros ótimos do SMP, ou seja, aqueles que fornecem o estado final com maior fidalidade, utilizamos o método de minimização Simplex Nelder-Mead (30). O programa parte de um valor inicial aleatório para os parâmetros que constituem o pulso 


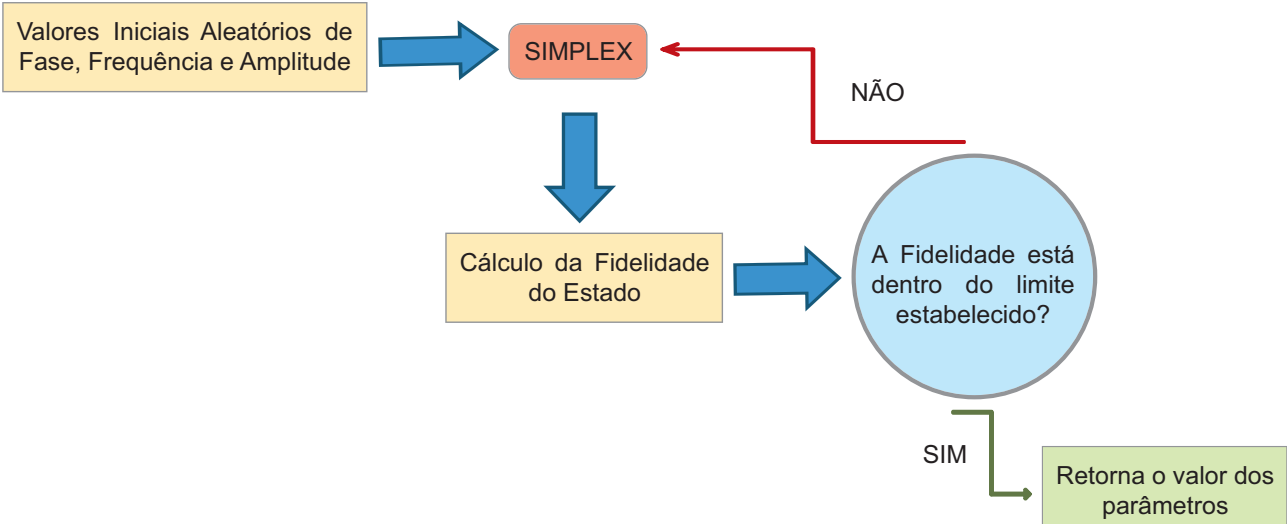

Figura 3.1- Fluxograma descrevendo o programa de otimização de SMPs.

em busca do SMP ideal, após uma execução do Simplex a fidelidade do resultado obtido é verificada. Caso a fidelidade esteja dentro de um limite pré-estabelecido, o programa retorna os parâmetros encontrados. Caso contrário, outra seqüência de Simplex é executada até que um valor suficientemente bom seja obtido, o fluxograma na Figura 3.1 ilustra este procedimento. Mais detalhes sobre este método podem ser encontrados nas Ref. (27, 31).

Para a busca dos valores de amplitude, frequência e fase dos pulsos é necessário definir um intervalo de varredura dentro das restrições experimentais destes parâmetros. Esta delimitação foi feita através da redefinição da função fidelidade na forma $F_{-}^{\prime}=F_{-}+P$, onde $\mathrm{P}$ é denominada função Penalidade e assume valores positivos altos para pontos correspondentes à valores de amplitude, frequência e fase fora dos limites e valor zero para pontos dentro destes limites. Desta forma, o algoritmo não fornecerá valores para os parâmetros que não poderão ser implementados. Além destas restrições, a qualidade de um SMP também deve levar em consideração a duração de cada segmento de pulso e a variação da amplitude entre segmentos consecutivos, o que é importante devido à resposta do sistema real. Como a criação dos pulsos de RF é feita via indução de Faraday, por mais que a eletrônica seja capaz de criar com precisão pulsos das mais variadas formas, pulsos extremamente curtos não fornecem tempo hábil para uma boa resposta da bobina, bem como variações bruscas nos valores de amplitude também não apresentam boa resposta. Considerando estes fatores, estabelecemos os limites de:

- 0 a $\frac{\pi}{40} \cdot 10^{-6}$ para a amplitude;

- 0 a $2 \pi$ para a fase;

- 0 a $90 \cdot 10^{-6}$ para a duração total de cada uma das 4 etapas da média, sendo $5 \cdot 10^{-6}$ a duração mínima de cada segmento. 
Além disso, estabelecemos o critério de que a variação da amplitude de um dos segmento do pulso para outro não poderia ser maior que $35 \%$.

Como discutido na seção anterior, 3.1, não é possível produzir um estado pseudo puro diretamente a partir de uma mistura estatística, mas isto pode ser feito empregando-se os métodos de média temporal ou espacial. Por esta razão, na otimização dos estados utilizamos um algoritmo que produzia 4 sequências de SMP, necessárias para a realização da média temporal. No caso dos estados aqui implementados, utilizamos SMP's com 5 segmentos, o que já foi suficiente para obter bons resultados finais de fidelidade.

\subsection{Tomografia de Estado Quântico (TEQ)}

Como apresentado na seção 2.5, toda a informação relevante de um sistema está contida na matriz densidade que o representa. E no caso de sistemas de RMN, mais especificamente, na matriz de desvio. Sendo assim, dado um sistema qualquer de dois q-bits ( $I$ e $S$ ), descrito por uma matriz de desvio na forma,

$$
\Delta \rho=\left[\begin{array}{cccc}
\rho_{11} & \rho_{12} & \rho_{13} & \rho_{14} \\
\rho_{12} & \rho_{22} & \rho_{23} & \rho_{24} \\
\rho_{13} & \rho_{23} & \rho_{33} & \rho_{34} \\
\rho_{14} & \rho_{24} & \rho_{34} & \rho_{44}
\end{array}\right],
$$

se realizarmos uma medida de RMN sobre o primeiro q-bit, que matematicamente pode ser escrita como,

$$
M_{+} \propto \operatorname{Tr}\left\{\Delta \rho I_{+}\right\}
$$

onde $I_{+}=\left(I_{x}+i I_{y}\right)$, apenas algumas posições desta matriz densidade poderão ser observadas, ou seja, correspondem a observáveis diretos de RMN. Por exemplo, supondo que este sistema seja um sistema de 2 spins $1 / 2$ acoplados. Então, $I_{x}=\frac{1}{2}\left(\sigma_{x} \otimes \mathbb{I}\right)$ e $I_{y}=\frac{1}{2}\left(\sigma_{y} \otimes \mathbb{I}\right)$, onde $\sigma_{x}$ 
e $\sigma_{y}$ são os operadores de Pauli, dados pela Eq. (2.4.2). Com isso, segue que

$$
\begin{aligned}
M_{+} \propto \operatorname{Tr}\left\{\left[\begin{array}{cccc}
\rho_{11} & \rho_{12} & \rho_{13} & \rho_{14} \\
\rho_{12} & \rho_{22} & \rho_{23} & \rho_{24} \\
\rho_{13} & \rho_{23} & \rho_{33} & \rho_{34} \\
\rho_{14} & \rho_{24} & \rho_{34} & \rho_{44}
\end{array}\right] \cdot\left[\begin{array}{cccc}
0 & 0 & 1 & 0 \\
0 & 0 & 0 & 1 \\
0 & 0 & 0 & 0 \\
0 & 0 & 0 & 0
\end{array}\right]\right\} \\
=\rho_{13}+\rho_{24} .
\end{aligned}
$$

De forma semelhante, se uma medida for feita sobre o segundo q-bit,

$$
\begin{aligned}
M_{+} \propto \operatorname{Tr}\left\{\Delta \rho S_{+}\right\} \\
=\operatorname{Tr}\left\{\left[\begin{array}{llll}
\rho_{11} & \rho_{12} & \rho_{13} & \rho_{14} \\
\rho_{12} & \rho_{22} & \rho_{23} & \rho_{24} \\
\rho_{13} & \rho_{23} & \rho_{33} & \rho_{34} \\
\rho_{14} & \rho_{24} & \rho_{34} & \rho_{44}
\end{array}\right] \cdot\left[\begin{array}{llll}
0 & 1 & 0 & 0 \\
0 & 0 & 0 & 0 \\
0 & 0 & 0 & 1 \\
0 & 0 & 0 & 0
\end{array}\right]\right\} \\
=\rho_{12}+\rho_{34},
\end{aligned}
$$

onde $S_{+}=\left(S_{x}+i S_{y}\right)$, para $S_{x}=\frac{1}{2}\left(\mathbb{I} \otimes \sigma_{x}\right)$ e $S_{y}=\frac{1}{2}\left(\mathbb{I} \otimes \sigma_{y}\right)$. Assim, neste caso, apenas os elementos $\rho_{12}, \rho_{13}, \rho_{24}, \rho_{34}$ são observáveis diretos de RMN, também chamados de Posições de Leitura.

No caso de um sistema de spins $3 / 2$, o operador de medida direta é dado por

$$
I_{+}=I_{x}+i I_{y}=\left[\begin{array}{cccc}
0 & \sqrt{3} & 0 & 0 \\
0 & 0 & 2 & 0 \\
0 & 0 & 0 & \sqrt{3} \\
0 & 0 & 0 & 0
\end{array}\right] .
$$

Consequentemente, as posições de leitura serão $\rho_{12}, \rho_{23}, \rho_{34}$.

O método de TEQ tem como objetivo determinar completamente a matriz densidade de um sistema. No entanto, como apenas as posições de leitura são diretamente acessíveis, a tomografia consiste em aplicar pulsos de RF de forma que os elementos das demais posições sejam transferidos para as posições de leitura, de forma que quando uma nova leitura for realizada outros elementos da matriz densidade se tornem observáveis. Por exemplo, sendo 


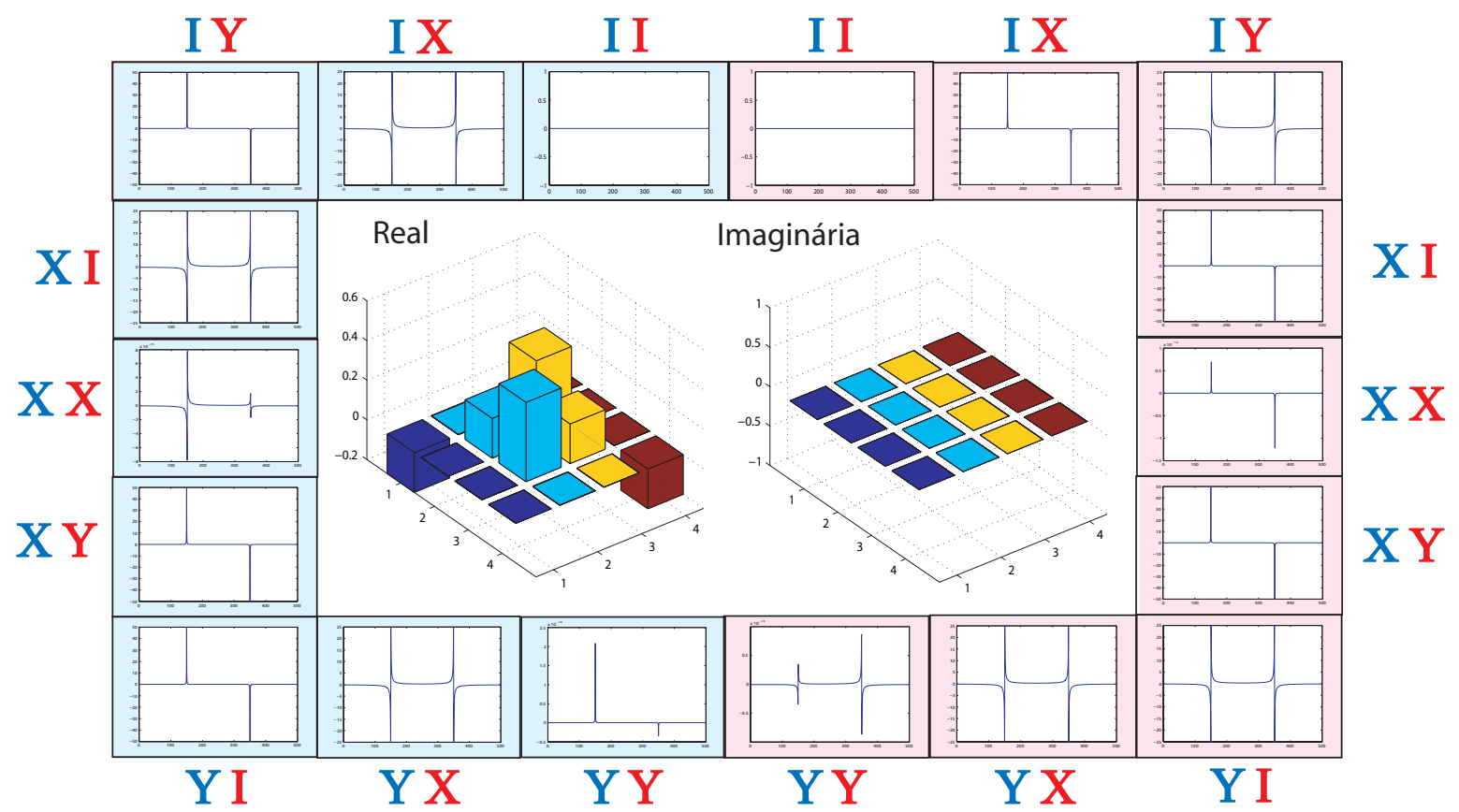

Figura 3.2 - Ilustração da técnica de tomografia para um sistema de dois spins $1 / 2$ acoplados via acoplamento J. No centro da figura, gráficos em barras representando as partes real e imaginária da matriz densidade e ao redor apresenta-se os espectros com os respectivos pulsos em destaque, onde $I$ representa o operador identidade e $X$ e $Y$ são as fases dos pulsos $\pi / 2$. Em azul estão as fases dos pulsos a serem aplicados no primeiro q-bit e em vermelho no segundo q-bit. Os espectros em azul indicam que a aquisição ocorreu no primeiro e em rosa no segundo q-bit.

um pulso $\pi / 2$ de fase $x$ sobre o primeiro q-bit de um sistema de 2 spins $1 / 2$ da forma,

$$
R_{x}(\pi / 2)=\left[\begin{array}{cccc}
\sqrt{3} & 0 & -i \sqrt{3} & 0 \\
0 & \sqrt{3} & 0 & -i \sqrt{3} \\
-i \sqrt{3} & 0 & \sqrt{3} & 0 \\
0 & -i \sqrt{3} & 0 & \sqrt{3}
\end{array}\right]
$$

então, após a aplicação deste pulso e de uma nova leitura, o resultado obtido será

$$
\begin{aligned}
M_{+} & \propto \operatorname{Tr}\left\{R_{x}(\pi / 2) \Delta \rho R_{x}(\pi / 2)^{\dagger} I_{+}\right\} \\
& =6\left(\rho_{13}+\rho_{24}\right)-3 i\left(\rho_{11}+\rho_{22}-\rho_{33}-\rho_{44}\right) .
\end{aligned}
$$

Com isto, os elementos diagonais na matriz de desvio também se tornam observáveis de RMN e, desta forma, é possível reconstruir completamente a matriz densidade.

A Figura 3.2 apresenta um exemplo de aplicação desta técnica em um sistema de 2 spins $1 / 2$ acoplados via acoplamento J. No centro da figura, gráficos em barras representam as partes real e imaginária da matriz densidade e ao redor apresenta-se os espectros com os respectivos pulsos em destaque, onde $I$ representa o operador identidade e $X$ e $Y$ são as 
fases dos pulsos $\pi / 2$. Em azul estão as fases dos pulsos a serem aplicados no primeiro q-bit e em vermelho no segundo q-bit. Os espectros em azul indicam que a aquisição ocorreu no primeiro e em rosa no segundo q-bit. Assim, para a reconstrução total da matriz densidade é necessário realizar 18 aquisições de espectro, 9 para cada q-bit. Os espectros contribuem com 4 valores de amplitude, referentes as partes real e imaginária de cada uma das duas linhas. Com isso, são obtidos 72 valores que serão associados, cada um, à uma equação como a Eq. (3.3.7). Estas equações compõem um sistema que poderá ser resolvido através de um método numérico modificado de mínimos quadrados (32). Portanto, apesar de eficiente, o método de TEQ pode implicar em experimentos de longa duração e que envolvam empregar vários cálculos matemáticos na reconstrução da matriz densidade desejada. Além deste método, existem outros métodos otimizados envolvendo um número menor de leituras, como o método apresentado por Nielsen e Chuang (10), no entanto, para algumas aplicações, este método não garante uma boa precisão nos resultados.

No caso de sistemas quadrupolares, o método de TEQ foi implementado inicialmente utilizando-se esta mesma idéia, ou seja, aplicar plusos de RF para transferir os elementos da matriz de desvio para as posições de leitura e, com isto, obter um conjunto de equações que permita reconstruir a matriz densidade. No entanto, para a realização deste procedimento era necessário aplicar pulsos seletivos (7, 33), o que, em geral, é pouco conveniente devido à sua longa duração. A implementação deste método via pulsos não-seletivos foi desenvolvida no trabalho de doutorado de João Teles de Carvalho Neto (27). Faremos aqui uma breve exposição deste método voltado para aplicação em sistemas de spin $3 / 2$, para maiores detalhes vide $(27,32)$.

Como o método de TEQ baseia-se na aplicação de rotações sobre um sistema para que elementos fora das posições de leitura possam ser observados, é interessante expandir o operador densidade na base dos Tensores Irredutíveis $\left(T_{l m}\right)$, visto que esta apresenta propriedades interessantes sob rotações. Com isto, escrevemos

$$
\rho=\sum_{l m} a_{l m} T_{l m}
$$

Assim, o objetivo deste método é determinar os coeficientes da expansão $\left(a_{l m}\right)$. Aplicandose uma rotação na matriz densidade $\rho$,

$$
\tilde{\rho}=U_{R} \rho U_{R}^{\dagger}
$$

onde $U_{R}=e^{i \theta I \hat{u}_{\phi}}$, representa uma rotação de um ângulo $\theta$ na direção $\phi$. Estes ângulos podem ser escrito em termos dos ângulos de Euler, $D(\alpha, \beta, \gamma)=e^{-i \alpha I_{z}} e^{-i \beta I_{y}} e^{-i \gamma I_{z}}$, que se 
relacionam com os ângulos de rotação de acordo com:

$$
\begin{aligned}
& \alpha=-\gamma=-\phi-\frac{\pi}{2} \\
& \beta=-\theta
\end{aligned}
$$

Sob rotações, os tensores irredutíveis se transformam de forma que,

$$
D(\alpha, \beta, \gamma) T_{l m} D^{\dagger}(\alpha, \beta, \gamma)=\sum_{m^{\prime}=-l}^{l} D_{m m^{\prime}}^{l}(\alpha, \beta, \gamma) T_{l m^{\prime}}
$$

onde as funções $D_{m m^{\prime}}^{l}$ podem ser expressas em termos das funções de Wigner reduzidas,

$$
D_{m m^{\prime}}^{l}(\alpha, \beta, \gamma)=e^{-i m^{\prime} \alpha} d_{m m^{\prime}}^{l}(\beta) e^{-i m \gamma}
$$

Com isto, a matriz densidade rotacionada pode ser escrita como,

$$
\tilde{\rho}=\sum_{l, m} a_{l m} \sum_{m^{\prime}} e^{i\left(m-m^{\prime}\right)(\phi-\pi / 2)} d_{m m^{\prime}}^{l}(-\theta) T_{l m^{\prime}}
$$

O sinal de RMN (proporcional à magnetização transversal) obtido a partir deste estado será, então

$$
M_{+}(t)=\operatorname{Tr}\left\{U_{\text {evol }}(t) \cdot \tilde{\rho} \cdot U_{\text {evol }}^{\dagger}(t) \cdot I_{+}\right\} e^{i \alpha_{R}},
$$

onde $I_{+}=I_{x}+i I_{y}, U_{\text {evol }}=e^{-i H t / \hbar}$ é o operador de evolução temporal, com $H$ a Hamiltoniana livre de perturbações de RF (como descrito na seção 2.3) e $\alpha_{R}$ o ângulo entre o eixo $x$ dos pulsos de RF e a direção definida como eixo real da detecção, ou seja, a fase do receptor.

Substituindo a equação (3.3.12) em (3.3.13), faz-se necessário calcular

$$
\operatorname{Tr}\left\{T_{l m^{\prime}} U_{\text {evol }}^{\dagger} I_{+} U_{\text {evol }}\right\}=\sum_{i j} e^{i \omega_{i j} t}\left[I_{+}\right]_{i j}\left[T_{l m^{\prime}}\right]_{j i}
$$

onde usamos que $\omega_{i j}=\left(E_{i}-E_{j}\right) / \hbar$. Como o operador $I_{+}$é função apenas dos tensores de ordem $m=1$ e os tensores irredutíveis satisfazem a relação,

$$
T_{l, m}=(-1)^{m} T_{l,-m}
$$

então segue que,

$$
\operatorname{Tr}\left\{T_{l m^{\prime}} U_{\text {evol }}^{\dagger} I_{+} U_{\text {evol }}\right\}=\delta_{m^{\prime},-1} \sum_{i, j} e^{i \omega_{i j} t}\left[I_{+}\right]_{i j}\left[T_{l,-1}\right]_{j i}
$$

Sendo $M(t)=\sum_{i j} f_{i j}(t) S_{i j}$, onde $f_{i j}$ são as oscilações correpondentes às frequências de 
transição e $S_{i j}$ as amplitudes espectrais. Então, substituindo (3.3.14) em (3.3.13) e aplicando a propriedade das funções de Wigner reduzidas: $d_{-1,-m}^{l}=(-1)^{m-1} d_{1, m}^{l}$ obtemos

$$
S_{i j}=\sum_{l m} a_{l m} e^{i(m+1)(\phi-\pi / 2)} d_{m,-1}^{l}(-\theta)\left[I_{+}\right]_{i j}\left[T_{l,-1}\right]_{j i} e^{i \alpha_{R}}
$$

O próximo passo do método consiste em realizar o processo conhecido como seleção de corerências, ou seja, obter um sinal que seja proveniente de uma única ordem $m$ de coerência. Isto pode ser feito aplicando-se o método de média temporal de forma similar ao que é feito na produção de estados pseudo-puros (como exposto na Seção 3.1). Em cada passo $N$ da média, as fases $\phi$ e $\alpha_{R}$ devem ser adequadamente variadas de forma que as contribuições indesejadas sejam eliminadas, assim

$$
\bar{S}_{i j}=\frac{1}{N} \sum_{n=0}^{N-1} S_{i j}\left(\phi_{n}, \alpha_{R n}\right)
$$

satizfazendo

$$
\begin{array}{r}
\phi_{n}=2 \pi n / N+\pi / 2 \\
\alpha_{R n}=2 \pi n(m-1) / N \\
N \geq 4+m,
\end{array}
$$

o que resulta em,

$$
\bar{S}_{i j}=\sum_{l, m} a_{l m} d_{1, m}^{l}(-\theta)\left[A_{l}\right]_{i j} \sum_{n=0}^{N-1} e^{i 2 \pi n\left(m^{\prime}-m\right) / N},
$$

onde $\left[A_{l}\right]_{i j}=\left[I_{+}\right]_{i j}\left[T_{l,-1}\right]_{j i}$. E com isto, obtém-se a seleção da coerência de ordem $m^{\prime}$,

$$
\sum_{n=0}^{N-1} e^{i 2 \pi n\left(m^{\prime}-m\right) / N}=N \delta_{m, m^{\prime}}
$$

Logo,

$$
\bar{S}_{i j}\left(m^{\prime}\right)=\sum_{l} a_{l m^{\prime}} d_{1, m^{\prime}}^{l}(-\theta)\left[A_{l}\right]_{i j}
$$

E com isto, obtém o sistema linear que permite obter os coeficientes $a_{l m}$,

$$
\begin{aligned}
& \mathbf{A} \cdot \mathbf{x}=\mathbf{b} \\
& A_{p, q}=\left[A_{l}\right]_{i j} \\
& x_{q}=a_{l m^{\prime}} d_{1, m^{\prime}}^{l}(-\theta) \\
& b_{p}=\bar{S}_{i j}\left(m^{\prime}\right)
\end{aligned}
$$




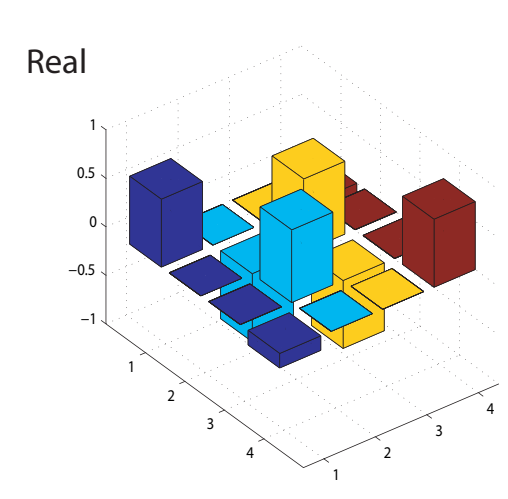

Imaginária

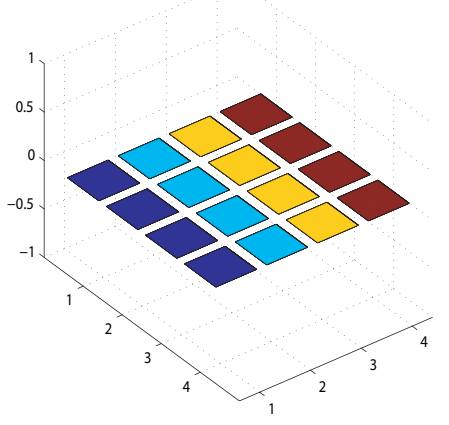

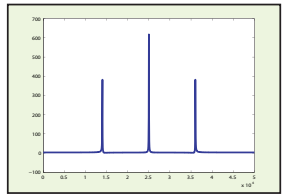

Equilíbrio
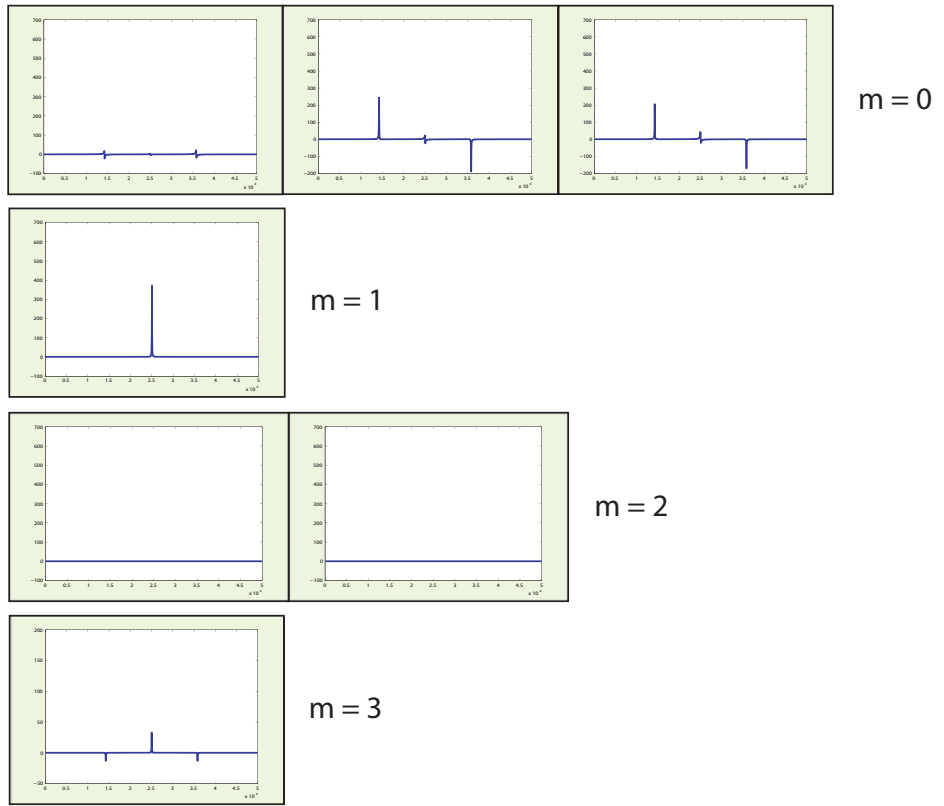

Figura 3.3 - Ilustração da técnica de tomografia para um sistema de spins $3 / 2$. À esquerda gráficos em barras representam as partes real e imaginária da matriz densidade utilizada neste exemplo. E à direita vemos os espectros obtidos após a realização do número correspondente de médias para cada ordem de coerência, bem como o espectro de equilíbrio que é utilizado para a normalização dos gráficos.

A Figura 3.3 apresenta um exemplo de tomografia para um sistema de spins $3 / 2$. Primeiramente adquire-se um espectro do equilíbrio do sistema, que é utilizado como referência no tratamento de dados. Para melhorar a precisão na determinação dos elementos da matriz densidade é necessário aplicar rotações adicionais para obter as coerências de ordem 0 e 2 , por esta razão foram obtidos mais de um espectro nestes casos. Assim, com os oito espectros apresentados na figura é possível reconstruir a matriz densidade representada pelo diagrama de blocos, à esquerda. Os valores de $\theta, \phi$ e $\alpha_{R}$ necessários para a realização da tomografia podem ser encontrados nas Referências (27, 32). 


\section{Medidas de Correlação Quântica}

Qual a diferença entre estados clássicos e quânticos? Por muito tempo, acreditou-se que o emaranhamento era o único responsável por esta diferença, o que foi embasado na demostração de que as desigualdades de Bell não poderiam ser violadas simplesmente por superposições clássicas ou quânticas (5), mas que era imprescindível a existência de emaranhamento para que o limite clássico fosse ultrapassado. Nas palavras de Schrödinger (5), o emaranhamento não era uma entre outras características da física quântica, mas a característica essencial dela. Com isto, as primeiras pesquisas na área de informação quântica foram baseadas nesta propriedade e muitos resultados experimentais foram obtidos.

Em 1997, a técnica de RMN passou a ser aplicada na área de informação/computação quântica, apresentando-se como uma candidata promissora para o desenvolvimento de estudos na área. No entanto, quando foi demonstrado, em 1999, que não é possível produzir emaranhamento em sistemas de RMN convencionais à temperatura ambiente, o uso da técnica em experimentos de informação quântica foi amplamente criticado (34). Mas devido ao modelo de computação desenvolvido por Knill e Laflamme (1) em 1998, denominado DQC1, onde um algoritmo quântico utilizando estados mistos para a determinação do traço normalizado de uma matriz poderia fornecer um ganho exponencial de eficiência em relação aos algoritmos clássicos, a aplicação da técnica de RMN nesta área permaneceu como uma possibilidade. Posteriormente, em 2001, Henderson e Vedral (2), e Ollivier e Zurek (3), mostraram que estados separáveis podem apresentar correlações não-clássicas diferentes do emaranhamento, o que foi denominado Discórdia Quântica.

Os quantificadores de Discórdia Quântica, sobre os quais trataremos neste trabalho, podem ser divididos em três grupos, (4):

1. Quantificadores que medem a quantidade de ruído que é injetada no sistema quando uma medida é realizada, um exemplo é a Discórdia Entrópica (seção 4.1).

2. Quantificadores que medem a distância mínima entre o estado e o estado clássico mais próximo, por exemplo as medidas de entropia relativa e a Discórdia Geométrica (seção 4.2). 


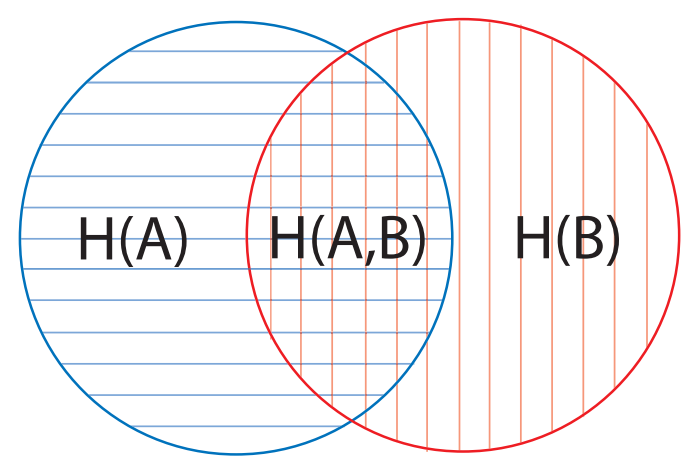

Figura 4.1 - Diagrama de Venn representando a informação mútua total devida a soma de informações contidas nas variáveis aleatória $A$ e $B, H(A)$ e $H(B)$ respectivamente. Observar que na soma a informação contida em ambas é considerada duas vezes.

3. Quantificadores que associam a quantidade mínima de emaranhamento que é criado entre o sistema e o instrumento de medida usado em uma medida local, com a discórdia presente no sistema inicial. Para este tipo de medida usaremos a Negatividade (seção 4.3).

\subsection{Correlação Clássica x Correlação Quântica}

Na teoria de informação clássica (10), define-se a entropia de Shannon de uma variável aleatória $A, H(A)$, como sendo a quantidade de informação que se ganha, em média, quando se conhece o seu valor, ou a incerteza sobre esta variável $A$ antes de se conhecê-la. Define-se como

$$
H(A)=-\sum_{a \in A} P(a) \log _{2} P(a)
$$

Dadas duas variáveis aleatórias $A$ e $B$, a informação mútua, $I_{c}(A: B)$, mede a correlação entre elas, ou seja, o quanto de informação elas podem fornecer conjuntamente. No entanto, quando se soma a informação contida em $A$ com a informação contida em $B$, a informação contida em ambas é somada duas vezes, como pode ser melhor vizualizado na Figura 4.1. Assim, define-se

$$
I_{c}(A: B)=H(A)+H(B)-H(A, B) .
$$


Com base na Regra de Bayes para a probabilidade condicional, $P(A / B)=\frac{P(A, B)}{P(B)}$, introduz-se o conceito de entropia condicional, $H(A / B)$, que corresponde à quantidade de incerteza sobre $A$ dado que se conhece o valor de $B$. Considerando ainda que $\sum_{A} \mathrm{P}(\mathrm{A}, \mathrm{B})$ $=P(B)$, então é possível reescrever a informação mútua, Eq. (4.1.2), na seguinte forma equivalente,

$$
J_{c}(A: B)=H(A)-H(A / B) .
$$

Portanto, no caso clássico $I_{c}$ e $J_{c}$ representam a mesma grandeza, valendo

$$
I_{c}(A: B)-J_{c}(A: B)=0
$$

Estados quânticos podem ser descritos de maneira semelhante substituindo-se as distribuições de probabilidade pelos operadores densidade. Von Neumann definiu a entropia de um estado quântico $\rho$ como sendo (10),

$$
S(\rho) \equiv-\operatorname{Tr}(\rho \log \rho)
$$

Assim, por analogia à Eq. (4.1.2), define-se a informação quântica mútua de um sistema biparticionado, $I\left(\rho_{A: B}\right)$, como sendo

$$
I\left(\rho_{A: B}\right)=S\left(\rho_{A}\right)+S\left(\rho_{B}\right)-S\left(\rho_{A: B}\right)
$$

que é a medida da correlação total (clássica e quântica) contida neste sistema (35).

No entanto, a correspondência da Eq. (4.1.3) para o caso quântico não é tão direta. Neste caso é necessário conhecer o correspondente quântico para a entropia condicional, $H(A / B)$. Conhecer o estado $\rho_{B}$ implica em realizar medidas sobre ele, o que pode ser escrito em termos de projetores, $\prod_{j}^{B}$, onde j distingue os resultados de cada medida (36). Então, após a medida-j sobre a partição $B, \rho_{A B} \rightarrow\left(\mathbb{I}_{A} \otimes \prod_{j}^{B}\right) \rho_{A B}\left(\mathbb{I}_{A} \otimes \prod_{j}^{B}\right)$, a matriz densidade da partição $A, \rho_{A}^{j}$, pode ser escrita como

$$
\rho_{A}^{j}=\frac{\operatorname{Tr}_{B}\left[\left(\mathbb{I}_{A} \otimes \prod_{j}^{B}\right) \rho_{A B}\left(\mathbb{I}_{A} \otimes \prod_{j}^{B}\right)\right]}{\operatorname{Tr}_{A B}\left[\left(\mathbb{I}_{A} \otimes \prod_{j}^{B}\right) \rho_{A B}\left(\mathbb{I}_{A} \otimes \prod_{j}^{B}\right)\right]} .
$$

Segue que, $S_{\left\{\prod_{j}^{B}\right\}}\left(\rho_{A / B}\right)=\sum_{j} q_{j} S\left(\rho_{A}^{j}\right)$, onde $q_{j}=\operatorname{Tr}_{A B}\left[\left(\mathbb{I}_{A} \otimes \prod_{j}^{B}\right) \rho_{A B}\left(\mathbb{I}_{A} \otimes \prod_{j}^{B}\right)\right]$. E assim, por analogia à equação (4.1.3), define-se a correlação clássica de um sistema como sendo

$$
J_{Q}\left(\rho_{A: B}\right)=S\left(\rho_{A}\right)-S_{\left\{\prod_{j}^{B}\right\}}\left(\rho_{A / B}\right)
$$

Ao contrário do que ocorre no caso clássico, Eq. (4.1.4), realizar uma medida sobre o sistema $\rho_{B}$ pode afetar o sistema $\rho_{A}$, devido às correlações que podem existir entre eles. 
Portanto, em geral $I\left(\rho_{A: B}\right) \neq J_{Q}\left(\rho_{A: B}\right)$. Define-se, assim, a discórdia quântica como sendo a diferença entre a informação mútua e a correlação clássica (3),

$$
D\left(\rho_{A B}\right)=I\left(\rho_{A: B}\right)-J_{Q}\left(\rho_{A: B}\right)
$$

$D\left(\rho_{A B}\right)=0$ implica em $I\left(\rho_{A: B}\right)=J_{Q}\left(\rho_{A: B}\right)$, o que significa que conhecer completamente um dos subsistemas não altera as correlações deste com o restante do sistema, caracterizando um sistema completamente clássico.

Nos casos em que $D\left(\rho_{A B}\right) \neq 0$, realizar uma medida sobre um dos subsistemas permite inferir informações sobre o estado do outro subsistema, ou seja, se o estado de $\rho_{B}$ passa a ser bem definido, então, neste processo, parte da informação original de $\rho_{A}$ é perdida. Esta perda de informação caracteriza um ganho de entropia, logo

$$
S_{\left\{\prod_{j}^{B}\right\}}\left(\rho_{A / B}\right) \geq S\left(\rho_{A: B}\right)-S\left(\rho_{B}\right)
$$

e pela Eq. (4.1.8), observa-se que $J_{Q}\left(\rho_{A: B}\right) \leq I\left(\rho_{A: B}\right)$, consequêntemente $D\left(\rho_{A B}\right) \geq 0$. Portanto, para a obtenção de informação é interessante encontrar o conjunto $\left\{\prod_{j}^{B}\right\}$ que minimiza a discórdia. Isto implica em encontrar a medida que perturba menos o estado quântico bipartido, permitindo extrair o máximo de informação possível sobre $A$,

$$
D_{\min }\left(\rho_{A B}\right)=I\left(\rho_{A: B}\right)-\max _{\left\{\prod_{j}^{B}\right\}} J_{Q}\left(\rho_{A: B}\right) .
$$

Por exemplo, para um sistema de 2 q-bits, o conjunto completo de medidas projetivas é dado por (36)

$$
\Pi_{j}^{k}=\left|\Theta_{j}^{k}\right\rangle\left\langle\Theta_{j}^{k}\right|, j=\|, \perp, k=A, B
$$

onde $\left|\Theta_{\|}^{k}\right\rangle \equiv \cos \left(\theta_{k}\right)\left|0_{k}\right\rangle+e^{i \phi_{k}} \sin \theta_{k}\left|1_{k}\right\rangle$ e $\left|\Theta_{\perp}^{k}\right\rangle \equiv e^{-i \phi_{k}} \sin \theta_{k}\left|0_{k}\right\rangle-\cos \left(\theta_{k}\right)\left|1_{k}\right\rangle$, com $0 \leq \theta_{k} \leq \pi$ e $0 \leq \theta_{k} \leq 2 \pi$. $\left\{\left|0_{k}\right\rangle,\left|1_{k}\right\rangle\right\}$ é a base computacional do q-bit lógico da partição $k$. Assim, para calcular o valor da discórdia entrópica definida pela Eq. (4.1.11) é preciso aplicar as medidas projetivas definidas anteriormente varrendo-se os ângulos $\theta$ e $\phi$ em passos suficientemente pequenos, de modo a se obter uma boa precisão quando a maximização for calculada.

A Tabela 4.1 apresenta uma classificação de estados de acordo com a presença, ou não, das propriedades de emaranhamento e discórdia. Daqui para frente utilizaremos esta nomenclatura e notação para diferenciar os diferentes tipos de estado.

Assim, de acordo com Vedral (37), ao contrário do que ocorre nos estados classicamente 
Tabela 4.1 - Classificação de Estados em termos da presença ou ausência de emaranhamento e discórdia.

\begin{tabular}{ccc}
\hline Separável & $\begin{array}{c}\text { Possui discórdia quântica } \\
\text { diferente de zero }\end{array}$ & $\sigma=\sum_{i j} p_{i j} \sigma_{i}^{A} \otimes \sigma_{j}^{B}$ \\
\hline Emaranhado & $\begin{array}{c}\text { Não pode ser escrito na } \\
\text { forma de estado separável }\end{array}$ & $\rho \neq \sum_{i j} p_{i j} \sigma_{i}^{A} \otimes \sigma_{j}^{B}$ \\
\hline Clássico-Quântico & $\begin{array}{c}\text { A discórdia é não-nula para } \\
\text { medidas sobre o 1o q-bit }\end{array}$ & $\sigma=\sum_{i j} p_{i j} \sigma_{i}^{A} \otimes|j\rangle\langle j|$ \\
\hline Clássico & $\begin{array}{c}\text { Possui discórdia nula, mas } \\
\text { pode apresentar correlações } \\
\text { clássicas }\end{array}$ & $\chi=\sum_{i j} p_{i} p_{j} \sigma_{i}^{A} \otimes \sigma_{j}^{B}$ \\
\hline
\end{tabular}

correlacionados, em estados separáveis com caráter quântico, a informação mútua é maior que a correlação clássica. Portanto, embora tenha-se mostrado que utilizando-se as técnicas convencionais de RMN não é possível produzir emaranhamento, estes sistemas ainda podem conter correlações quânticas de estados separáveis.

Em geral, a discórdia quântica entrópica é assimétrica em relação as partições do sistema, visto que a entropia condicional também o é, ou seja, para um sistema de dois q-bits $\rho_{A B}$, se compararmos as medidas de discórdia realizadas sobre o q-bit $A$ e sobre o q-bit $B$, observaremos resultados distintos. Assim, nestes casos, utiliza-se uma versão simetrizada para as medidas das correlações clássicas e quânticas, (36). A correlação clássica em um sistema com duas partições pode ser expressa como sendo o máximo de informação clássica mútua que é obtida por uma medida local sobre as duas partições (36, 38),

$$
\kappa\left(\rho_{A B}\right) \equiv \max _{\left\{\prod_{i}^{A} \otimes \prod_{j}^{B}\right\}}\left[I_{c}\left(\eta_{A B}\right)\right]
$$

onde $I_{c}\left(\eta_{A B}\right)$ é definido como na Eq. (4.1.2) e $\eta_{A B}$ é um estado que corresponde a medidas locais $\prod_{i}^{A} \otimes \prod_{j}^{B}$ realizadas sobre $\rho_{A B}$, ou seja

$$
\eta_{A B}=\sum_{i, j}\left(\prod_{i}^{A} \otimes \prod_{j}^{B}\right) \rho_{A B}\left(\prod_{i}^{A} \otimes \prod_{j}^{B}\right) .
$$

O sentido desta definição está no fato de que manipulações locais sobre os estados $\rho_{A}$ e $\rho_{B}$, ou sobre suas distribuições de probabilidade, não refletem em acréscimos na informação clássica mútua fornecida por eles.

Substituindo-se a Eq. (4.1.13) na Eq. (4.1.9), obtém-se a versão simetrizada para a 
discórdia quântica,

$$
D\left(\rho_{A B}\right) \equiv I\left(\rho_{A: B}\right)-\kappa\left(\rho_{A B}\right)
$$

\subsection{Discórdia Geométrica}

O cálculo da discórdia quântica, como definida anteriormente, implica na necessidade de se trabalhar com minimizações numéricas, de forma que expressões analíticas são conhecidas apenas para algumas classes de estados. Por esta razão, muitas outras versões ou quantificadores do caráter quântico de um sistema vem sendo propostas (5). Com base na idéia de que a medida de uma certa propriedade pode ser feita através da distância entre um estado e o estado mais próximo sem esta dada propriedade, Modi, K. et al. (39) propuseram uma medida de discórdia baseada na entropia relativa. Por exemplo, a medida da quantidade de emaranhamento de um estado pode ser medida através da distância entrópica entre este estado e o estado separável mais próximo, o que é denominado Entropia Relativa do Emaranhamento $\left(E_{R}\right)$, matematicamente definida como

$$
E_{R}=\min _{\sigma \in \mathcal{S}} S(\rho \| \sigma)
$$

onde $S(X \| Y)=-\operatorname{Tr}(X \log Y)-S(X)$. O estado $\rho$ pertence ao conjunto $\mathcal{E}$ de estados emaranhados e $\sigma$ ao conjunto $\mathcal{S}$ de estados separáveis. De forma semelhante, define-se a Entropia Relativa da Discórdia $\left(D_{R}\right)$

$$
D_{R}=\min _{\chi \in \mathcal{C}} S(\rho \| \chi),
$$

onde $\chi$ pertence ao conjundo $\mathcal{C}$ de estados clássicos. Vale notar que neste contexto a discórdia quântica corresponde à correlação quântica total do sistema, incluindo o emaranhamento (39). No entanto, em alguns momentos na literatura utiliza-se a denominação de discórdia para a correlação quântica excluindo-se o emaranhamento (37). Nesta representação, a correlação quântica sem o emaranhamento é denominada de Dissonância (Q) e a Entropia Relativa da Dissonância $\left(Q_{R}\right)$ é definida como,

$$
Q_{R}=\min _{\chi \in \mathcal{C}} S(\sigma \| \chi)
$$




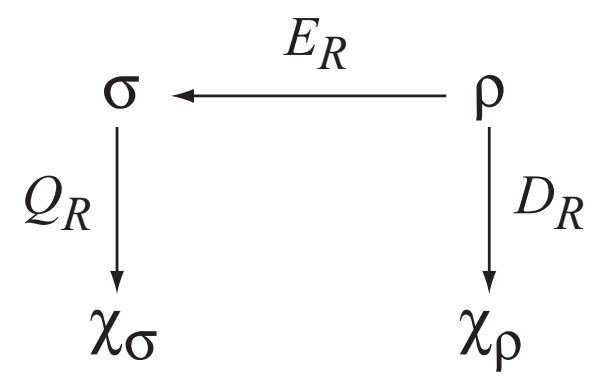

Figura 4.2 - Representação esquemática das medidas de correlação através da entropia relativa. A seta de $x$ para $y(x \rightarrow y)$ indica que $y$ é o estado, que não possui a propriedade que se deseja medir, mais próximo de $x$. O estado $\rho \in \mathcal{E}$ (conjunto de estados emaranhados), $\sigma \in \mathcal{S}$ (conjunto de estados separáveis) e $\chi \in \mathcal{C}$ (conjunto de estados clássicos). As distâncias $E_{R}, D_{R}, Q_{R}$, correspondem aos valores de entropia, discórdia e dissonância relativas, respectivamente.

A Figura 4.2 apresenta uma representação esquemática destas definições.

Como estas medidas relativas de entropia não são simétricas, então este tipo de medida não constitui uma métrica verdadeira. Por esta razão, Dakić, Vedral e Brukner (40) propuseram uma outra medida de distância entre estados baseada na métrica do espaço de Hilbert-Schmidt. Denominada de Discórdia Geométrica, este tipo de medida foi definida matematicamente como (41),

$$
D_{G}(\rho)=2 \min _{\chi \in \mathcal{C}}\|\rho-\chi\|_{2}^{2}
$$

onde $\|\rho-\chi\|_{2}=\sqrt{\operatorname{Tr}\left[(\rho-\chi)(\rho-\chi)^{\dagger}\right]}$ é a norma quadrática no espaço de Hilbert-Schmidt. Assim, como para as medidas de entropia relativa, as medidas geométricas são realizadas após a medida ótima, logo é possível reescrever a Eq. (4.2.4) na forma

$$
D_{G}=2 \min _{\left\{\prod_{a}\right\}}\left\|\rho-\rho^{\prime}\right\|_{2}^{2}
$$

onde $\rho^{\prime}=\sum_{a} \prod_{a} \rho \prod_{a}$.

A grande vantagem deste tipo de medida geométrica é que a minimização presente na definição, Eq. (4.2.4), pode ser explicitamente efetuada para o caso de um sistema de dois q-bits. Como definimos na Eq. (2.8.7), a forma geral para estes sistemas é escrita na representação de Bloch como,

$$
\rho=\frac{1}{4}\left(\mathbb{I} \otimes \mathbb{I}+\sum_{i=1}^{3} x_{i} \sigma_{i} \otimes \mathbb{I}+\sum_{i=1}^{3} y_{i} \mathbb{I} \otimes \sigma_{i}+\sum_{i, j=1}^{3} C_{i j} \sigma_{i} \otimes \sigma_{j}\right) .
$$

Assim, cada estado $\rho$ pode ser caracterizado pelo tripleto $\{\vec{x}, \vec{y}, C\}$. Já um estado de discórdia 
nula, para medidas realizadas sobre o $1^{\circ}$ q-bit (como definido na Tabela 4.1) é da forma,

$$
\chi=p_{1}\left|\psi_{1}\right\rangle\left\langle\psi_{1}\left|\otimes \rho_{1}+p_{2}\right| \psi_{2}\right\rangle\left\langle\psi_{2}\right| \otimes \rho_{2},
$$

onde $\left\{\left|\psi_{1}\right\rangle,\left|\psi_{2}\right\rangle\right\}$ forma uma base ortonormal para um q-bit, $\rho_{1,2}$ são matrizes densidade $2 \times 2$ e $p_{1,2}$ são números não-negativos tais que $p_{1}+p_{2}=1$.

Em analogia ao caso do estado $\rho$, calculamos o tripleto que caracteriza o estado clássico $\chi, \operatorname{assim}$

1. $\operatorname{Tr}[\chi(\vec{\sigma} \otimes \mathbb{I})]:$

$$
\begin{aligned}
\operatorname{Tr}[\chi(\vec{\sigma} \otimes \mathbb{I})] & =\sum_{i j}\left\langle\psi_{i}^{A}, \psi_{j}^{B}|\chi(\vec{\sigma} \otimes \mathbb{I})| \psi_{i}^{A}, \psi_{j}^{B}\right\rangle \\
& =\sum_{i j}\left\langle\psi_{i}^{A}, \psi_{j}^{B}\left|\left[p_{1}\left|\psi_{1}^{A}\right\rangle\left\langle\psi_{1}^{A}\left|\otimes \rho_{1}+p_{2}\right| \psi_{2}^{A}\right\rangle\left\langle\psi_{2}^{A}\right| \otimes \rho_{2}\right](\vec{\sigma} \otimes \mathbb{I})\right| \psi_{i}^{A}, \psi_{j}^{B}\right\rangle \\
& =\sum_{j}\left[p_{1}\left\langle\psi_{1}^{A}|\vec{\sigma}| \psi_{1}^{A}\right\rangle\left\langle\psi_{j}^{B}\left|\rho_{1}\right| \psi_{j}^{B}\right\rangle+p_{2}\left\langle\psi_{2}^{A}|\vec{\sigma}| \psi_{2}^{A}\right\rangle\left\langle\psi_{j}^{B}\left|\rho_{2}\right| \psi_{j}^{B}\right\rangle\right]
\end{aligned}
$$

Usando a propriedade das matrizes de Pauli, $\operatorname{Tr}\left(\sigma_{i}\right)=0 \Rightarrow\left\langle\psi_{1}^{A}\left|\sigma_{i}\right| \psi_{1}^{A}\right\rangle+\left\langle\psi_{2}^{A}\left|\sigma_{i}\right| \psi_{2}^{A}\right\rangle=0$ e o fato de que por definição $\operatorname{Tr}(\rho)=1$, segue que

$$
\operatorname{Tr}[\chi(\vec{\sigma} \otimes \mathbb{I})]=\left(p_{1}-p_{2}\right)\left\langle\psi_{1}|\vec{\sigma}| \psi_{1}\right\rangle
$$

definimos, então

$$
\begin{aligned}
\vec{e} & =\left\langle\psi_{1}|\vec{\sigma}| \psi_{1}\right\rangle \\
t & =p_{1}-p_{2}
\end{aligned}
$$

de modo que

$$
\operatorname{Tr}[\chi(\vec{\sigma} \otimes \mathbb{I})]=t \vec{e}
$$

2. $\operatorname{Tr}[\chi(\mathbb{I} \otimes \vec{\sigma})]:$

De forma semelhante ao calculado no item 1, segue que

$$
\begin{aligned}
\operatorname{Tr}[\chi(\mathbb{I} \otimes \vec{\sigma})] & =\sum_{i j}\left\langle\psi_{i}^{A}, \psi_{j}^{B}|\chi(\mathbb{I} \otimes \vec{\sigma})| \psi_{i}^{A}, \psi_{j}^{B}\right\rangle \\
& =\sum_{j}\left[p_{1}\left\langle\psi_{j}^{B}\left|\rho_{1} \vec{\sigma}\right| \psi_{j}^{B}\right\rangle+p_{2}\left\langle\psi_{j}^{B}\left|\rho_{2} \vec{\sigma}\right| \psi_{j}^{B}\right\rangle\right] \\
& =\operatorname{Tr}\left[\left(p_{1} \rho_{1}+p_{2} \rho_{2}\right) \vec{\sigma}\right]
\end{aligned}
$$


Definimos, então

$$
\vec{s}_{+} \equiv \operatorname{Tr}\left[\left(p_{1} \rho_{1}+p_{2} \rho_{2}\right) \vec{\sigma}\right]
$$

3. $\operatorname{Tr}\left[\chi\left(\sigma_{i} \otimes \sigma_{j}\right)\right]$ :

$$
\begin{aligned}
\operatorname{Tr}\left[\chi\left(\sigma_{i} \otimes \sigma_{j}\right)\right] & =\sum_{l k}\left\langle\psi_{l}^{A}, \psi_{k}^{B}\left|\chi\left(\sigma_{i} \otimes \sigma_{j}\right)\right| \psi_{l}^{A}, \psi_{k}^{B}\right\rangle \\
& =\sum_{l}\left[p_{1}\left\langle\psi_{1}^{A}\left|\sigma_{i}\right| \psi_{1}^{A}\right\rangle\left\langle\psi_{l}^{B}\left|\rho_{1} \sigma_{j}\right| \psi_{l}^{B}\right\rangle-p_{2}\left\langle\psi_{1}^{A}\left|\sigma_{i}\right| \psi_{1}^{A}\right\rangle\left\langle\psi_{l}^{B}\left|\rho_{2} \sigma_{j}\right| \psi_{l}^{B}\right\rangle\right] \\
& =\sum_{l}\left\langle\psi_{1}\left|\sigma_{i}\right| \psi_{1}\right\rangle\left\langle\psi_{l}\left|\left(p_{1} \rho_{1}-p_{2} \rho_{2}\right) \sigma_{j}\right| \psi_{l}\right\rangle \\
& =\left\langle\psi_{1}\left|\sigma_{i}\right| \psi_{1}\right\rangle \operatorname{Tr}\left[\left(p_{1} \rho_{1}-p_{2} \rho_{2}\right) \sigma_{j}\right]
\end{aligned}
$$

E com isto, definimos o tensor de correlação para os estados clássicos,

$$
C \equiv \vec{e} \vec{s}_{-}^{t}
$$

Retornando ao cálculo da discórdia geométrica, como definido pela Eq. 4.2.4, encontramos que

$$
\begin{aligned}
\|\rho-\chi\|_{2}^{2} & =\operatorname{Tr}(\rho-\chi)^{2} \\
& =\operatorname{Tr}\left(\rho^{2}-2 \rho \chi+\chi^{2}\right) \\
& =\|\rho\|_{2}^{2}-2 \operatorname{Tr}(\rho \chi)+\|\chi\|_{2}^{2}
\end{aligned}
$$

Substituindo os resultados encontrados nos itens 1 a 3 e usando o fato de que $\|\vec{e}\|=1$, então

$$
\begin{aligned}
\|\rho-\chi\|_{2}^{2}= & \frac{1}{4}\left(1+\|\vec{x}\|_{2}^{2}+\|\vec{y}\|_{2}^{2}+\|C\|_{2}^{2}\right)+ \\
& -\frac{1}{2}\left(1+t \vec{x} \vec{e}+\vec{y} \vec{s}_{+}+\vec{e} C \vec{s}_{-}^{t}\right)+ \\
& +\frac{1}{4}\left(1+t^{2}+\left\|\vec{s}_{+}\right\|_{2}^{2}+\left\|\vec{s}_{-}\right\|_{2}^{2}\right) .
\end{aligned}
$$

Como o valor de $D_{G}$ corresponde à distância mínima entre $\rho$ e $\chi$, então o mínimo global da função (4.2.16) pode ser calculado em termos do tripleto que descreve o estado $\chi$, de forma 
que

$$
\begin{array}{r}
\frac{\|\rho-\chi\|_{2}^{2}}{\partial t}=\frac{1}{2}(-\vec{x} \vec{e}+t)=0 \Rightarrow t=\vec{x} \vec{e} \\
\frac{\|\rho-\chi\|_{2}^{2}}{\partial \vec{s}_{+}}=\frac{1}{2}\left(-\vec{y}+\vec{s}_{+}\right)=0 \Rightarrow \vec{s}_{+}=\vec{y} \\
\frac{\|\rho-\chi\|_{2}^{2}}{\partial \vec{s}_{-}}=\frac{1}{2}\left(-\vec{e} C+\vec{s}_{-}\right)=0 \Rightarrow \vec{s}_{-}=\vec{e} C
\end{array}
$$

Assim, substituindo estes resultados na Eq. (4.2.16), encontramos a expressão geral para a discórdia geométrica de um sistema de dois q-bits,

$$
D_{G}(\rho)=\frac{1}{2}\left[\|\vec{x}\|_{2}^{2}+\|C\|_{2}^{2}-4 k_{\max }\right]
$$

onde $k_{\max }$ é o maior autovalor da matriz $S=\frac{1}{4} \vec{x} \vec{x}^{t}+C C^{t}$, para que a minimização requerida em (4.2.4) seja satisfeita.

A equação característica da matriz $S$ pode ser resolvida analiticamente (41). Limitando-se a solução ao domínio dos reais, os autovalores são dados por,

$$
k_{i}=\frac{\operatorname{Tr}[S]}{3}+\frac{\sqrt{6 \operatorname{Tr}\left(S^{2}\right)-2 \operatorname{Tr}(S)^{2}}}{3} \cos \left(\frac{\theta+\alpha_{i}}{3}\right),
$$

onde $\left\{\alpha_{i}\right\}=\{0,2 \pi, 4 \pi\}$ e

$$
\theta=\arccos \left\{\frac{\left[2 \operatorname{Tr}(S)^{3}-9 \operatorname{Tr}(S) \operatorname{Tr}\left(S^{2}\right)+9 \operatorname{Tr}\left(S^{3}\right)\right] \sqrt{2}}{\left[3 \operatorname{Tr}\left(S^{2}\right)-\operatorname{Tr}(S)^{2}\right]^{3 / 2}}\right\} .
$$

Ou seja, $0 \leq \theta / 3 \leq \pi / 3$ e o autovalor máximo ocorre para $\alpha_{i}=\alpha_{1}=0$. Portanto, para um sistema de dois q-bits, a discódia geométrica pode ser reescrita na forma

$$
D_{G}(\rho)=2\left[\operatorname{Tr}(S)-k_{1}\right]
$$

Com o objetivo de obter um quantificador para as correlações quânticas mais simples e acessível experimentalmente, Girolami e Adesso (41), substituindo $\theta$ por 0 na Eq. (4.2.19), definiram a quantidade $Q$,

$$
Q(\rho)=\frac{2}{3}\left[2 \operatorname{Tr}(S)-\sqrt{6 \operatorname{Tr}\left(S^{2}\right)-2 \operatorname{Tr}(S)^{2}}\right]
$$

que corresponde a um limite inferior para a discórdia geométrica, $Q \leq D_{G}$.

Luo e Fu (42) generalizaram a expressão (4.2.18) para sistemas biparticionados de di- 
mensão qualquer. Além disso, mostraram que a medida da discórdia geométrica como definida em (4.2.4) é equivalente à

$$
\bar{D}_{G}(\rho):=\min _{\left\{\Pi_{a}\right\}}\left\|\rho-\Pi_{a}(\rho)\right\|_{2}^{2},
$$

onde o mínimo é sobre o conjunto de projetores $\left\{\Pi_{a}\right\}$ do subsistema A.

Apesar de ter se apresentado como um quantificador mais acessível que a Discórdia Entrópica, recentemente foram apontados dois grandes problemas relacionados à definição da discórdia geométrica:

1. Ao contrário do que ocorre com a quantidade de emaranhamento de um sistema, outros tipos de correlação quântica podem aumentar sob a ação de operações locais na partição do sistema que sofre a medida, visto que, por definição, a discórdia se anula somente se a partição do sistema a ser medida for tipo clássica. Por exemplo (43), dado um mapa local $\Lambda_{a}$ (sobre o $1^{o}$ q-bit) tal que

$$
\begin{gathered}
\Lambda_{a}(|0\rangle\langle 0|)=|0\rangle\langle 0| \\
\Lambda_{a}(|1\rangle\langle 1|)=|+\rangle\langle+|
\end{gathered}
$$

onde $|+\rangle=(|0\rangle+|1\rangle) / \sqrt{2}$. Assim, partindo do estado de discórdia nula

$$
\rho_{0}=\frac{|0\rangle\langle 0|\otimes| 0\rangle\langle 0|+| 1\rangle\langle 1|\otimes| 1\rangle\langle 1|}{\sqrt{2}}
$$

e aplicando-se o mapa $\Lambda_{a}$, observa-se que

$$
\Lambda_{a} \rho_{0} \Lambda_{a}^{\dagger}=\frac{|0\rangle\langle 0|\otimes| 0\rangle\langle 0|+|+\rangle\langle+|\otimes| 1\rangle\langle 1|}{\sqrt{2}},
$$

que, segundo a Tabela 4.1, é um estado que não pode ser escrito na forma de estado um estado clássico e, portanto, é um estado de discórdia não-nula. Ou seja, para medidas realizadas sobre o $1^{o}$ q-bit, ocorre a criação de discórdia nesse sistema. No entanto, esta criação ocorre às custas de uma diminuição da correlação total, o que pode ser medido através do cálculo da informação mútua do sistema (44).

Para a medida entrópica de discórdia, Streltsov, Kampermann e Bruß(45) mostraram que não pode haver um aumento de correlação quântica quando uma operação não-unitária é aplicada sobre o $2^{\circ}$ q-bit (partição que não sofrerá a medida). No entanto, utilizando medidas de discórdia geométrica, Piani (43) mostrou que este quantificador poderia apresentar um crescimento sem qualquer custo sobre a correlação total do sistema, ou seja, de forma completamente reversível. 
2. Para sistemas de dimensão grande, foram observadas discrepâncias entre os resultados obtidos para medidas de discórdia entrópica e geométrica.

Passante, Moussa e Laflamme (46) mostraram que a expressão geral da discórdia geométrica para o caso geral de um estado DQC1 de $(1+n)$ q-bits decai exponencialmente com $n$, o que discorda do fato da discórdia entrópica, para estes estados, não depender do valor de $n(1)$. No campo da informação quântica relativística, Brown et al. (47) mostraram casos em que a discórdia geométrica se anula enquanto que a discórdia entrópica convergia para um valor finito e diferente de zero.

Em resposta a estas alegações, Tufarelli et al. (48) alegaram que os problemas observados no item 1 estão relacionados à propriedade de não-contratividade da norma de Hilbert-Schmidt. O problema do item 2 seria explicado pela sensibilidade da distância de Hilbert-Schmidt à pureza do estado. Ambos os problemas seriam resolvidos se uma métrica distinta fosse aplicada, no entanto, a facilidade de cálculo seria comprometida (5). Piani (43) sugeriu uma redefinição da $D_{G}$ incluindo-se uma maximização sobre os canais locais do $2^{\circ} \mathrm{q}$-bit, de forma a prevenir o crescimento observado pela definição inicial. No entanto, como apontado pelo próprio autor, isto dificultaria o calcula da $D_{G}$ de tal forma que não existiria mais vantagem no seu uso em relação à discórdia entrópica.

Com o objetivo de contornar a sensibilidade da métrica de Hilbert-Schmidt à pureza do estado, sem comprometer a facilidade de cálculo demandada por ela, Tufarelli et al. (48) propuzeram que para o cálculo da distância entre estados de pureza distinta, cada um deles deveria ser normalizado de acordo com sua própria norma, de forma que

$$
d_{T}\left(\rho_{1}, \rho_{2}\right) \equiv\left\|\frac{\rho_{1}}{\left\|\rho_{1}\right\|}-\frac{\rho_{2}}{\left\|\rho_{2}\right\|}\right\|,
$$

onde $\|A\|=\sqrt{A^{\dagger} A}$ é a norma de Hilbert-Schmidt. Com isto, definiu-se a Discórdia Geométrica Reescalada $\left(D_{T}(\rho)\right)$ modificando-se a Eq. (4.2.23) para

$$
D_{T}(\rho)=\beta_{A} \min _{\Pi_{a}} d_{T}\left(\rho, \Pi_{a}[\rho]\right)^{2},
$$

onde $\beta_{A}$ é uma constante de normalização.

Com a definição da norma pela Eq. (4.2.28), segue que

$$
\begin{aligned}
d_{T}\left(\rho, \Pi_{a}(\rho)\right)^{2} & =\left\|\frac{\rho}{\|\rho\|}-\frac{\Pi_{a}(\rho)}{\left\|\Pi_{a}(\rho)\right\|}\right\|^{2} \\
& =2-2\left(\frac{\operatorname{Tr}\left[\rho \Pi_{a}(\rho)\right]}{\sqrt{\operatorname{Tr}\left(\rho^{2}\right)} \sqrt{\operatorname{Tr}\left[\Pi_{a}(\rho)\right]^{2}}}\right)
\end{aligned}
$$


é fácil ver que $\operatorname{Tr}\left[\Pi_{a}(\rho)^{2}\right]=\operatorname{Tr}\left[\rho \Pi_{a}(\rho)\right]$, logo

$$
\min _{\Pi_{a}} d_{T}\left(\rho, \Pi_{a}(\rho)\right)^{2}=\min _{\Pi_{a}}\left\{2-2 \sqrt{\frac{\operatorname{Tr}\left[\rho \Pi_{a}(\rho)^{2}\right]}{\operatorname{Tr}\left(\rho^{2}\right)}}\right\} .
$$

Considerando a definição da discórdia geométrica na forma,

$$
D_{G}=\alpha_{A} \min _{\Pi_{a}}\left\|\rho-\Pi_{a}(\rho)\right\|^{2}
$$

como na Eq.(4.2.23), onde $\alpha_{A}=\frac{d_{A}}{d_{A}-1}$, sendo $d_{A}$ a dimensão do espaço do q-bit $A$. Então,

$$
\begin{aligned}
D_{G} & =\alpha_{A} \min _{\Pi_{a}}\left\{\operatorname{Tr}\left(\rho^{2}\right)-\operatorname{Tr}\left[\Pi_{a}(\rho)^{2}\right]\right\} \\
& =\alpha_{A} \min _{\Pi_{a}}\left\{\operatorname{Tr}\left(\rho^{2}\right)-\operatorname{Tr}\left(\rho \Pi_{a}[\rho)\right]\right\}
\end{aligned}
$$

Logo,

$$
\min _{\Pi_{a}} \operatorname{Tr}\left[\rho \Pi_{a}(\rho)\right]=\operatorname{Tr}\left(\rho^{2}\right)-\frac{D_{G}}{\alpha_{A}}
$$

Substituindo este resultado na Eq. (4.2.31) e, em seguida, na Eq. (4.2.29), segue que

$$
D_{T}(\rho)=\beta_{A}\left[2-2 \sqrt{1-\frac{D_{G}(\rho)}{\alpha_{A} \operatorname{Tr}\left(\rho^{2}\right)}}\right] .
$$

Como para estados puros a discórdia geométrica e a discórdia reescalada devem ser iguais, então

$$
\beta_{A}=\frac{D_{G}^{\max }}{2-2 \sqrt{1-D_{G}^{\max } / \alpha_{A}}} .
$$

Com isto, a discórdia geométrica pode ser definida de forma simplificada, a menos de uma constante, como sendo,

$$
\tilde{D}_{G}(\rho)=\frac{D_{G}(\rho)}{\mathcal{P}}
$$

onde $\mathcal{P}=\operatorname{Tr}\left\{\rho^{2}\right\}$ é a pureza do estado $\rho$. Assim, fica garantido que o comportamento da $\tilde{D}_{G}$ não sofrerá alterações devido à operações reversíveis sobre a partição não-medida da matriz densidade. No entanto, a introdução desta nova escala ainda herda o problema da nãocontratividade da métrica de Hilbert-Schmidt, de forma que problemas na aplicação de canais apenas sobre o sistema não-medido ainda poderão ser observados. Apesar disso, a introdução da nova métrica assegura a confiabilidade das medidas geométricas como testemunhas da correlação quântica presente em um sistema, (48). 


\subsection{Negatividade}

Piani e et al. (49) demonstraram um protocolo onde a correlação não-clássica presente em qualquer sistema multiparticionado (incluindo sistemas de estados separáveis) pode ser relacionada à uma medida de emaranhamento. De fato, eles mostraram que a entropia relativa entre o sistema multiparticionado e o estado clássico mais próximo é igual à quantidade mínima de emaranhamento criada entre o sistema e a ancilla local.

Por exemplo (45), dado um sistema biparticionado $\rho_{A B}$ e um certo instrumento de medida no estado puro $\left|0_{M}\right\rangle\left\langle 0_{M}\right|$. O acoplamento "instrumento de medida + sistema" resulta no estado $\tilde{\rho}=\left|0_{M}\right\rangle\left\langle 0_{M}\right| \otimes \rho_{A B}$. O operador unitário correspondente à realização de uma medida de von Neumann apenas sobre o subsistema $A$ é dado por $U=U_{M A} \otimes 1_{B}$. Streltsov, Kampermann e Bruß(45), de forma semelhante ao que foi demonstrado por Piani e at al. (49), mostraram que sempre que o sistema $\rho_{A B}$ possuir discórdia quântica não nula, a medida de von Neumann criará emaranhamento entre o subsistema medido, $\rho_{A}$, e o instrumento de medida. O resultado da medida é obtido medindo-se o instrumento $M$ em sua auto-base. A quantidade de informação sobre $A$ que poderá ser inferida através desta medida é, então, equivalente à quantidade de emaranhamento criado entre $\mathrm{M}$ e $\rho_{A}$.

Com base nessas idéias, surgiu uma nova abordagem para a quantificação da não-classicalidade de um sistema, feita através de medidas de emaranhamento. Dentre os diversos quantificadores de emaranhamento, utilizaremos a Negatividade, definida por Vidal e Werner (50), em 2002.

Segundo o critério de Peres-Horodecki (14, 51), uma matriz densidade $\rho_{A B}$ pode ser escrita na forma de estado separável,

$$
\rho_{A B}=\sum_{i j} p_{i j} \rho_{i}^{A} \otimes \rho_{j}^{B}
$$

se, e somente se, os autovalores de $\sigma_{A^{t} B}$ forem não-negativos, onde

$$
\sigma_{A^{t} B}=\sum_{i j} p_{i j}\left(\rho_{i}^{A}\right)^{t} \otimes \rho_{j}^{B}
$$

Ou seja, de acordo com este critério, se a transposição parcial de uma matriz densidade resultar em autovalores negativos, então as partições do estado inicial estão emaranhadas (14). 
Com isso, a Negatividade foi definida como (50),

$$
\mathcal{N}(\rho) \equiv \frac{\left\|\sigma_{A^{t} B}\right\|_{1}-1}{2},
$$

o que corresponde ao quanto $\sigma_{A^{t} B}$ está longe de ser positiva, e consequêntemente, à quantidade de emaranhamento entre os subsistemas $A$ e $B$.

Nakano, Piani e Adesso (4) aplicaram esta definição de negatividade para medir a quantidade de emaranhamento entre o instrumento de medida e o sistema. Com isto, definiram a Negatividade do Caráter Quântico - NoQ ("negativity of quantumness") de um sistema bipartido, como sendo

$$
Q_{N}^{A}\left(\rho_{A B}\right):=\min _{\mathcal{B}(A)} \mathcal{N}(\tilde{\rho})
$$

onde $\tilde{\rho}$ é o estado correspondente ao acoplamento "sistema + medida" e a minimização é tomada sobre todos os estados medidos na base de $A, \mathcal{B}(A)=\left\{\left|a_{i}\right\rangle\right\}$. Ou seja,

$$
Q_{N}^{A}\left(\rho_{A B}\right)=\min _{\mathcal{B}(A)} \mathcal{N}\left(\sum_{i j}\left\langle a_{i}\left|\rho_{A B}\right| a_{j}\right\rangle\right)
$$

Então, definindo $\rho_{i j} \equiv\left\langle a_{i}\left|\rho_{A B}\right| a_{j}\right\rangle$ e substituindo-se a definição da Eq. (4.3.3), Nakano, Piani e Adesso (4) chegaram a

$$
Q_{N}^{A}\left(\rho_{A B}\right)=\min _{\mathcal{B}(A)} \frac{1}{2}\left(\sum_{i j}\left\|\rho_{i j}\right\|_{1}-1\right) .
$$

Um conjunto de estados importantes de se tratar são os chamados estados Bell diagonal. Utilizando a notação de Bloch para um sistema de dois q-bits, Eq. (4.2.6), a matriz de correlação $C$, é dada por

$$
C=\left[\begin{array}{ccc}
\left\langle\sigma_{1} \otimes \sigma_{1}\right\rangle & \left\langle\sigma_{1} \otimes \sigma_{2}\right\rangle & \left\langle\sigma_{1} \otimes \sigma_{3}\right\rangle \\
\left\langle\sigma_{2} \otimes \sigma_{1}\right\rangle & \left\langle\sigma_{2} \otimes \sigma_{2}\right\rangle & \left\langle\sigma_{2} \otimes \sigma_{3}\right\rangle \\
\left\langle\sigma_{3} \otimes \sigma_{1}\right\rangle & \left\langle\sigma_{3} \otimes \sigma_{2}\right\rangle & \left\langle\sigma_{3} \otimes \sigma_{3}\right\rangle
\end{array}\right] .
$$

Com isto, denomina-se estado Bell-diagonal os casos em que a Eq. (4.2.6) apresenta,

$$
\left\{\begin{array}{c}
x_{1}=x_{2}=y_{1}=y_{2}=0 \\
c_{i j}=0 \text { para } i \neq j
\end{array}\right.
$$

assumindo, portanto, a forma

$$
\rho=\frac{1}{4}\left(\mathbb{I}+\sum_{j=1}^{3} c_{j} \sigma_{j} \otimes \sigma_{j}\right),
$$


ou seja, neste caso a matriz de correlação é diagonal, possuindo apenas três elementos

$$
C=\left[\begin{array}{ccc}
\left\langle\sigma_{1} \otimes \sigma_{1}\right\rangle & 0 & 0 \\
0 & \left\langle\sigma_{2} \otimes \sigma_{2}\right\rangle & 0 \\
0 & 0 & \left\langle\sigma_{3} \otimes \sigma_{3}\right\rangle
\end{array}\right] .
$$

Para estados deste tipo, Nakano, Piani e Adesso (4) mostraram que a Eq. (4.3.11) possui uma forma analítica simples. Com base nas propriedades destes estados sobre a ação dos canais de Pauli e com o auxílio de argumentos geométricos, foi demonstrado que

$$
Q_{N}^{A}\left(\rho_{A B}\right)=\frac{\left|c_{i n t}\right|}{2}
$$

onde $c_{\text {int }}$ é o elemento da matriz de correlação de valor intermediário, $c_{i n t}=\operatorname{int}\left\{c_{1}, c_{2}, c_{3}\right\}$. Os detalhes desta demonstração, bem como dos teoremas à ela relacionados, podem ser encontrados na Ref.(4).

Além desta interpretação, envolvendo uma medida de emaranhamento, recentemente Montealegre e et al. demonstraram que a negatividade do caráter quântico pode ser entendida a partir de uma medida geométrica de distância envolvendo a norma traço (tipo 1) (52, 53). 
CAPÍtulo 5

\section{Efeitos da Decoerência na Discórdia Quântica}

Ao realizar-se experimentos de informação quântica, não é possível isolar completamente o sistema envolvido do ambiente ao redor. Com isso, ruído é introduzido ao sistema de forma que após um certo tempo o estado de equilíbrio é atingido. Neste processo, sistemas classico ou quanticamente correlacionados tendem a sofrer relaxação, em geral, evoluindo para estados completamente clássicos. Dependendo do tipo de banho térmico associado ao sistema, foram observados diferentes regimes de relaxação (54-56), sendo que para certas classes de estados iniciais também observou-se transições abruptas no comportamento das correlações (suddenchange) e até períodos de congelamento das mesmas, o que ficou conhecido como fenômeno de freezing $(57,58)$. Para certos sistemas de spins, foi demonstrado que estes pontos de suddenchange observados nas correlações quânticas fornecem uma assinatura para a existência de transição quânticas de fase (59-61). Do ponto de vista das correlações clássicas, observou-se que o ponto de sudden-change está associado ao colapso do subsistema medido em uma base não afetada pelo processo de decoerência (62). Assim, classificar os estados para os quais estas transições ocorrem e compreender os mecanismos físicos por trás destes fenômenos tornaram-se problemas de grande interesse.

Neste capítulo, trataremos dos efeitos dos canais de decoerência sobre as correlações de sistemas de RMN biparticionados, em especial para estados tipo Bell diagonal. 


\subsection{Informação Mútua, Correlações Clássicas e Quânticas}

Para estados Bell diagonal,

$$
\rho=\frac{1}{4}\left(\mathbb{I}+\sum_{j=1}^{3} c_{j} \sigma_{j} \otimes \sigma_{j}\right),
$$

Luo, S. (63) encontrou uma expressão analítica para a discórdia quântica entrópica em termos dos elementos da matriz de correlação. Com esta expressão é possível analizar e compreender melhor a dinâmica de decoerência desta classe de estados.

Os autovalores de uma matriz desta forma podem ser escritos como,

$$
\begin{aligned}
& \lambda_{0}=\frac{1}{4}\left(1-c_{1}-c_{2}-c_{3}\right) \\
& \lambda_{1}=\frac{1}{4}\left(1-c_{1}+c_{2}+c_{3}\right) \\
& \lambda_{2}=\frac{1}{4}\left(1+c_{1}-c_{2}+c_{3}\right) \\
& \lambda_{3}=\frac{1}{4}\left(1+c_{1}+c_{2}-c_{3}\right)
\end{aligned}
$$

onde $c_{1}, c_{2}$ e $c_{3}$ são os elementos da matriz de correlação.

Para calcular a discórdia quântica é preciso conhecer a informação mútua e a correlação clássica, Eq. (4.1.15) do sistema. Assim, sendo a informação mútua de um sistema quântico dada pela Eq. (4.1.6) e como para este sistema $S\left(\rho_{A}\right)=S\left(\rho_{B}\right)=1$, então

$$
I\left(\rho_{A B}\right)=2+\sum_{l=0}^{3} \lambda_{l} \log _{2} \lambda_{l} .
$$

Já a correlação clássica é dada pela Eq. (4.1.8), onde escreveremos a medida local sobre o q-bit $B$ em termos da base computacional, $\prod_{j}^{B}=|j\rangle\langle j|$ para $j=0,1$. Estes projetores podem ainda ser escritos na forma,

$$
B_{j}=V \Pi_{j}^{B} V^{\dagger}
$$

onde $V$ é um operador unitário qualquer de $\operatorname{dim}(2)$. A menos de uma fase constante, esse operador unitário pode ser escrito como,

$$
V=t \mathbb{I}+i \vec{y} \cdot \vec{\sigma}
$$


onde $t \in \Re, \vec{y}=\left(y_{1}, y_{2}, y_{3}\right) \in \Re^{3} \mathrm{e}$

$$
t^{2}+y_{1}^{2}+y_{2}^{2}+y_{3}^{2}=1
$$

Após a realização da medida $\prod_{j}^{B}$, o sistema se encontrará no estado

$$
\rho_{j}=\frac{1}{p_{j}}\left(\mathbb{I} \otimes B_{j}\right) \rho\left(\mathbb{I} \otimes B_{j}\right),
$$

para $p_{j}=\operatorname{Tr}\left\{\left(\mathbb{I} \otimes B_{j}\right) \rho\left(\mathbb{I} \otimes B_{j}\right)\right\}$.

Substituindo as Eqs. (5.1.4) e (5.1.1) na equação anterior, obtemos

$$
\begin{aligned}
p_{j} \rho_{j} & =\frac{1}{4}(\mathbb{I} \otimes V)\left(\mathbb{I} \otimes \Pi_{j}\right)\left(\mathbb{I} \otimes V^{\dagger}\right)\left[1+\sum_{k=1}^{3} c_{k} \sigma_{k} \otimes \sigma_{k}\right](\mathbb{I} \otimes V)\left(\mathbb{I} \otimes \Pi_{j}\right)\left(\mathbb{I} \otimes V^{\dagger}\right) \\
& =\frac{1}{4}(\mathbb{I} \otimes V)\left(\mathbb{I} \otimes \Pi_{j}\right)\left[1+\sum_{k=1}^{3} c_{k} \sigma_{j} \otimes\left(V^{\dagger} \sigma_{j} V\right)\right]\left(\mathbb{I} \otimes \Pi_{j}\right)\left(\mathbb{I} \otimes V^{\dagger}\right)
\end{aligned}
$$

onde omitimos o superíndice $B$ do projetor, por estar claro que o mesmo é aplicado no $2^{\circ}$ q-bit.

Aplicando-se a Eq. (5.1.5), observa-se que

$$
\left\{\begin{array}{l}
V^{\dagger} \sigma_{1} V=\left(t^{2}+y_{1}^{2}-y_{2}^{2}-y_{3}^{2}\right) \sigma_{1}+2\left(t y_{3}+y_{1} y_{2}\right) \sigma_{2}+2\left(-t y_{2}+y_{1} y_{3}\right) \sigma_{3} \\
V^{\dagger} \sigma_{2} V=2\left(-t y_{3}+y_{1} y_{2}\right) \sigma_{1}+\left(t^{2}+y_{2}^{2}-y_{1}^{2}-y_{3}^{2}\right) \sigma_{2}+2\left(t y_{1}+y_{2} y_{3}\right) \sigma_{3} \\
V^{\dagger} \sigma_{3} V=2\left(t y_{2}+y_{1} y_{3}\right) \sigma_{1}+2\left(-t y_{1}+y_{2} y_{3}\right) \sigma_{2}+\left(t^{2}+y_{3}^{2}-y_{1}^{2}-y_{2}^{2}\right) \sigma_{3}
\end{array}\right.
$$

Além disso, sendo $\Pi_{0}$ e $\Pi_{1}$ os projetores na base computacional, então

$$
\left\{\begin{array}{l}
\Pi_{0} \sigma_{3} \Pi_{0}=\Pi_{0} \\
\Pi_{1} \sigma_{3} \Pi_{1}=-\Pi_{1} \\
\Pi_{j} \sigma_{k} \Pi_{j}=0, \text { para } \mathbf{j}=0,1 \text { e } \mathrm{k}=1,2
\end{array} .\right.
$$

Assim, segue que

$$
\begin{aligned}
& p_{0} \rho_{0}=\frac{1}{4}\left[\mathbb{I}_{2 \times 2}+c_{1} z_{1} \sigma_{1}+c_{2} z_{2} \sigma_{2}+c_{3} z_{3} \sigma_{3}\right] \otimes V \Pi_{0} V^{\dagger} \\
& p_{1} \rho_{1}=\frac{1}{4}\left[\mathbb{I}_{2 \times 2}-c_{1} z_{1} \sigma_{1}-c_{2} z_{2} \sigma_{2}-c_{3} z_{3} \sigma_{3}\right] \otimes V \Pi_{1} V^{\dagger}
\end{aligned}
$$

onde $z_{1}=2\left(-t y_{2}+y_{1} y_{3}\right), z_{2}=2\left(t y_{1}+y_{2} y_{3}\right)$ e $z_{3}=t^{2}+y_{3}^{2}-y_{1}^{2}-y_{2}^{2}$. Como a operação traço é invariante por transformações unitárias, então $p_{0}=p_{1}=1 / 2$. 
Logo, a entropia de von Neumann será dada por,

$$
S\left(\rho_{0}\right)=S\left(\rho_{1}\right)=-\frac{1-\theta}{2} \log _{2} \frac{1-\theta}{2}-\frac{1+\theta}{2} \log _{2} \frac{1+\theta}{2}
$$

onde $\theta=\sqrt{\left|c_{1} z_{1}\right|^{2}+\left|c_{2} z_{2}\right|^{2}+\left|c_{3} z_{3}\right|^{2}}$. Como a entropia condicional pode ser escrita na forma $S_{\left\{B_{j}\right\}}\left(\rho_{A / B}\right)=\sum_{j} p_{j} S\left(\rho_{A}^{j}\right)$, então

$$
\begin{aligned}
S_{\left\{B_{j}\right\}}\left(\rho_{A / B}\right) & =p_{0} S\left(\rho_{0}\right)+p_{1} S\left(\rho_{1}\right) \\
& =-\frac{1-\theta}{2} \log _{2} \frac{1-\theta}{2}-\frac{1+\theta}{2} \log _{2} \frac{1+\theta}{2} .
\end{aligned}
$$

Com isto, a correlação clássica, Eq. 4.1.8, será dada por

$$
\begin{aligned}
J_{Q}\left(\rho_{A: B}\right) & =S\left(\rho_{a}\right)-S_{\left\{B_{j}\right\}}\left(\rho_{A / B}\right) \\
& =\frac{1-\theta}{2} \log _{2}(1-\theta)+\frac{1+\theta}{2} \log _{2}(1+\theta) .
\end{aligned}
$$

É fácil ver que $z_{1}^{2}+z_{2}^{2}+z_{3}^{2}=1$. Assim, definindo-se

$$
c=\max \left\{\left|c_{1}\right|,\left|c_{2}\right|,\left|c_{3}\right|\right\}
$$

segue que $\theta \leq \sqrt{\left|c^{2}\right|\left(z_{1}^{2}+z_{2}^{2}+z_{3}^{2}\right)}=c$. Portanto

$$
C(\rho)=\max _{\Pi_{j}^{B}} J_{Q}\left(\rho_{A: B}\right)=\frac{1-c}{2} \log _{2}(1-c)+\frac{1+c}{2} \log _{2}(1+c) .
$$

Logo, substituindo as Eqs. (5.1.3) e (5.1.17) a discórdia quântica será dada por

$$
\begin{aligned}
D\left(\rho_{A B}\right) & =I\left(\rho_{A B}\right)-C\left(\rho_{A B}\right) \\
& =\frac{1}{4}\left[\left(1-c_{1}-c_{2}-c_{3}\right) \log _{2}\left(1-c_{1}-c_{2}-c_{3}\right)\right. \\
& +\left(1-c_{1}+c_{2}+c_{3}\right) \log _{2}\left(1-c_{1}+c_{2}+c_{3}\right) \\
& +\left(1+c_{1}-c_{2}+c_{3}\right) \log _{2}\left(1+c_{1}-c_{2}+c_{3}\right) \\
& \left.+\left(1+c_{1}+c_{2}-c_{3}\right) \log _{2}\left(1+c_{1}+c_{2}-c_{3}\right)\right] \\
& -\frac{1-c}{2} \log _{2}(1-c)-\frac{1+c}{2} \log _{2}(1+c)
\end{aligned}
$$

Assim, para analizar o efeito da relaxação basta analizar como os elementos da matriz de correlação são modificados pelos canais relevantes. Como em RMN os responsáveis pelo processo de decoerência são os canais de Fase e de Amplitude Generalizada, analizaremos a influência deles sobre os elementos da matriz de correlação e, conseqüêntemente, o comportamento das correlações clássicas e quânticas. 


\subsection{Sistema de 2 q-bits representados por Spins 1/2 Aco- plados}

Em RMN, uma das formas de se representar sistemas de 2 q-bits são os sistemas de 2 spins $1 / 2$ acoplados via acoplamento J, fazendo-se a associação entre a orientação dos spins em relação ao campo magnético $B_{0}$ e a base lógica de 2 q-bits como ilustrado na Figura 2.2 . Neste caso, como descrito na seção 2.8.1, os canais responsáveis pelo processo de relaxação são: Atenuação de Fase e Atenuação de Amplitude Generalizada, como definido na Tabela 2.1. Primeiramente analizaremos os efeitos do canal de atenuação de fase.

Aplicando-se o canal de fase no estado Bell-diagonal, Eq. (5.1.1), e sendo $T_{2}^{A}$ e $T_{2}^{B}$ os tempos de relaxação para os q-bits $A$ e $B$, respectivamente, observamos que

$$
\varepsilon\left(\rho_{A B}\right)=\left[\begin{array}{cccc}
1+c_{3}(t) & 0 & 0 & c_{1}(t)-c_{2}(t) \\
0 & 1-c_{3}(t) & c_{1}(t)+c_{2}(t) & 0 \\
0 & c_{1}(t)+c_{2}(t) & 1-c_{3}(t) & 0 \\
c_{1}(t)-c_{2}(t) & 0 & 0 & 1+c_{3}(t)
\end{array}\right],
$$

onde $c_{1}(t)=e^{-\gamma t} c_{1}(0), c_{2}(t)=e^{-\gamma t} c_{2}(0)$ e $c_{3}(t)=c_{3}(0)$, sendo $\gamma=T_{2}^{A}+T_{2}^{B} / T_{2}^{A} T_{2}^{B}$.

Com isto, é possível caracterizar três diferentes dinâmicas de relaxação para a discórdia de um sistema a partir do seu estado inicial $(55,56)$ :

1. $\left|c_{3}(0)\right| \geq\left|c_{1}(0)\right|$ e $\left|c_{2}(0)\right|$. Como $c_{3}(t)$ é constante ao longo do tempo, então neste caso $c=c_{3}(0)$ na Eq. (5.1.17), o que faz com que a correlação clássica permaneça constante durante toda a evolução temporal, enquanto a Informação Mútua e a Discórdia Entrópica decaem monotonicamente, Figura 5.1-a.

2. $\left|c_{3}(0)\right|=0$. Os três tipos de correlação tendem assintoticamente para zero, Figura 5.1 b.

3. $\left|c_{3}(0)\right|<\left|c_{1}(0)\right|$ e/ou $\left|c_{2}(0)\right|$. Neste caso, a correlação clássica decai monotonicamente até o ponto em que $\left|c_{3}(0)\right| \geq\left|c_{1}(0)\right|,\left|c_{2}(0)\right|$, onde passa a ser constante. Neste mesmo instante de tempo a discórdia sofre uma mudança em sua taxa de decaimento, fenômeno conhecido como "sudden-change". Observa-se, portanto, neste caso, uma transição do regime de decoerência clássico para o quântico, Figura 5.17c.

Mazzola, L., Piilo, J. e Maniscalco, S. (54, 57) mostraram que para certas condições 

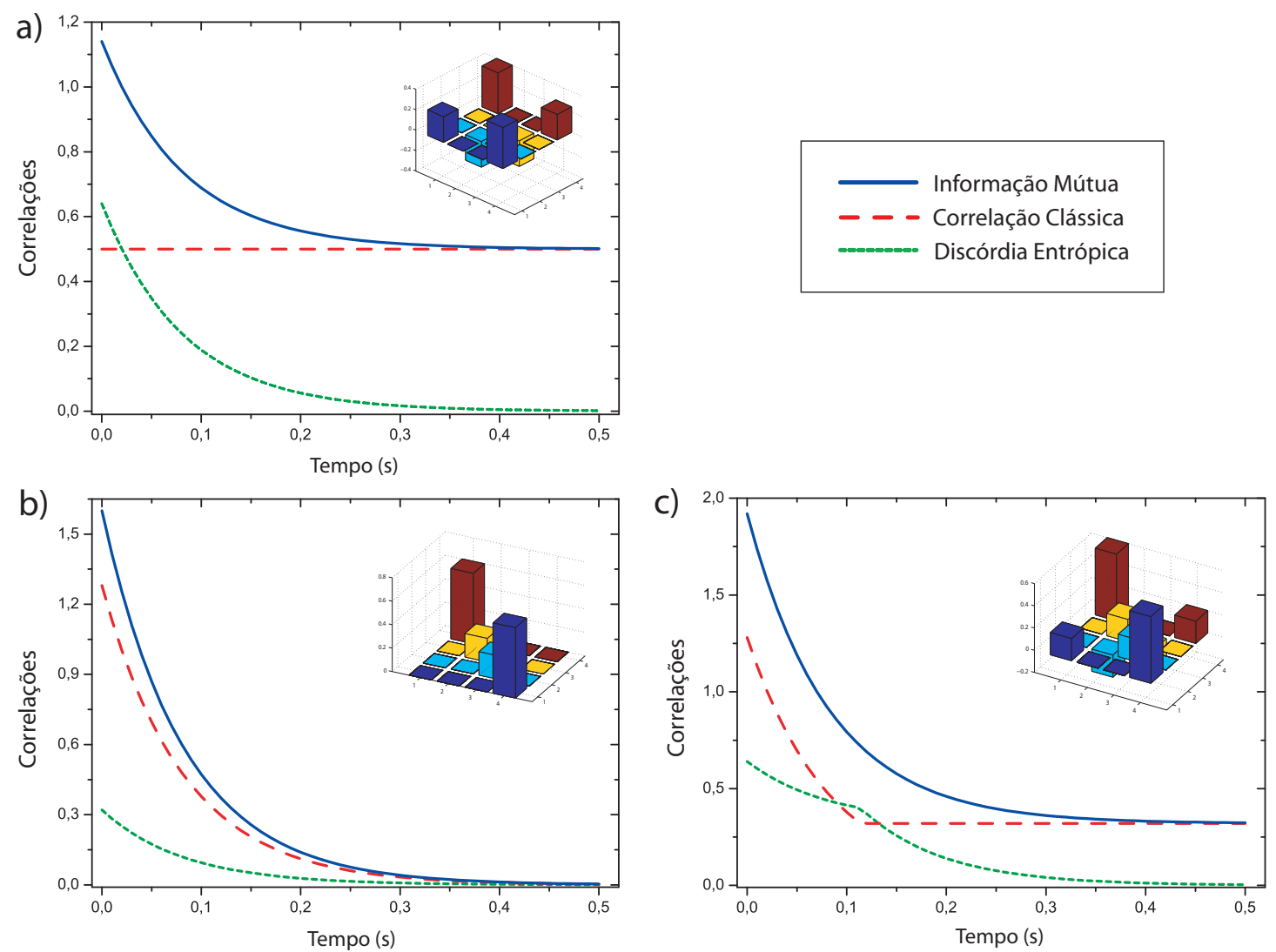

Figura 5.1 - Exemplo da dinâmica das correlações (Informação Mútua - linha azul, Correlação Clássica - tracejado vermelho e Discórdia Entrópica - pontilhado verde) de um sistema de 2 q-bits sob o efeito do canal de atenuação de fase, para $T_{2}^{A}=1.2$ e $T_{2}^{B}=0.19$. a) Dinâmica para o regime 1] $c_{1}=0.2, c_{2}=-0.2, c_{3}=0.25$. b) Regime 2 $c_{1}=0.4, c_{2}=-0.2$, $c_{3}=0$. c) Regime 3. $c_{1}=0.4, c_{2}=-0.2, c_{3}=0.2$. 


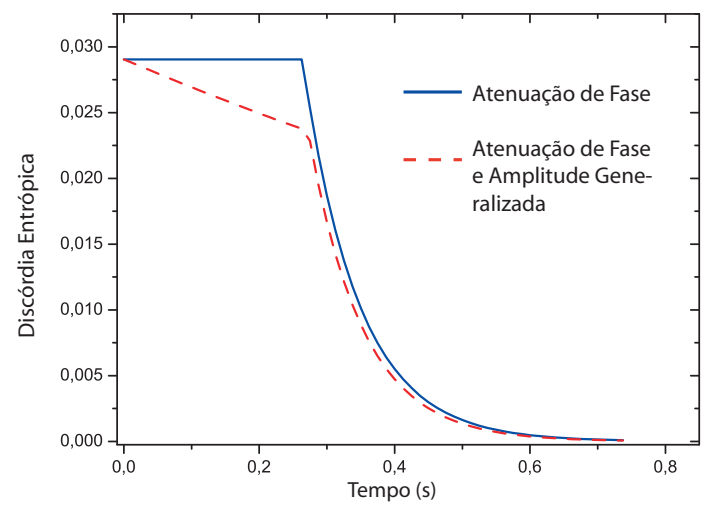

Figura 5.2 - Previsão teórica para a discórdia entrópica do estado Bell-diagonal correspondente à $c_{1}=1, c_{2}=-0.2, c_{3}=0.2$. A linha cheia azul representa a evolução temporal do sistema sujeito ao canal de atenuação de fase com $T_{2}=1.2$ e $0.19 \mathrm{seg}$, respectivamente para cada q-bit. E a linha pontilhada vermelha corresponde ao mesmo estado sujeito aos canais de atenuação de amplitude generalizada, com $T_{1}=3.57$ e $10 \mathrm{seg}$, e ao canal de atenuação de fase descrito anteriormente.

do estado inicial, quando apenas o canal de atenuação de fase está presente, não apenas uma transição abrupta no comportamento das correlações quânticas pode ser observada, mas também um congelamento das mesmas, fenômeno denominado como freezing. As condições que os autovalores de um estado devem satisfazer para que isto ocorra são (58),

$$
\begin{aligned}
& \lambda_{0} \lambda_{3}=\lambda_{1} \lambda_{2} \text { e }\left(\lambda_{0}-\lambda_{3}\right)\left(\lambda_{1}-\lambda_{2}\right)>0 \\
& \text { ou } \lambda_{0} \lambda_{1}=\lambda_{2} \lambda_{3} \text { e }\left(\lambda_{0}-\lambda_{1}\right)\left(\lambda_{3}-\lambda_{2}\right)>0
\end{aligned} .
$$

onde a relação entre os autovalores e os elementos da matriz de correlação é dada pela Eq. (5.1.2). A Figura 5.2 apresenta um exemplo de estado onde este fenômeno ocorre.

O surgimento deste fênomeno pode ser melhor entendido em termos da medida da negatividade do sistema. Como apresentamos na Seção 4.3, para estados Bell-diagonal temos

$$
Q_{N}^{A}\left(\rho_{A B}\right)=\frac{\left|c_{i n t}\right|}{2}
$$

onde $c_{i n t}$ é o elemento da matriz de correlação de valor intermediário. Assim, como $c_{3}$ não é afetado pela relaxação introduzida pelo canal de atenuação de fase, então sempre que $c_{3}$ for inicialmente o valor intermediário a negatividade do caráter quântico será constante, até o momento em que ocorra o cruzamento entre a curvas de $c_{3}$ e de $c_{1}$ ou $c_{2}$. Ou seja, o freezing será sempre observado nos instantes de tempo em que $c_{3}$ é o elemento de valor intermediário. A Figura 5.3 apresenta um exemplo para esta situação. Em a) $c_{3}$ é maior que $c_{1}$ e $c_{2}$ e em b) $c_{3}$ é menor que $c_{1}$ e $c_{2}$, e, em ambos os casos, o freezing não é observado. Já em c), $c_{3}$ é o valor intermediário, portanto ocorre o cruzamento entre $c_{3}$ e $c_{1}$, o que acarreta no aparecimento do fenômeno de freezing. 


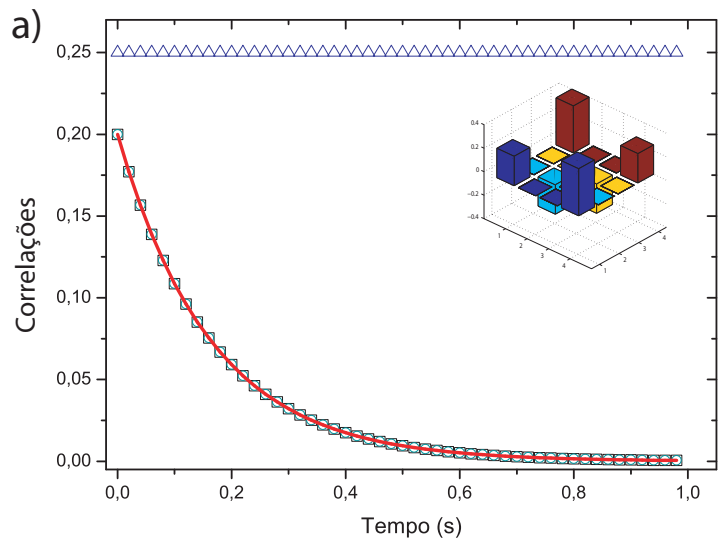

c)
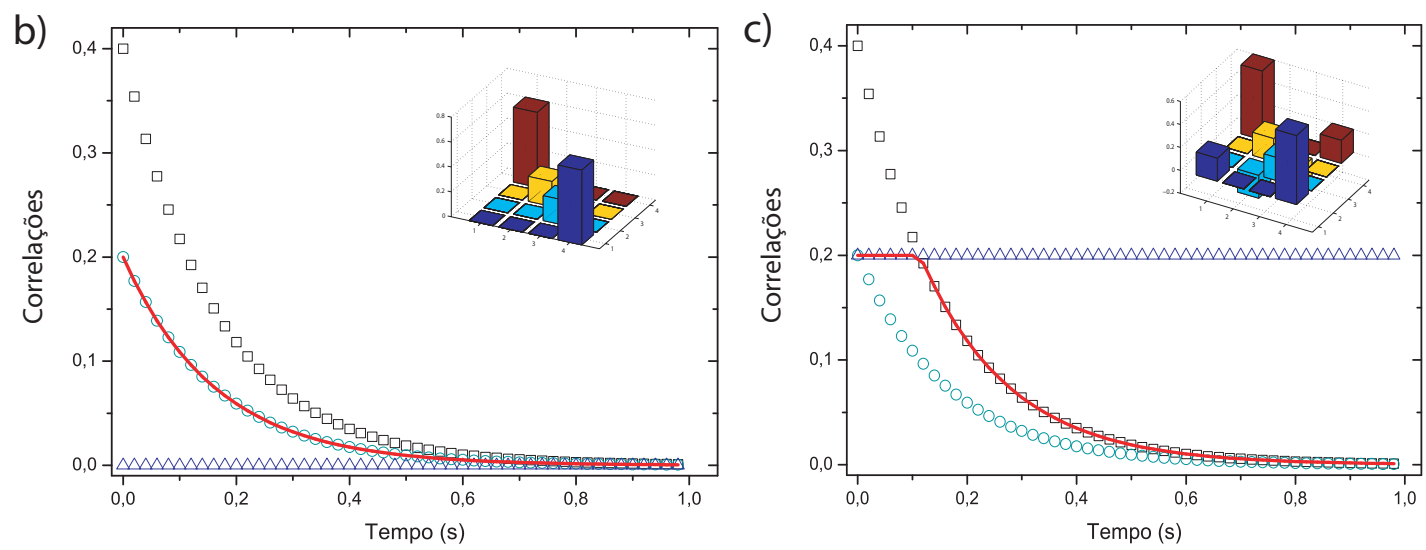

Figura 5.3 - Previsão teórica para os efeitos do canal de atenuação de fase sobre a medida de negatividade do caráter quântco em estados Bell diagonal na forma: a) $c_{1}=0.2, c_{2}=-0.2$, $c_{3}=0.25$; b) $c_{1}=0.4, c_{2}=-0.2, c_{3}=0$; c) $c_{1}=0.4, c_{2}=-0.2, c_{3}=0.2$. Os quadrados de borda preta representam a relaxação do elemento $c_{1}$, os círculos de borda verde $c_{2}$ e os triângulos de borda azul $c_{3}$. A linha vermelha corresponde à duas vezes $\mathrm{o}$ valor da negatividade. 
Para o canal de atenuação de amplitude generalizada, observamos a seguinte evolução temporal para uma matriz densidade tipo Bell-diagonal,

$$
\varepsilon\left(\rho_{A B}\right)=4 p_{a} p_{b}\left[\begin{array}{cccc}
1+c_{3}(t) & 0 & 0 & c_{1}(t)-c_{2}(t) \\
0 & 1-c_{3}(t) & c_{1}(t)+c_{2}(t) & 0 \\
0 & c_{1}(t)+c_{2}(t) & 1-c_{3}(t) & 0 \\
c_{1}(t)-c_{2}(t) & 0 & 0 & 1+c_{3}(t)
\end{array}\right],
$$

onde $c_{1}(t)=\sqrt{1-\gamma_{a}} \sqrt{1-\gamma_{b}} c_{1}(0), c_{2}(t)=\sqrt{1-\gamma_{a}} \sqrt{1-\gamma_{b}} c_{2}(0), c_{3}(t)=\left(1+\gamma_{a} \gamma_{b}-\right.$ $\left.\gamma_{a}-\gamma_{b}\right) c_{3}(0)$ para $\gamma_{a}$ e $\gamma_{b}$ os decaimentos relacionados ao $T_{1}$ de cada espécie nuclear e $p_{a}, p_{b} \approx 1 / 2$.

Portanto, ao contrário do observado para o canal de atenuação de fase, o canal de atenuação de amplitude induz um decaimento no elemento $c_{3}$ da matriz de correlação, bem como em $c_{1}$ e $c_{2}$. Logo, a presença deste canal faz com que o fenômeno de freezing não possa ser efetivamente observado. Isto esta ilustrado na Figura 5.2 através da comparação entre o comportamento das correlações clássicas e quânticas na presença conjunta dos canais de atenuação de fase e amplitude generalizada com a situação em que apenas o canal de atenuação de fase está presente. Vale ressaltar que o freezing é um caso particular do fenômeno de sudden-change, sujeito à uma condição muito mais restrita. Ou seja, todos os estados que apresentarem freezing quando apenas o canal de atenuação de fase estiver presente sofrerão uma alteração em sua taxa de decaimento quando o canal de atenuação de amplitude for adicionado (como mostra a Figura 5.2), no entanto isto não significa que todo estado que apresentar um sudden-change na presença dos dois canais corresponderá à um freezing caso o canal de atenuação de amplitude generalizada seja retirado. Um exemplo disto é o gráfico apresentado na Figura [5.1 - c, onde apenas o canal de atenuação de fase está presente e observa-se o fenômeno de sudden-change.

\subsection{Sistema de Spin $3 / 2$}

Como apresentado na seção [2.6. para um sistema de spin $3 / 2$ a descrição da relaxação transversal do sistema é feita através de um canal de fase global, definido pelos operadores de Kraus da Eq. (2.8.18). No entanto, a aplicação deste canal só afeta os elementos $\rho_{12}$, 

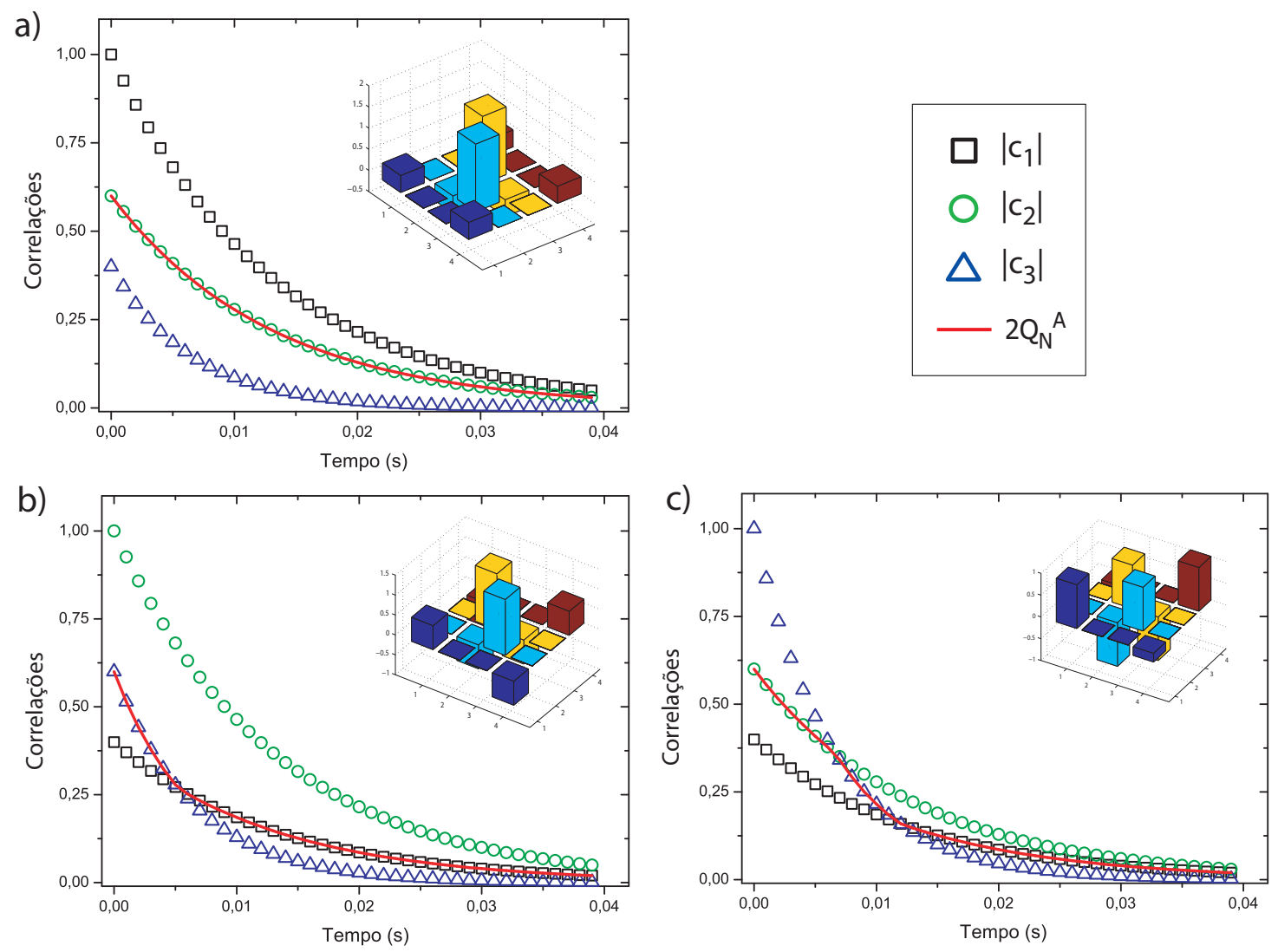

Figura 5.4 - Previsão teórica para os efeitos do canal de atenuação de amplitude generalizada sobre a medida de negatividade do caráter quântico em estados Bell diagonais na forma: a) $c_{1}=1, c_{2}=0,6$ e $c_{3}=0,4$; b) $c_{1}=0,4, c_{2}=1$ e $c_{3}=0,6$; c) $c_{1}=0,4, c_{2}=0,6$ e $c_{3}=1$. Os quadrados de borda preta representam a relaxação do elemento $c_{1}$, os círculos de borda verde $c_{2}$ e os triângulos de borda azul $c_{3}$. A linha vermelha corresponde à duas vezes o valor da negatividade.

$\rho_{13}, \rho_{24}$ e $\rho_{34}$ da matriz densidade e, portanto, este canal não produz nenhum efeito sobre estados Bell diagonais, onde os elementos da matriz densidade citados são nulos. Logo, para esta classe de estados, apenas o canal de atenuação de amplitude generalizada é suficiente para descrever completamente a relaxação do sistema. Assim, podemos aplicar a descrição da Eq. (5.2.4) também neste sistema. Com isto, fica claro que para sistemas deste tipo não é possível observar o fenômeno de freezing. No entanto, como discutido por Montealegre, J. et. al (52) para certas condições é possível ver efeitos de sudden change se utilizarmos o NoQ como quantificador.

A Eq. (5.2.4) deixa claro que, sob o efeito do canal de atenuação de amplitude generalizada, os elementos $c_{1}(t)$ e $c_{2}(t)$ da matriz de correlação possuem a mesma taxa de decaimento. Portanto, do ponto de vista da medida de negatividade do caráter quântico, o fenômeno de sudden-change só será observado quando no processo de relaxação houver um cruzamento entre uma destas correlações com a correlação $c_{3}(t)$. Assim, três situações distintas podem 
ocorrer:

1. $\left|c_{3}(0)\right|<\left|c_{1}(0)\right|,\left|c_{2}(0)\right|$. Nenhum efeito de sudden-change será observado, pois durante o processo de relaxação não há o cruzamento entre os elementos da matriz de correlação, como pode ser visto no exemplo teórico da Figura 5.4 -

2. $c_{3}(0)>c_{1}(0)$ ou $c_{3}(0)>c_{2}(0)$. Observa-se o cruzamento entre $c_{1(2)}(t)$ com $c_{3}(t) \mathrm{e}$ consequentemente o efeito de uma mudança súbita no comportamento do NoQ, Figura 5.4. b.

3. $c_{3}(0)>c_{1}(0), c_{2}(0)$. Neste caso ocorre o cruzamento entre $c_{3}(t)$ e $c_{1}(t)$ e, pra um outro instante de tempo, o cruzamento entre $c_{3}(t)$ e $c_{2}(t)$. Assim, para esta situação específica observa-se um fenômeno de double sudden-change, Figura 5.4-c.

Nos casos 2 e 3 mencionados a cima, os valores de $c_{1}(0)$ e/ou $c_{2}(0)$ devem ser suficiententemente maiores que zero para que o fenômeno de sudden-change seja observado. Caso contrário, os três elementos da matriz de correlação atingiram o equilíbrio antes do cruzamento entre as linhas.

Apesar deste fenômeno de sudden-change ser bem evidente para medidas de negatividade, estes efeitos não são observados se medidas de discórdia entrópica e geométrica forem realizadas sobre estes mesmos estados. Até este momento, não foi desenvolvida uma teoria sobre a universalidade deste fenômeno em relação aos quantificadores de correlações quânticas, como foi feito para o caso do fenômeno de freezing (64). 


\section{Medida de Observável de Correlações Quânticas}

Este capítulo é dedicado aos resultados experimentais. A partir da técnica de RMN e das ferramentas desenvolvidas para o estudo de informação quântica, discutidas nos capítulos 2 e 3, e do estudo teórico das correlações não-clássicas presentes em certos estados quânticos, capítulos 4 e 5, apresentaremos aqui alguns resultados experimentais. Em primeiro lugar, comprovaremos a eficiência de um método de medida direta que, para certos casos, pode substituir a aplicação do método de tomografia, seção 6.1. Em seguida, partindo de alguns estados iniciais específicos, observaremos experimentalmente os fenômenos de freezing e de double sudden-change, seções 6.2 e 6.3 .

\subsection{Método de Medida Direta}

O procedimento experimental tradicional no estudo de informação quântica via RMN consiste em preparar um estado inicial utilizando, por exemplo, a técnica de SMP (seção 3.2) e, em seguida, aplicar as transformações desejadas e, por fim, executar a leitura do estado final usando o método de TEQ (seção 3.3) ou equivalente. Quando se deseja monitorar a relaxação do sistema um intervalo de tempo é inserido após a preparação do estado e, então, a leitura é realizada. Variando-se esse intervalo de tempo em aquisições sucessivas é possível monitorar a relaxação do sistema. Este intervalo de tempo deve ser múltiplo da evolução característica do sistema (acoplamento J ou evolução quadrupolar). Além disso, um pulso de $180^{\circ}$ é inserido no meio período de relaxação para refocalizar o efeito de homogeneidade de campo. A Figura 6.1 ilustra este procedimento experimental. Assim, conhecendo-se completamente a matriz densidade em cada instante de tempo seria possível estudar o comportamento de quaisquer propriedades do estado inicialmente preparado. 


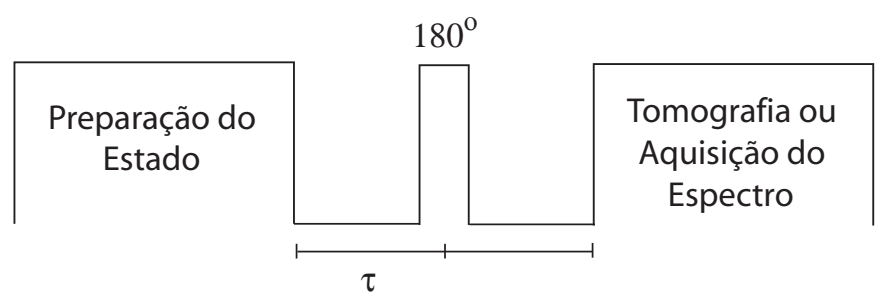

Figura 6.1 - Representação esquemática dos experimentos de RMN voltados para o estudo da relaxação de sistema quânticos. Após a preparação do estado o sistema é deixado para evoluir livremente sobre a ação do acoplamento J ou interação quadrupolar e após um certo tempo, $2 \tau$, que deve ser um múltiplo da evolução característica do sistema $(1 / 2 J$ ou $\left.1 / \omega_{Q}\right)$, a leitura é realizada. No meio deste período de relaxação, $\tau$, um pulso de $180^{\circ}$ é inserido, com o intuito de refocalizar o efeito de homogeneidade de campo.

No entanto, muitas vezes a análise que se deseja processar não envolve toda a matriz densidade mas apenas alguns de seus elementos. Nestes casos, empregar todo o método de TEQ torna-se ainda mais dispendioso, visto que boa parte da informação obtida será descartada. Por esta razão, apresentaremos um método de medida direta que permite calcular cada elemento da matriz densidade de forma independente dos demais.

Como definido na Eq. (2.8.7), utilizando a representação de Bloch, o operador densidade de um sistema de 2 q-bits pode ser escrito como

$$
\rho=\frac{1}{4}\left(\mathbb{I} \otimes \mathbb{I}+\sum_{i=1}^{3} x_{i} \sigma_{i} \otimes \mathbb{I}+\sum_{i=1}^{3} y_{i} \mathbb{I} \otimes \sigma_{i}+\sum_{i, j=1}^{3} c_{i j} \sigma_{i} \otimes \sigma_{j}\right),
$$

onde,

$$
\begin{aligned}
& x_{i}=\operatorname{Tr}\left\{\rho\left(\sigma_{i} \otimes \mathbb{I}\right)\right\}=\left\langle\sigma_{i} \otimes \mathbb{I}\right\rangle \\
& y_{i}=\operatorname{Tr}\left\{\rho\left(\mathbb{I} \otimes \sigma_{i}\right)\right\}=\left\langle\mathbb{I} \otimes \sigma_{i}\right\rangle
\end{aligned}
$$

Assim, como a magnetização transversal é proporcional ao valor esperado do operador de spin $I_{x(y)}$, Eq. (3.3.2), então as componentes dos vetores coluna $\vec{x}$ e $\vec{y}$ nada mais são que observáveis diretos de RMN.

Já os elementos da matriz de correlação $c_{i j}$ podem ser escritos como

$$
c_{i j}=\operatorname{Tr}\left\{\rho\left(\sigma_{i} \otimes \sigma_{j}\right)\right\}=\left\langle\sigma_{i} \otimes \sigma_{j}\right\rangle=4\left\langle I_{i} \otimes I_{j}\right\rangle,
$$

e, sendo

$$
\begin{aligned}
\left\langle I_{i x} \otimes I_{j x}\right\rangle & =\frac{1}{4}\left(\left\langle I_{i+} \otimes I_{j+}\right\rangle+\left\langle I_{i-} \otimes I_{j-}\right\rangle+\left\langle I_{i+} \otimes I_{j-}\right\rangle+\left\langle I_{i-} \otimes I_{j-}\right\rangle\right) \\
\left\langle I_{i y} \otimes I_{j y}\right\rangle & =-\frac{1}{4}\left(\left\langle I_{i+} \otimes I_{j+}\right\rangle+\left\langle I_{i-} \otimes I_{j-}\right\rangle-\left\langle I_{i+} \otimes I_{j-}\right\rangle-\left\langle I_{i-} \otimes I_{j-}\right\rangle\right)
\end{aligned}
$$


Tabela 6.1 - Ângulos de rotação $\theta_{i j}$ necessários para obter todos os elementos da matriz de correlação.

\begin{tabular}{|c|c|c|c|}
\hline $\mathrm{j} / \mathrm{i}$ & 1 & 2 & 3 \\
\hline 1 & 0 & $3 \pi / 2$ & $\pi / 2$ \\
\hline 2 & $3 \pi / 2$ & $\pi / 2$ & $-\pi / 2$ \\
\hline 3 & $\pi / 2$ & $-\pi / 2$ & $\pi / 2$ \\
\hline
\end{tabular}

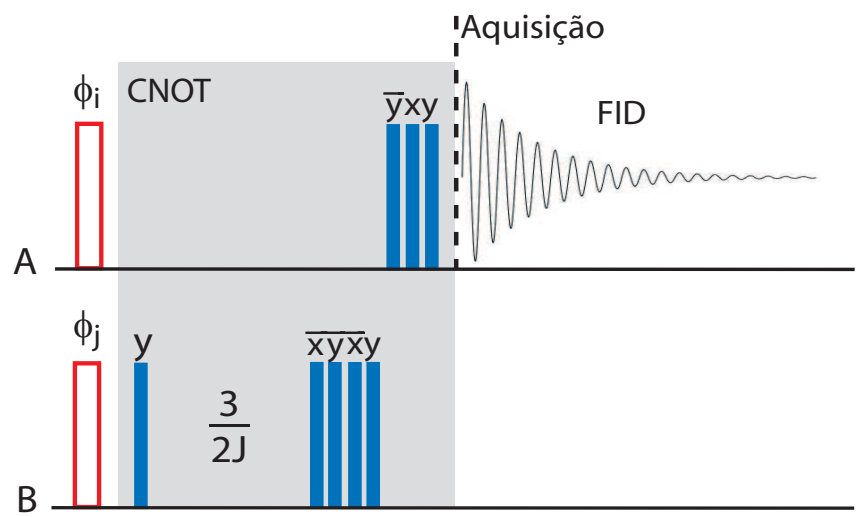

Figura 6.2 - Representação esquemática da sequência de pulsos para medida de coerências de zero e duplo quantum através de medidas locais. As barras vermelhas vazadas representam pulsos de ângulo $\theta$ e fase $\phi$ que dependem dos índices $i, j=1,2,3$, de forma que $\phi_{1}=x$, $\phi_{2}=y$ e $\phi_{3}=z$ e os ângulos de rotação $\theta$ estão descritos na Tabela 6.1. As barras azuis cheias representam pulsos $\pi / 2$ com a respectiva fase indicada na figura, o conjunto delas compõem a porta lógica CNOT.

então os elementos $c_{i j}$ são claramente proporcionais à transições com $\Delta m=0, \pm 2$, ou seja, coerências de zero e duplo quantum (65). Portanto, estas coerências não são diretamente acessíveis. Porém, graças às propriedades da função traço, estas medidas globais podem ser transformadas em medidas locais $(66,67)$ através da aplicação de um conjundo de operações unitárias $(U)$ tais que,

$$
\operatorname{Tr}\left[\left(\sigma_{i} \otimes \sigma_{j}\right) \rho\right]=\operatorname{Tr}\left[\left(\sigma_{1} \otimes \mathbb{I}\right) \xi_{i j}\right], \text { onde } \xi_{i j}=U_{i j} \rho U_{i j}^{\dagger}
$$

onde $U_{i j}=\operatorname{Cnot}_{A \rightarrow B} R_{\phi_{i}, \phi_{j}}\left(\theta_{i j}\right)$, para $R_{\phi_{i}, \phi_{j}}\left(\theta_{i j}\right)=R_{\phi_{i}}^{A}\left(\theta_{i j}\right) \otimes R_{\phi_{j}}^{B}\left(\theta_{i j}\right)$, sendo $R_{\phi_{i(j)}}^{A(B)}\left(\theta_{i j}\right)$ uma rotação de um ângulo $\theta_{i j}$ na direção $\phi_{i(j)}$ e $\operatorname{Cnot}_{A \rightarrow B}$ a porta lógica CNOT com o q-bit A como controle. A Figura 6.2 apresenta uma representação esquemática desta sequência de pulsos. A fase $\phi$ de cada pulso é tal que $\phi_{1}=x, \phi_{2}=z$ e $\phi_{3}=y$ e os ângulos de rotação $\theta_{i j}$ encontram-se descritos na Tabela 6.1.

Assim, é possível medir todos os elementos da matriz de correlação, o que juntamente com os observáveis diretos de RMN (vetores $\vec{x}$ e $\vec{y}$ ) permite reconstruir completamente uma matriz densidade. A grande vantagem deste método em relação ao método convencional 
de tomografia é que é possível conhecer cada um dos elementos da matriz densidade na representação de Bloch de forma independente. Sendo ainda possível separar as medidas que dependem de cada um dos q-bits.

Um exemplo interessante onde a aplicação desta técnica é bastante útil é o cálculo da discórdia geométrica. Observando-se a expressão para a discórdia geométrica de um sistema de 2 q-bits, Eq. (4.2.18),

$$
D_{G}(\rho)=\frac{1}{2}\left[\|\vec{x}\|_{2}^{2}+\|C\|_{2}^{2}-4 k_{\max }\right]
$$

vemos que esta quantidade só depende do vetor $\vec{x}$ e dos elementos da matriz de correlação $C$. Assim, fica clara a possibilidade de medi-la diretamente através deste método e com a vantagem de se realizar a medida apenas sobre um dos q-bits, visto que não há dependência com os elementos do vetor $\vec{y}$. Caso o estado inicial seja tipo Bell diagonal a medida torna-se ainda mais simples, já que a matriz de correlação possui apenas os elementos da diagonal.

Como apresentamos na seção 4.3, no caso da Negatividade do caráter quântico para estados tipo Bell-diagonal, esta medida também é simples e depende apenas dos elementos diagonais da matriz de correlação $C$, Eq. (4.3.11). E, portanto, também é possível medir esta quantidade de forma bem simples utilizando-se o método de medida direta. Vale ressaltar aqui que, neste caso, o método de medida direta envolve a realização de medidas apenas sobre um dos q-bits, ao contrário do método de TEQ que exige que ambos os q-bits sejam medidos.

Um ponto importante que merece ser mencionado é o processo de normalização dos dados obtidos via medida direta. Para cada instante de tempo foram feitas medidas da magnetização de equilíbrio e das magnetizações correspondentes aos elementos do vetor $\vec{x}$ e da matriz de correlação $C$. Como citado anteriormente, do ponto de vista teórico, podemos escrever,

$$
\left(M_{z}\right)_{e q}^{t e o}=\operatorname{Tr}\left\{\left(\sigma_{z} \otimes \mathbb{I}\right) \rho_{e q}^{t e o}\right\}
$$

mas como apenas a matriz de desvio contribui para o sinal de RMN, podemos reescrever esta equação como,

$$
\left(M_{z}\right)_{e q}^{t e o}=\operatorname{Tr}\left\{\left(\sigma_{z} \otimes \mathbb{I}\right) \varepsilon \Delta \rho_{e q}^{t e o}\right\}
$$

No entanto, o sinal obtido experimentalmente corresponde à,

$$
\left(M_{z}\right)_{e q}^{e x p} \propto \operatorname{Tr}\left\{I_{z} \Delta \rho_{e q}^{e x p}\right\}
$$

Ou seja, podemos dizer que os sinais obtidos experimental e teoricamente são iguais à menos 
de uma constante, que denominaremos de $\alpha$, que depende de

$$
\left(M_{z}\right)_{e q}^{t e o}=\alpha\left(M_{z}\right)_{e q}^{e x p}
$$

Assim, substituindo-se as Eqs. (6.1.8) e (6.1.9) em (6.1.10) segue que

$$
\frac{\varepsilon}{2} \operatorname{Tr}\left\{I_{z} \Delta \rho_{e q}^{t e o}\right\}=\alpha \operatorname{Tr}\left\{I_{z} \Delta \rho_{e q}^{e x p}\right\}
$$

onde utilizamos que $I_{z}=\frac{1}{2}\left(\sigma_{z} \otimes \mathbb{I}\right)$, para $I_{z}$ o operador de spin no espaço $4 \times 4$. Como $\operatorname{Tr}\left\{I_{z} \Delta \rho_{e q}^{t e o}\right\}=1$, então segue que

$$
\alpha=\frac{1}{\operatorname{Tr}\left\{I_{z} \Delta \rho_{e q}^{\exp }\right\}} \varepsilon
$$

que foi o fator de normalização utilizado. Para minimizar os erros experimentais, a magnetização de equilíbrio foi medida para cada instante de tempo e, por esta razão, o fator $\alpha$ permite eliminar parte dos erros oriundos de variações nas condições do experimento.

Na próxima seção apresentaremos resultados experimentais utilizando-se o método de medida direta. Com o objetivo de demonstrar a sua validade, faremos a comparação destes resultados com resultados obtidos via tomografia. Para que fosse possível fazer esta comparação, os valores dos elementos da matriz de correlação $C$ e do vetor $\vec{x}$ foram renormalizados pelo primeiro ponto obtido via tomografia.

\subsection{Comprovação experimental para o fenômeno de Fre- ezing das correlações quânticas}

O experimento foi realizado no espectrômetro Varian 500 MHz Premium Shielded, localizado no Centro Brasileiro de Pesquisas Físicas (CBPF, Rio de Janeiro). Utilizamos uma sonda de dupla ressonância de $5 \mathrm{~mm}$ equipada com bobinas de gradiente de campo. A amostra utilizada foi de clorofórmio enriquecido com carbono-13 à $99 \%,\left({ }^{13} \mathrm{CHCL}_{3}\right)$, onde ${ }^{1} \mathrm{H}$ e ${ }^{13} \mathrm{C}$ foram associados aos q-bits $A$ e $B$, respectivamente. Uma representação esquemática desta molécula é apresentada na Figura 6.3. A amostra foi preparada misturando-se $100 \mathrm{mg}$ de ${ }^{13} \mathrm{CHCL}_{3}$ à $99 \%$ em $0.7 \mathrm{~mL}$ de $\mathrm{CDCl}_{3}$ para a realização de locking de campo durante o experimento, os dois compostos foram adquiridos junto à Cambridge Isotope Laboratories Inc.. O 


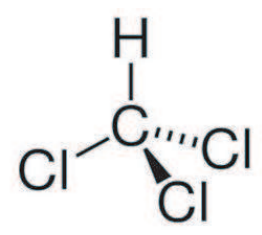

Figura 6.3 - Molécula de clorofórmio, $\mathrm{CHCl}_{3}$, utilizada como a amostra para os experimentos em sistemas de 2 spins $1 / 2$ acoplados. Utizamos uma amostra enriquecida com com carbono$13\left(\mathrm{CHCL}_{3}\right)$. Para as análises em informação quântica, ${ }^{1} \mathrm{H} \mathrm{e}{ }^{13} \mathrm{C}$ foram associados aos q-bits $A$ e $B$, respectivamente.

experimento foi realizado à $25^{\circ} \mathrm{C}$ e os pulsos $\pi / 2$ corresponderam à pulsos de $7.4 \mu \mathrm{s}$ e $8.0 \mu \mathrm{s}$ de duração para ${ }^{1} \mathrm{H}$ e ${ }^{13} \mathrm{C}$, respectivamente.

O sinal do hidrogênio foi encontrado à uma freqüência de aproximadamente $500 \mathrm{MHz}$ e do carbono por volta de $125 \mathrm{MHz}$, enquanto que o acoplamento J (spin-spin) era de 215.1 $\mathrm{Hz}$.

O experimento foi realizado preparando-se dois estados iniciais, ambos tipo Bell-diagonal. O primeiro estado é descrito por $\left|c_{1}\right|=\left|c_{2}\right|=\left|c_{3}\right|=0.2$ e foi preparado aplicando-se a seqüência de pulsos descrita na Figura 6.4 - O segundo estado tem como elementos da matriz de correlação $\left|c_{1}\right|=0.5,\left|c_{2}\right|=0.06$ e $\left|c_{3}\right|=0.24$ e foi preparado através da aplicação de uma seqüência de pulsos de SMP, seguida da aplicação de um pulso de grandiente de campo de $2 \mathrm{~ms}$, responsável por eliminar as coerências existentes, e da porta lógica conhecida como pseudo-EPR, como ilustrado pela Figura 6.4 c. A sequência de pulsos de SMP é construída de forma a produzir um estado diagonal com populações $\alpha, \beta, \gamma$ e $\delta$. Após a aplicação da porta pseudo-EPR, a forma da matriz de desvio obtida será,

$$
\Delta \rho=\frac{1}{2}\left[\begin{array}{cccc}
\alpha+\gamma & 0 & 0 & -\alpha+\gamma \\
0 & \beta+\delta & -\beta+\delta & 0 \\
0 & -\beta+\delta & \beta+\delta & 0 \\
-\alpha+\gamma & 0 & 0 & \alpha+\gamma
\end{array}\right]
$$

A Figura 6.4 b,d apresenta os diagramas de blocos correspondentes a estas duas matrizes densidade de desvio.

Com o intuito de validar o processo de medida direta empregamos o método de TEQ e o utilizamos como base para comparação. A Figura 6.5 apresenta as curvas experimentais de tomografia e medida direta juntamente com a previsão teórica para medidas de $Q, D_{G}$ e $Q_{N}^{A}$ dos dois estados especificados a cima. Em todos estes casos, os resultados para a tomografia estão representados pelos quadrados de borda preta enquanto que a medida direta corresponde aos círculos verdes. Assim, é possível ver que os resultados obtidos por ambos os métodos 
a)

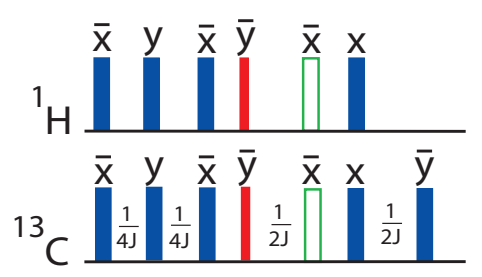

Gradiente

c)

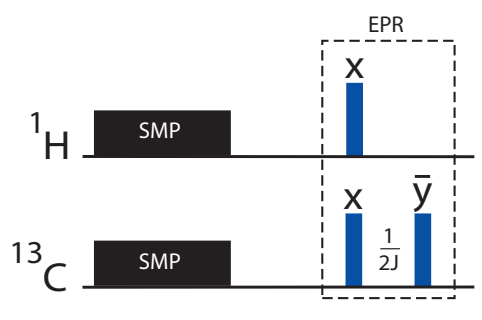

Gradiente b)

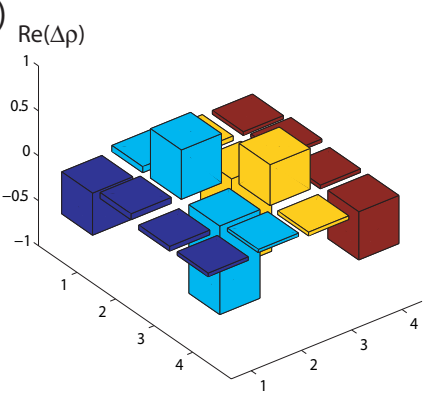

d)

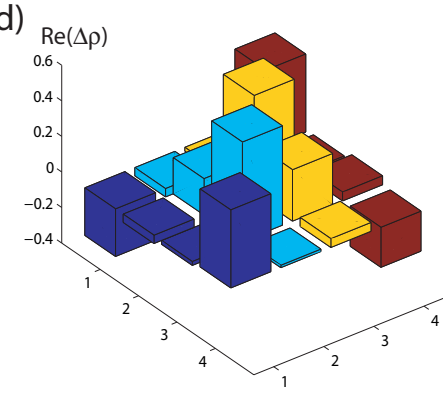

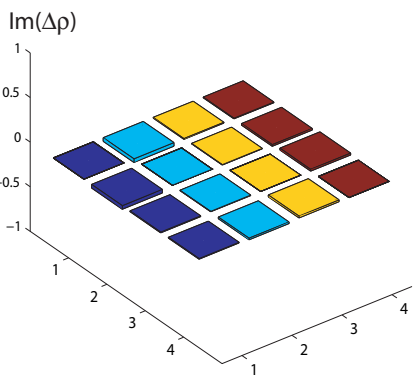

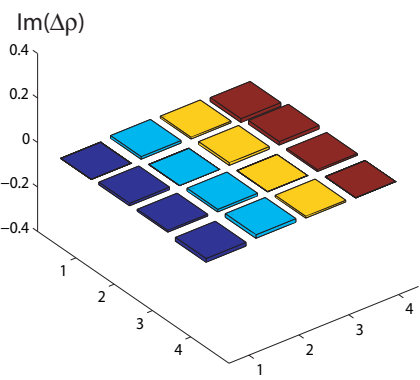

Figura $6.4-$

a) Seqüência de pulsos para criação do estado cuja matriz densidade de desvio está ilustrada em b) na forma de diagrama de blocos, onde $\left|c_{1}\right|=\left|c_{2}\right|=\left|c_{3}\right|=0.2$. As barras azuis cheias representam pulsos $\pi / 2$, as barras vermelhas finas representam pulsos $\pi / 4$ e as barras vazadas verdes são pulsos $\pi / 6$. A última linha representa os monmentos de aplicação de gradientes de campo, responsáveis por eliminar todas as coerências do estado. Os períodos $1 / 4 \mathrm{~J}$ e $1 / 2 \mathrm{~J}$ representam evoluções livres sobre acoplamento J. c) Seqüência de pulsos para criação do estado Bell diagonal com $\left|c_{1}\right|=0.5,\left|c_{2}\right|=0.06 \mathrm{e}$ $\left|c_{3}\right|=0.24$, representado em d) na forma de diagrama de blocos. 

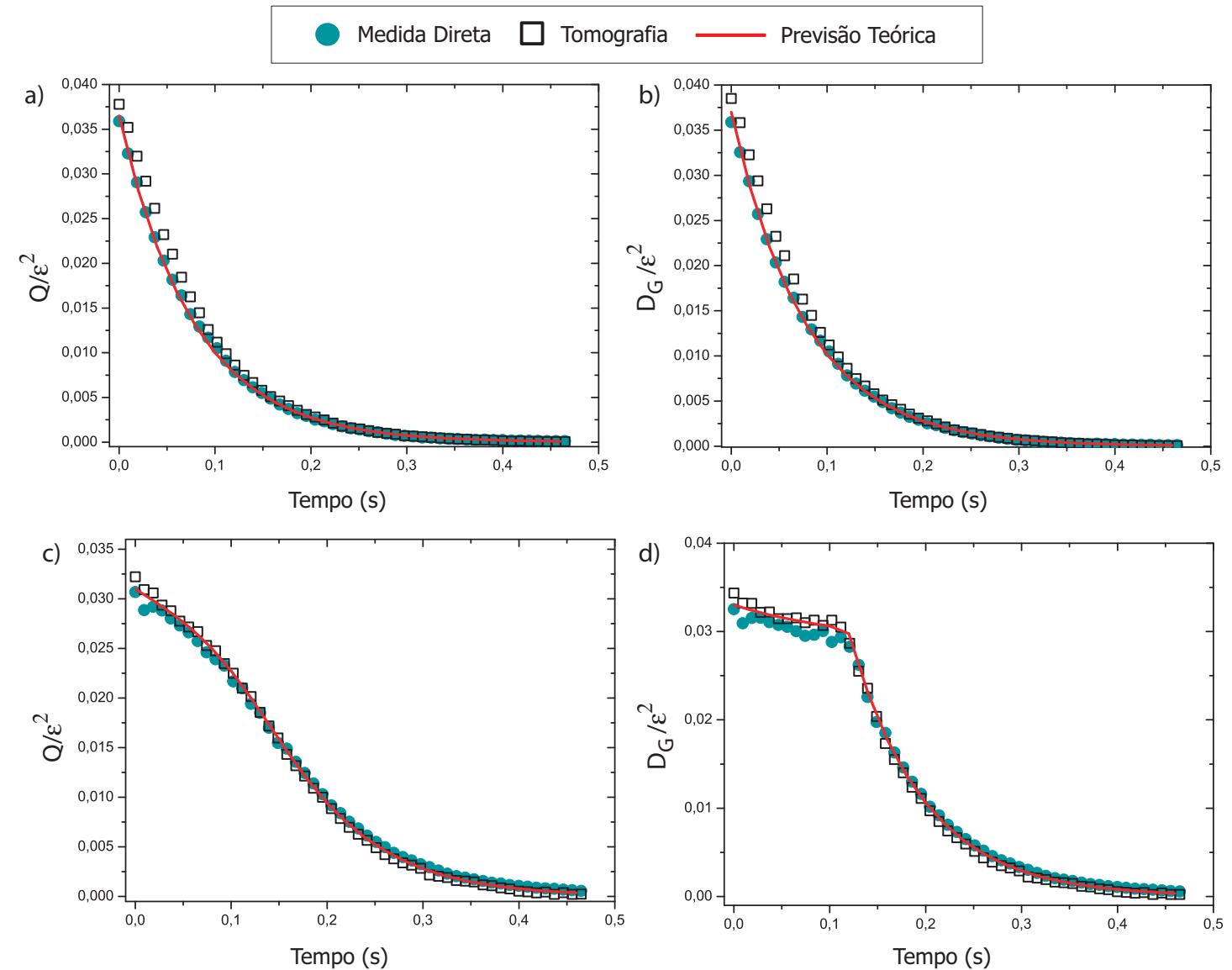

Figura 6.5 - Evolução temporal para $Q$ e $D_{G}$. As curvas em a) e b) correspondem ao estado na Figura 6.4- b e as curvas c) e d) ao estado na Figura 6.4- c. Os círculos verdes correspondem aos resultados experimentais para o método de medida direta e os quadrados pretos para a tomografia. As linhas vermelhas são as previsões teóricas. Os tempos de relaxação medidos experimentalmente foram $T_{1}=9 \mathrm{~s}$ e $T_{2}=1.2 \mathrm{~s}$ para o hidrogênio, e $T_{1}=25 \mathrm{~s}$ e $T_{2}=0.18 \mathrm{~s}$ para o carbono. As correlações quânticas estão apresentadas em unidades de $\varepsilon^{2}$. 
apresentam uma boa concordância. A Figura 6.5 também apresenta a previsão teórica para estes resultados, simbolizados pela linha vermelha. Desta forma também observa-se a boa relação entre os dados experimentais e a simulação teórica.

Com estes resultados comprovamos a eficiência do método de medida direta. Vale ressaltar que com este método somos capazes de calcular a discórdia geométrica de um estado "desconhecido", no sentido de que não é necessário conhecer completamente a matriz densidade do sistema como no caso da tomografia. A previsão teórica foi obtida aplicando-se os canais de atenuação de fase e amplitude generalizada para sistemas de 2 spins $1 / 2$ acoplados, como descrevemos nas seções anteriores e com isto observamos o perfeito ajuste desta previsão com os resultados experimentais.

Apesar do estado da Figura 6.4 - b apresentar um resultado muito próximo do comportamento de freezing é interessante destacar que o decaimento observado no intervalo entre 0 e 0.11 seg é em parte devido à presença do canal de atenuação de amplitude generalizada e parte devido ao fato do estado não satisfazer exatamente as condições de freezing, Eq. (5.2.2) já que $\left|c_{1}\right|=0.5,\left|c_{2}\right|=0.06$ e $\left|c_{3}\right|=0.24$ correspondem aos autovalores: $\lambda_{0}=0.05, \lambda_{1}=0.2$, $\lambda_{2}=0.42, \lambda_{3}=0.465$. Assim, a segunda parte da condição $1\left(\left(\lambda_{0}-\lambda_{3}\right)\left(\lambda_{1}-\lambda_{2}\right) \geq 0\right)$ é satisfeita, no entanto, a primeira parte $\left(\lambda_{0} \lambda_{3}=\lambda_{1} \lambda_{2}\right)$ corresponde à uma condição bastante restritiva. Neste caso temos, $\lambda_{0} \lambda_{3}=0.02$ e $\lambda_{1} \lambda_{2}=0.08$, ou seja, o estado está próximo da condição mas não a satisfaz completamente. É importante frizar que a condição exata de freezing é difícil de se obter experimentalmente, já que os erros experimentais são da ordem de $5 \%$.

A Figura 6.6 apresenta a previsão teórica e as curvas experimentais (medida direta e tomografia) para a negatividade dos mesmos dois estados descritos. Assim como no resultado anterior, vemos a concordância entre a medida direta e a tomografia, bem como a concordância da previsão teórica com estes resultados. Além disso, apresentamos as curvas dos elementos da matriz de correlação onde vemos claramente o surgimento do fenômeno de freezing para situações onde ocorre o cruzamento entre estas curvas.

Na Figura 6.7, apresentamos, para os dois estados descritos anteriormente, as curvas de Informação Mútua, Correlação Clássica e Discórdia Entrópica. Em c) e d), os símbolos cheios indicam os cálculos feitos utilizando-se os resultados experimentais para a Eq. (5.1.18) e os símbolos vazios representam o cálculo destes quantificadores mas empregando-se toda a matriz densidade, a partir do cálculo da Eq. (4.1.11), onde é necessário realizar o processo de minimização sobre os projetores de medida. Com esta comparação podemos avaliar a qualidade do estado implementado experimentalmente. A Eq. (5.1.18) considera que a matriz 


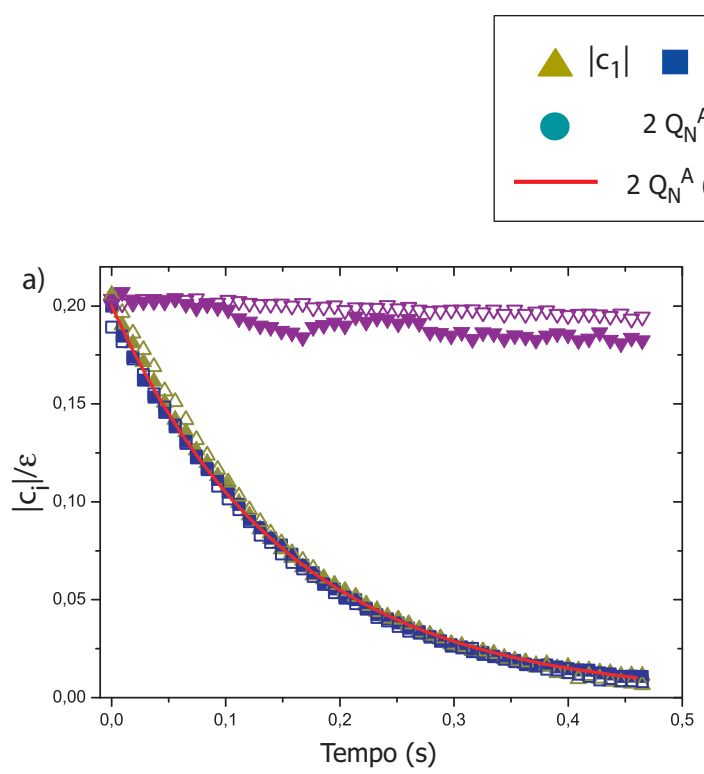

\section{$\left|c_{2}\right| \nabla\left|c_{3}\right|$}

$2 \mathrm{Q}_{\mathrm{N}}{ }^{\mathrm{A}}$ (Experimental)

$2 \mathrm{Q}_{\mathrm{N}}{ }^{\mathrm{A}}$ (Previsão Teórica)
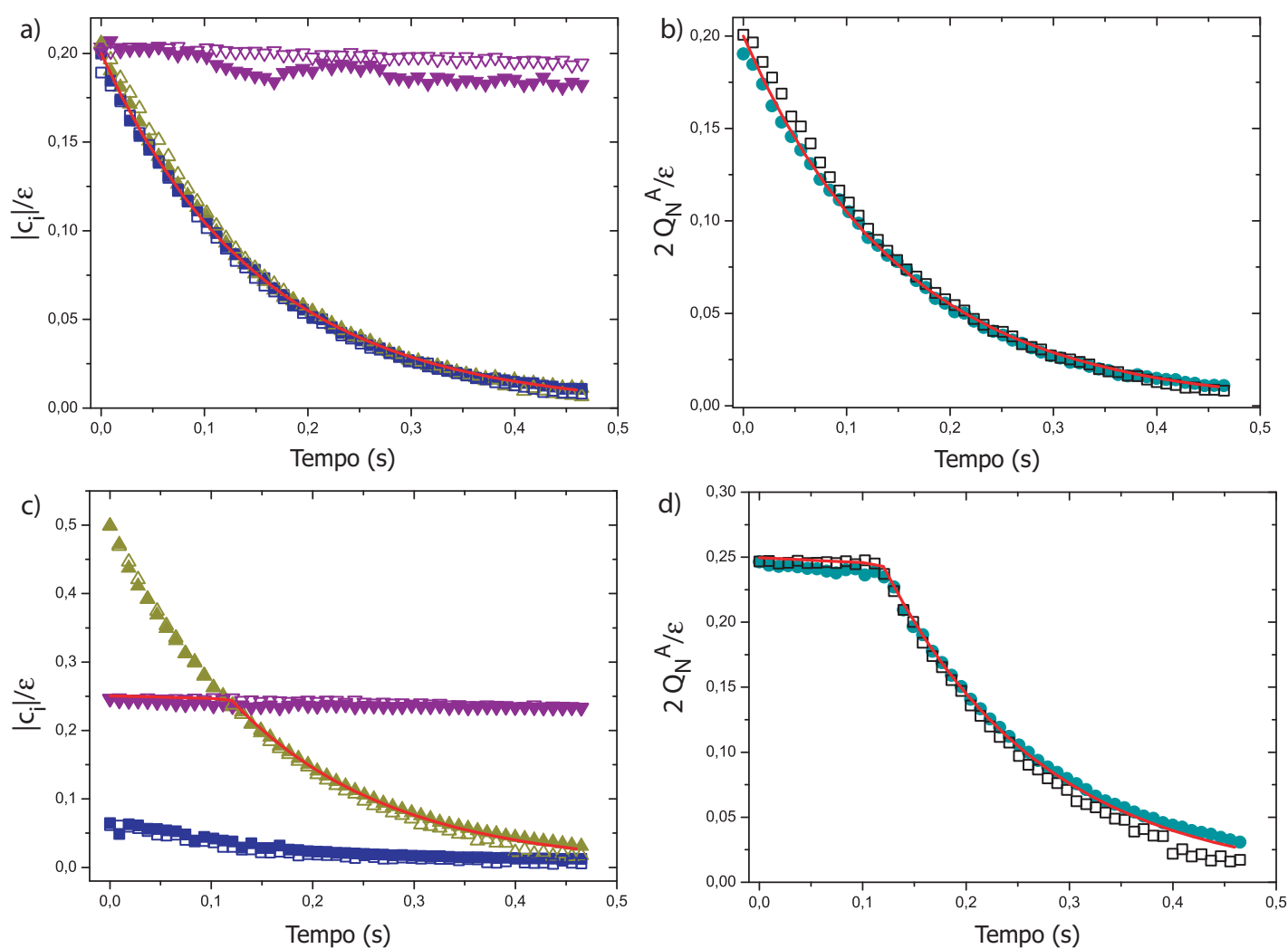

Figura 6.6 - a) e c) Evolução temporal para $2\left|c_{1}\right|$ (quadrado), $2\left|c_{2}\right|$ (círculo) e $2\left|c_{3}\right|$ (triângulo) dos estados apresentados na Figura 6.4 - b,c, respectivamente. Onde as figuras vazadas correspondem à medidas de tomografia e as figuras cheias à medidas diretas. A linha vermelha corresponde à previsão teórica para o $Q_{N}^{A}$. E em b) e d) apresentamos os resultados experimentais para a medida direta(círculos verdes) e tomografia (quadrado reto vazado), bem como a previsão teórica (linha vermelha) para a negatividade dos estados na Figura 6.4- b,c, respectivamente. 


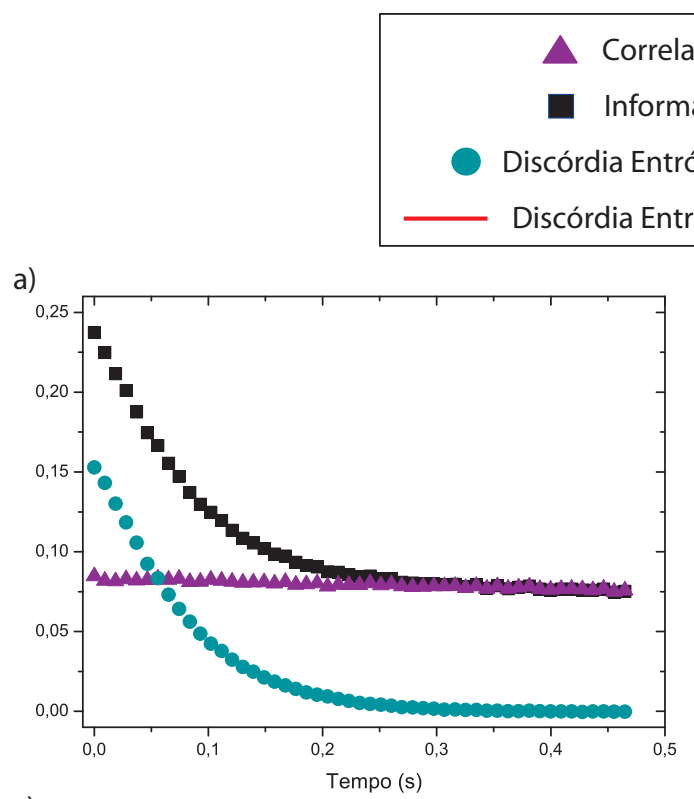

c)
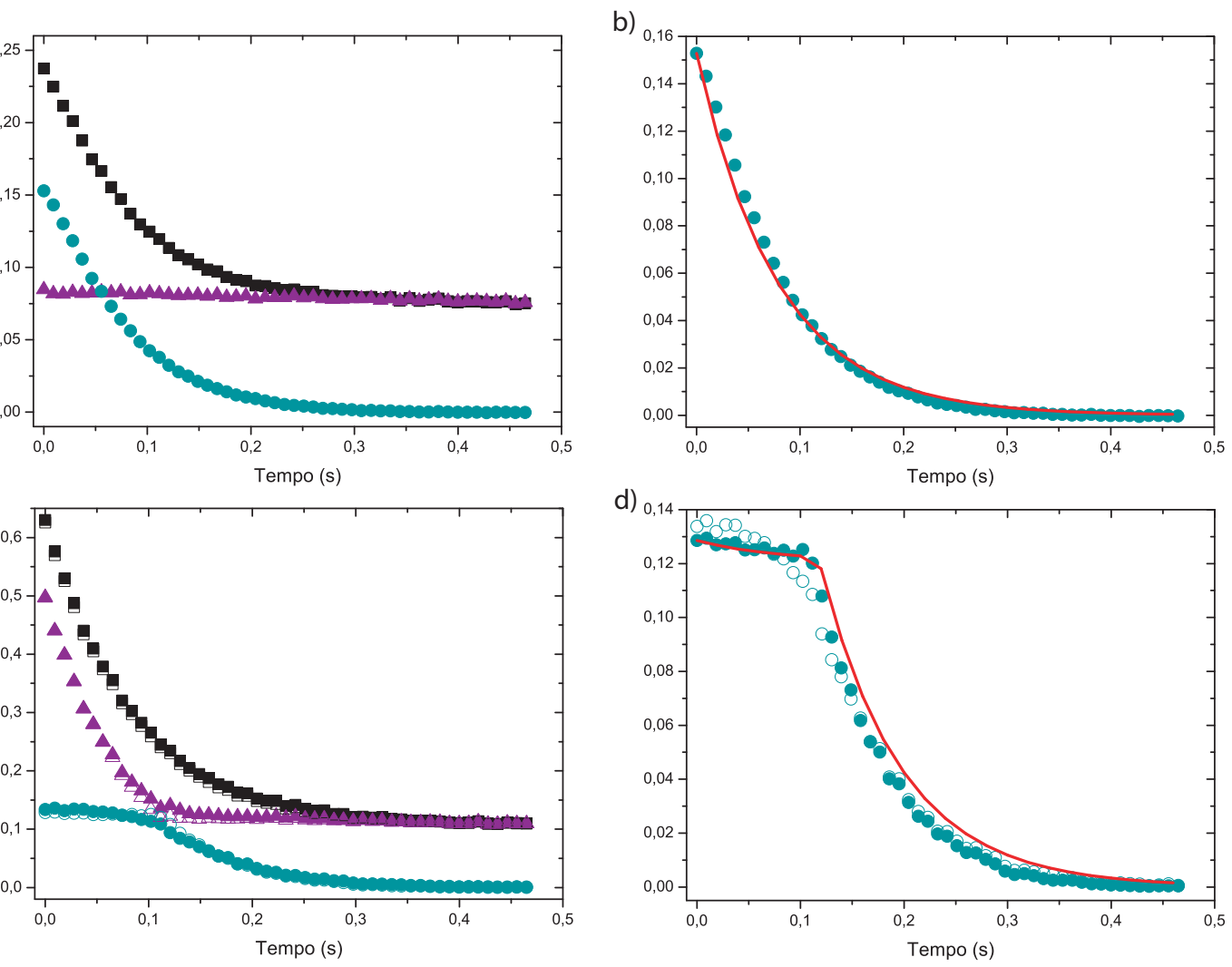

Figura 6.7 - Evolução temporal para a correlação clássica (triângulo roxo), a informação mútua (quadrado preto) e a discórdia entrópica (cículo verde). As curvas em a) e b) correspondem ao estado representado na Figura 6.4- b e as curvas c) e d) ao estado da Figura 6.4- c. As linhas vermelhas são as previsões teóricas para a discórdia entrópica. Os tempos de relaxação utilizados para a previsão teórica são $T_{1}=9 \mathrm{~s}$ e $T_{2}=1.2 \mathrm{~s}$ para o hidrogênio, e $T_{1}=25 \mathrm{~s}$ e $T_{2}=0.18 \mathrm{~s}$ para o carbono. 
implementada é exatamente Bell diagonal, ou seja, todos os elementos com exceção das diagonais principal e secundária são nulos, por outro lado, a Eq. (4.1.11) leva em consideração toda a matriz densidade. Assim, as diferenças observadas são fruto da presença de coerências fora das diagonais, devido à imperfeições experimentais.

Comparando-se as curvas nas Figuras 6.5- $d$, 6.6- $d$ e 6.7- $d$ vemos que a mudança de comportamento ocorre exatamente no mesmo instante de tempo. No entanto, a forma das curvas é ligeiramente distinta. Recentemente Aaronson, Franco e Adesso (64) mostraram uma previsão teórica de que apenas para certas condições sobre o estado incial o aparecimento do fenômeno de freezing é universal, ou seja, pode ser igualmente observado utilizando-se qualquer tipo de quantificador. Nos outros casos, será observado um comportamento diferente para cada quantificador, no entanto a mudança de comportamento ocorrerá sempre no mesmo instante de tempo, como podemos observar que nos exemplos apresentados a mudança ocorre aproximadamente em $110 \mathrm{~ms}$.

É interessante observar ainda que, de acordo com o que foi exposto na seção [5.2, o elemento $c_{3}$ da matriz de correlação não é afetado pelo canal de atenuação de fase mas apenas pelo canal de atenuação de amplitude generalizada. Então, como o aparecimento do fenômeno de freezing, do ponto de vista da medida da negatividade do caráter quântico, depende apenas de $c_{3}$ ser inicialmente o valor intermediário dentre os elementos da matriz de correlação, segue que a curva de NoQ pode ser utilizada para medir o tempo de decaimento $T_{1}$ da amostra. Ou seja, no caso das medidas de NoQ, a inclinação observada no período de freezing está associada apenas ao efeito do canal de atenuação de amplitude generalizada, já que a condição sobre os elementos da matriz de correlação $\left(c_{1}, c_{2}, c_{3}\right)$ para o aparecimento do freezing, neste caso, é bastante abrangente.

No caso das discórdias geométrica $\left(D_{G}\right)$ e entrópica $\left(D_{E}\right)$, a inclinação observada durante o "período de freezing" sofre efeitos da presença do canal de amplitude generalizada e da qualidade do estado implementado, pois quanto mais distante da condição de freezing o estado estiver mais as curvas de $D_{G}$ e $D_{E}$ apresentarão o decaimento inicial, ou seja, será observado apenas um sudden-change. Portanto, a comparação entre as inclinações destas duas curvas com a curva de NoQ também pode fornecer um idéia da qualidade do estado implementado, sem que seja necessário executar a tomografia de estado, já que a $D_{G}$ pode ser obtida pelo método de medida direta. Além disso, caso o objetivo seja apenas conhecer o ponto onde a mudança súbita de comportamento ocorre, a medida do NoQ pode ser utilizada para determinar este ponto de forma mais rápida que se as outras medidas forem utilizadas. 
a) $\operatorname{Re}(\Delta \rho)$

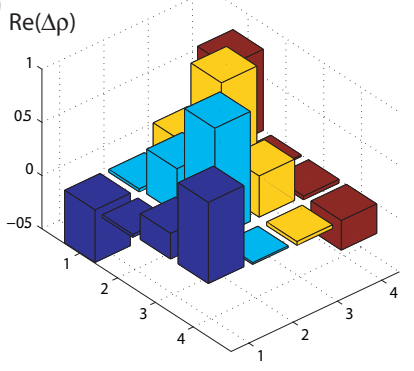

b) $\operatorname{Re}(\Delta \rho)$

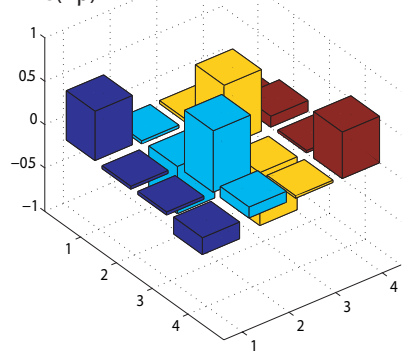

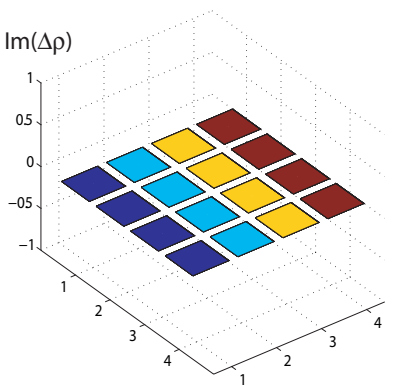

$\operatorname{Im}(\Delta \rho)$

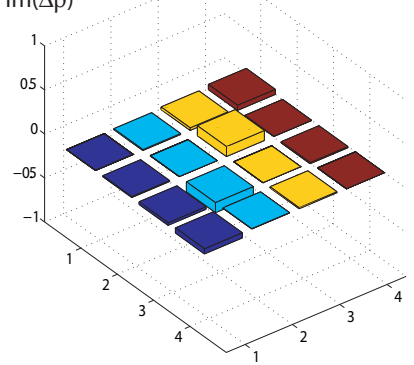

Figura 6.8 - Diagramas de blocos representando as partes real e imaginária das matrizes de desvio correspondentes à a) $c_{1}=0.89, c_{2}=0.14, c_{3}=0.39$ e b) $c_{1}=0.27, c_{2}=0.43$, $c_{3}=0.62$.

\subsection{Fenômeno de Duplo Sudden-Change}

Para a realização deste experimento foi utilizada uma amostra de cristal líquido liotrópico contendo núcleos de ${ }^{23} \mathrm{Na}$. A amostra foi preparada no Instituto de Física de São Carlos conforme descrito na tese de doutorado de Ruben Auccaise (32). O experimento foi realizado à $23.5^{\circ} \mathrm{C}$ em um espectrômetro VARIAN INOVA - $8 \mathrm{~T}$ utilizando-se uma sonda de $5 \mathrm{~mm}$ para sólidos. A frequência quadrupolar $\left(\nu_{Q}\right)$ foi medida diretamente do espectro, sendo encontrado o valor de 10.4 kHz. Neste caso, a associação entre os níveis de energia e a base computacional é feita como na Figura 2.3 .

Através da técnica de SMP, iniciamos o experimento com a preparação dos estados iniciais apresentados na Figura [6.8, correspondentes à a) $c_{1}=0.89, c_{2}=0.14, c_{3}=0.39$ e b) $c_{1}=0.27, c_{2}=0.43, c_{3}=0.62$. Em seguida, aplicamos o mesmo procedimento ilustrado na Figura 6.1], sendo os períodos de evolução múltiplos da evolução quadrupolar. Ao final de cada período de evolução, aplicamos o procedimento de TEQ, com o intuito de observar a relaxação deste sistema.

A Figura $[6.9$ apresenta os resultados obtidos para a evolução temporal das medidas de 


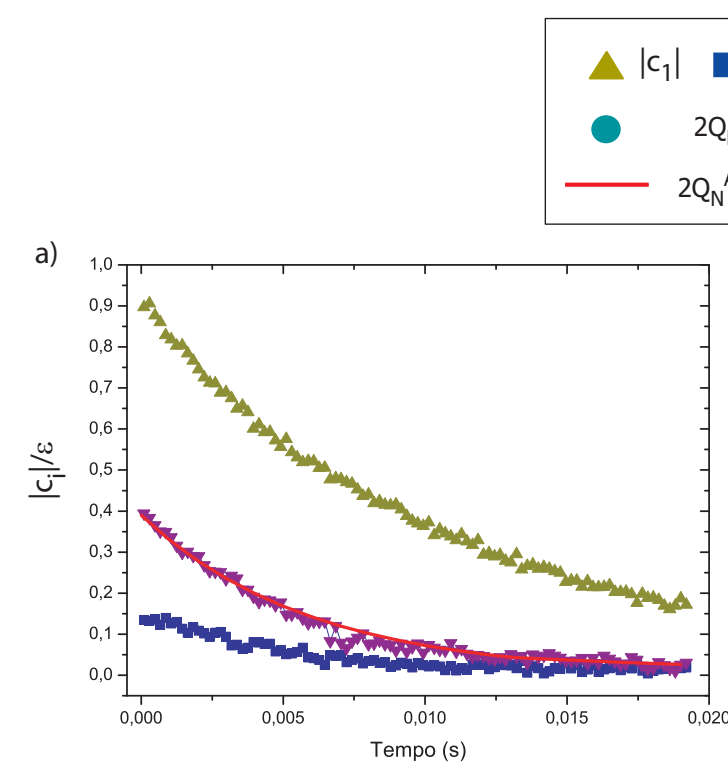

$c_{2}|\nabla| c_{3} \mid$

$2 \mathrm{Q}_{\mathrm{N}}^{\mathrm{A}}$ (Experimental)

$2 \mathrm{Q}_{\mathrm{N}}{ }^{\mathrm{A}}$ (Previsão Teórica)
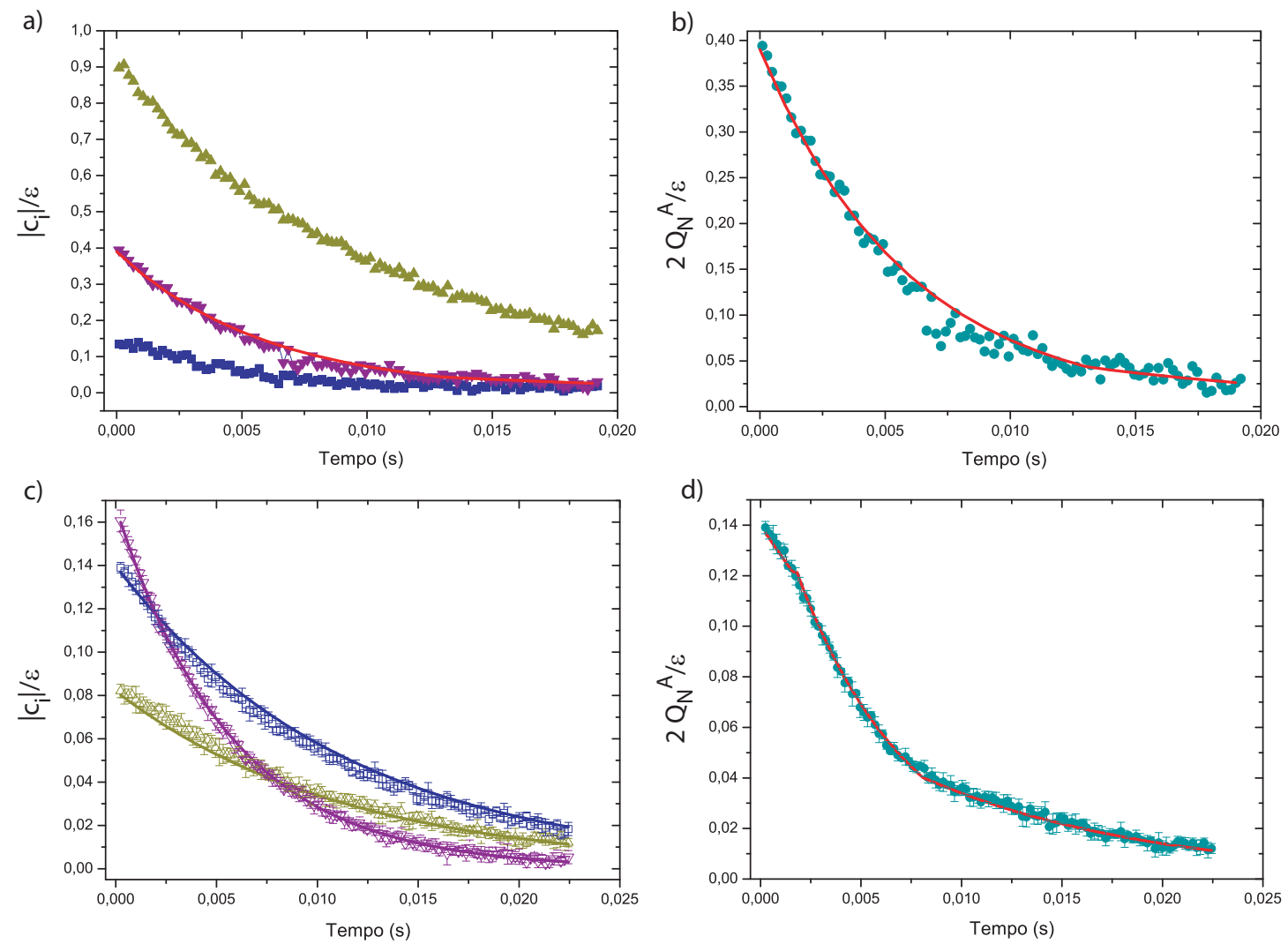

Figura 6.9 - a) Evolução temporal para os elementos da matriz de correlação $c_{1}$ (quadrado preto), $c_{2}$ (círculo verde) e $c_{3}$ (triângulo roxo) da matriz densidade Bell diagonal apresentada na Fig. 6.8, A linha vermelha em destaque representa a previsão teórica para o QnA. b) Os círculos verdes representam o valor de QnA experimental e a linha vermelha a previsão teórica. 
negatividade dos estados apresentados acima. Como, em ambos os casos, tratam-se de estados Bell diagonal, então podemos associar a completa relaxação do sistema ao canal de atenuação de amplitude generalizada. Para o estado da Figura 6.8-a, observa-se que nenhum efeito de sudden-change é observado (Figura 6.9 - a e b). Isto é justificado pelo fato de $c_{2}(0) \approx 0$ e $c_{3}(0)<c_{1}(0)$ e, de acordo com o que foi discutido na seção $5.3, c_{3}(0)$ decai mais rapidamente que $c_{1}(0)$, portanto, o cruzamento entre os elementos da matriz de correlação não ocorre.

Na Figura 6.9 - c observa-se a evolução temporal dos elementos da matriz de correlação $c_{1}, c_{2}, c_{3}$ do estado da Figura 6.8 - b, onde nota-se claramente o cruzamento das curvas, nos pontos correspondente à $4 \mathrm{~ms}$ e $10 \mathrm{~ms}$ (indicados por setas na figura). A linha vermelha em destaque corresponde à previsão teórica para a negatividade. Para esta simulação utilizamos a constante $C$ igual a $1.2 \times 10^{10} \mathrm{seg}^{-2}$ e as densidades espectrais como sendo $J_{0}=14 \times 10^{-9} \mathrm{seg}$, $J_{1}=3.5 \times 10^{-9} \mathrm{seg}$ e $J_{2}=3.5 \times 10^{-9} \mathrm{seg}$. Na Figura [6.9 - d apresentamos a comparação entre esta curva teórica e o resultado experimental para a curva de negatividade. Como a mudança de comportamento que desejamos observar é bastante discreta, até mesmo para a curva teórica, este experimento foi repetido por cinco vezes e assim, calculamos a média e desvio-padrão de cada um dos pontos, o que nos forneceu as barras de erro observadas nas Figuras 6.9 - c e d. Nos demais experimentos realizados nesta dissertação, não julgamos necessário aplicar este procedimento, visto que os fenômenos que desejávamos observar se apresentaram de forma bastante clara. 


\title{
Conclusões e Perspectivas
}

\author{
Do meu telescópio, eu via Deus \\ caminhar! A maravilhosa disposição e a \\ harmonia do Universo só podem ter tido \\ origem segundo o plano de um Ser que \\ tudo sabe e que tudo pode. Isto fica \\ sendo a minha última e mais elevada \\ descoberta. \\ Isaac Newton
}

O objetivo desta dissertação consistia em estudar a presença de correlações não-clássicas em sistemas biparticionados utilizando a técnica de Ressonânca Magnética Nuclear como ferramenta para a análise experimental. Estes sistemas nos permitiram desenvolver o trabalho em duas frentes distintas, descrevendo o sistema de q-bits a partir de um sistema de 2 spins $1 / 2$ acoplados via acoplamento $\mathrm{J}$ e através de um sistema de spin $3 / 2$ sujeito ao acoplamento quadrupolar, como consequência da presença de banhos de fase distintos em cada um destes sistemas.

Do ponto de vista do ferramentário de RMN necessário para se processar o estudo de informação quântica, introduzimos o método de medida direta. Este método constitui uma opção simples para substituir o processo de tomografia de estado quântico, nos casos em que não é necessário determinar completamente o estado em estudo. Dentre as vantagens deste novo método em relação ao TEQ, está o fato de que só é necessário realizar medidas sobre um dos q-bits. Além disso, os resultados obtidos correspondem diretamente aos dados desejados, não sendo necessário resolver sistemas numéricos de reconstrução, como no caso da TEQ. As Figuras 6.5 e 6.6 apresentam os resultados obtidos via medida direta e tomografia e com isto podemos observar a boa concordância entre eles.

Experimentalmente, apresentamos um exemplo da existência do fenômeno de freezing no sistema de 2 spins $1 / 2$ acoplados via acoplamento J, seção 6.2 e um exemplo do fenômeno de duplo sudden-change para o sistema de spin $3 / 2$, seção 6.3. Em ambos os casos, a 
previsão teórica apresentou-se de acordo com os resultados experimentais obtidos, como pode ser comprovado através da análise das Figuras 6.5, 6.6] e 6.9. Assim, fica claro como os diferentes processos de relaxação que afetam este sistemas podem ser explorados no estudo de informação quântica. Além disso, fica claro que nem sempre a analogia entre estes dois sistemas é direta, ou seja, nem sempre é possível descrever os mesmos fenômenos utilizando as duas descrições. Como por exemplo o fenômeno de freezing, que não pode ser observado utilizando-se o sistema de spins $3 / 2$.

Para o desenvolvimento dessas análises foi necessário estudar alguns dos vários quantificadores de discórdia, tais como a discórdia entrópica, geométrica e a medida de negatividade. Para cada um destes quantificadores, demos destaque para o cálculo em estados Bell diagonal, para os quais é possível obter formas analíticas simples de cálculo. Com isto, apresentamos as vantagens e desvantagens do uso de casa um destes quantificadores, a saber:

- Discórdia Entrópica, seção 4.1: apesar de permitir uma análise completa do sistema, em geral, envolve o uso de extremizações matemáticas e nem sempre nos permite compreender intuitivamente os fenômenos observados.

- Discórdia Geométrica, seções 4.2 apesar de fornecer uma maneira de cálculo e de medida simples, em sistemas de RMN, apresenta alguns problemas em sua definição como métrica. Ainda assim, pode ser utilizada como um limite inferior para a quantificação das correlações quânticas.

- Negatividade do Caráter Quântico, seção 4.3: corresponde a uma definição fisicamente abstrata, no entanto, para estados tipo Bell diagonal, isto se traduz matematicamente de forma simples, facilitando a observação dos fenômenos estudados.

Com isto, fica claro que os critérios que validam as medidas das correlações não-clássicas, além do emaranhamento, ainda estão sendo estabelecidos e necessitam ser validados matematicamente e fisicamente. Este trabalho pretendia contribuir neste sentido, apresentando uma revisão teórica sobre o assunto e apresentando alguns resultados experimentais que comprovam as teorias desenvolvidas até aqui.

Neste contexto, vale ressaltar que nas medidas da relaxação para os diferentes quantificadores observamos comportamentos ligeiramente diferentes para o estado de freezing, o que levanta a questão da universalidade deste fenômeno. Recentemente, Aaronson, Franco e Adesso (64) apresentaram condições sobre os estados iniciais para a universalidade deste fenômeno em relação às medidas dos mais variados quantificadores. Pretendemos, então, comprovar experimentalmente estas condições através da aplicação do método de direta. No 
caso do fenômeno de duplo sudden-change, apenas pudemos observá-lo para o caso de medidas de negatividade. Por esta razão, utilizando a idéia aplicada para o cálculo da universalidade do freezing, pretendemos estudar condições em que o duplo sudden-change também seja universal sobre medidas de diferentes quantificadores, validando-se, assim, sua existência física. 


\section{REFERÊNCIAS}

1 KNILL, E.; LAFLAMME, R. Power of one bit of quantum information. Physical Review Letters, v. 81, n. 25, p. 5672-5675, 1998.

2 HENDERSON, L.; VEDRAL, V. Classical, quantum and total correlations. Journal of Physics A: mathematical and general, v. 34, n. 35, p. 6899-6905, 2001.

3 OLLIVIER, H; ZUREK, W. Quantum discord: a measure of the quantumness of correlations. Physical Review Letters, v. 88, n. 1, p. 017901-1-017901-4, 2002.

4 NAKANO, T.; PIANI, M.; ADESSO, G. Negativity of quantumness and its interpretations. Disponível em: 〈arXiv:1211.4022v2〉, Acesso em: 11/06/2013.

5 MODI, K.; BRODUTCH, A.; CABLE, H.; PATEREK, T.; VEDRAL, V. The classicalquantum boundary for correlations: discord and related measures. Review of Modern Physics, v. 84, n. 4, p. 1655-1707, 2012.

6 LEVITT, M. H. Spin dynamics: basis of nuclear magnetic resonance. Chichester: John Wiley \& Sons, 2008.

7 OLIVEIRA, I. S.; BONAGAMBA, T. J.; SARTHOUR, R. S.; FREITAS, J. C. C.; DEAZEVEDO, E. R. Nmr quantum information processing. Oxford: Elsevier, 2007.

8 SLICHTER, C. P. Principles of magnetic resonance. New York: Springer, 1989.

9 COHEN-TANOUDJI, C. Quantum mechanics. New York: John Wiley \& Sons, 1977.

10 NIELSEN, M. A.; CHUANG, I. L. Quantum computation and quantum information. Cambridge: Cambridge University Press, 2000.

11 BONK, F.; DEAZEVEDO, E.; SARTHOUR, R.; BULNES, J.; FREITAS, J.; GUIMARAES, A.; OLIVEIRA, I.; BONAGAMBA, T. Quantum logical operations for spin 3/2 quadrupolar nuclei monitored by quantum state tomography. Journal of Magnetic Resonance, v. 175, n. 2, p. 226-234, 2005.

12 WOKAUN, A.; ERNST, R. Selective excitation and detection in multilevel spin systems: application of single transition operators. Journal of Chemical Physics, v. 67, n. 4, p. 17521758, 1977. 
13 BALIAN, R. From microphysics to macrophysics: methods and applications of statistical physics. New York: Springer, 1991.

14 PINTO, D. O. S. Emaranhamento térmico e simulações quânticas de sistemas magnéticos por ressonância magnética nuclear. 2009. p. 122. Tese (Doutorado em Física) - Centro Brasileiro de Pesquisas Físicas, Rio de Janeiro, 2009.

15 LEVITT, M. The signs of frequencies and phases in nmr. Journal of Magnetic Resonance, v. 126, n. 2, p. 164-182, 1997.

16 ABRAgAM, A. Principles of nuclear magnetism. New York: Oxford Science Publications, 1994.

17 SOARES-PINTO, D. O.; MOUSSA, M. H. Y.; MAZIERO, J.; DEAZEVEDO, E. R.; BONAGAMBA, T. J.; SERRA, R. M.; CÉLERI, L. C. Equivalence between redfield and master-equation approaches for a time-dependent quantum system and coherence control. Physical Review A, v. 83, n. 6, p. 062336-1-062336-11, 2011.

18 HUANG, P.; ZHU, J.; QI, X. X.; HE, G. Q.; ZENG, G. H. Different dynamics of classical and quantum correlations under decoherence. Quantum Information Processing, v. 11, n. 6, p. 1845-1865, 2012.

19 MAZIERO, J.; WERLANG, T.; FANCHINI, F.; CELERI, L.; SERRA, R. System-reservoir dynamics of quantum and classical correlations. Physical Review A, v. 81, n. 2, p. 022116-1022116-13, 2010.

20 AUCCAISE, R.; TELES, J.; SARTHOUR, R. S.; BONAGAMBA, T. J.; OLIVEIRA, I. S.; DEAZEVEDO, E. R. A study of the relaxation dynamics in a quadrupolar $\mathrm{nmr}$ system using quantum state tomography. Journal of Magnetic Resonance, v. 192, n. 1, p. 17-26, 2008.

21 JACCARD, G.; WIMPERIS, S.; BODENHAUSEN, G. Multiplequantum nmr spectroscopy of $s=3 / 2$ spins in isotropic phase: a new probe for multiexponential relaxation. Journal of Chemical Physics, v. 85, n. 11, p. 6282-6293, 1986.

22 SOUZA, A. M.; GAVINI-VIANA, A.; OLIVERIA, I. S.; SARTHOR, R. S.; AUCCAISE, R.; DEAZEVEDO, E. R.; BONAGAMBA, T. J. Nuclear spin 3/2 eletric quadrupole relaxation as a quantum computation process. Quantum Information Computation, v. 10, n. 7-8, p. 653-668, 2010.

23 DIVINCENZO, D. The physical implementation of quantum computation. Fortschritte Der Physik - Progress of Physics, v. 48, n. 9-11, p. 771-783, 2000.

24 LADD, T.; JELEZKO, F.; LAFLAMME, R.; NAKAMURA, Y.; MONROE, C.; O'BRIEN, J. Quantum computers. Nature, v. 464, n. 7285, p. 45-53, 2010. 
25 GERSHENFELD, N.; CHUANG, I. Bulk spin-resonance quantum computation. Science, v. 275, n. 5298, p. $350-356,1997$.

26 CORY, D.; FAHMY, A.; HAVEL, T. Ensemble quantum computing by nmr spectroscopy. Proceedings of the National Academy of Sciences USA, v. 94, n. 5, p. 1634-1639, 1997.

27 DE CARVALHO NETO, J. T. Tomografia de estado quântico via ressonância magnética nuclear através de rotações globais do sistema de spins. 2007. p. 170. Tese (Doutorado em Física) - Instituto de Física de São Carlos, Universidade de São Paulo, São Carlos, 2007.

28 KNILL, E.; CHUANG, I.; LAFLAMME, R. Effective pure states for bulk quantum computation. Physical Review A, v. 57, n. 5, p. 3348-3363, 1998.

29 FORTUNATO, E.; PRAVIA, M.; BOULANT, N.; TEKLEMARIAM, G.; HAVEL, T.; CORY, D. Design of strongly modulating pulses to implement precise effective hamiltonians for quantum information processing. Journal of Chemical Physics, v. 116, n. 17, p. 7599-7606, 2002.

30 NELDER, J.A.; MEAD, R. A simplex-method for function minimization. Computer Journal, v. 7, n. 4, p. 308-313, 1965.

31 DE ARAÚJO FERREIRA, A. G. Utilização de pulsos de radiofrequência fortemente modulados no processamento de informação quântica via ressonância magnética nuclear. 2009. p. 132. Dissertação (Mestrado em Física) - Instituto de Física de São Carlos, Universidade de São Paulo, São Carlos, 2009.

32 AUCCAISE, R. Estudo de processos quânticos através da ressonância magnética nuclear em sistemas quadrupolares. 2008. p. 195. Tese (Doutorado em Física) - Centro Brasileiro de Pesquisas Físicas, Rio de Janeiro, 2008.

33 BONK, F. A. Tomografia de estados quânticos em sistemas de núcleos quadrupolares em spin 3/2: uma aplicação da ressonância magnética nuclear à computação quântica. 2005. p. 117. Tese (Doutorado em Física) - Instituto de Física de São Carlos, Universidade de São Paulo, São Carlos, 2005.

34 BRAUNSTEIN, S.; CAVES, C.; JOZSA, R.; LINDEN, N.; POPESCU, S.; SCHACK, R. Separability of very noisy mixed states and implications for nmr quantum computing. Physical Review Letters, v. 83, n. 5, p. 1054-1057, 1999.

35 GROISMAN, B.; POPESCU, S.; WINTER, A. Quantum, classical, and total amount of correlations in a quantum state. Physical Review A, v. 72, n. 3, p. 032317-1-032317-11, 2005.

36 SOARES-PINTO, D. O.; CELERI, L. C.; AUCCAISE, R.; FANCHINI, F. F.; DEAZEVEDO, E. R.; MAZIERO, J.; BONAGAMBA, T. J.; SERRA, R. M. Nonclassical correlation in nmr quadrupolar systems. Physical Review A, v. 81, n. 6, p. 062118-1-062118-9, 2010. 
37 VEDRAL, V. The elusive source of quantum speedup. Foundations of Physics, v. 40, n. 8, p. 1141-1154, 2010.

38 DIVINCENZO, D.; HORODECKI, M.; LEUNG, D.; SMOLIN, J.; TERHAL, B. Locking classical correlations in quantum states. Physical Review Letters, v. 92, n. 6, p. 067902-1067902-4, 2004.

39 MODI, K.; PATEREK, T.; SON, W.; VEDRAL, V.; WILLIAMSON, M. Unified view of quantum and classical correlations. Physical Review Letters, v. 104, n. 8, p. 080501-1080501-4, 2010.

40 DAKIĆ, B.; VEDRAL, V.; BRUKNER, C. Necessary and sufficient condition for nonzero quantum discord. Physical Review Letters, v. 105, n. 19, p. 190502-1-190502-4, 2010.

41 GIROLAMI, D.; ADESSO, G. Observable measure of bipartite quantum correlations. Physical Review Letters, v. 108, n. 15, p. 150403-1-150403-6, 2012.

42 LUO, S.; FU, S. Geometric measure of quantum discord. Physical Review A, v. 82, n. 3, p. 034302-1-034302-4, 2010.

43 PIANI, M. Problem with geometric discord. Physical Review A, v. 86, n. 3, p. 0341011-034101-3, 2012.

44 PIANI, M.; HORODECKI, P.; HORODECKI, R. No-local-broadcasting theorem for multipartite quantum correlations. Physical Review Letters, v. 100, n. 9, p. 090502-1-090502-4, 2008.

45 STRELTSOV, A.; KAMPERMANN, H.; BRUB, D. Linking quantum discord to entanglement in a measurement. Physical Review Letters, v. 106, n. 16, p. 160401-1-160401-4, 2011.

46 PASSANTE, G.; MOUSSA, O.; LAFLAMME, R. Meansuring geometric quantum discord using one bit of quantum information. Physical Review A, v. 85, n. 3, p. 032325-1-032325-5, 2012.

47 BROWN, E.; CORMIER, K.; MARTÍN-MARTÍNEZ, E.; MANN, R. Vanishing geometric discord in noninertial frames. Physical Review A, v. 86, n. 3, p. 032108-1-032108-9, 2012.

48 TUFARELLI, T.; MACLEAN, T.; GIROLAMI, D.; VASILE, R.; ADESSO, G. The geometric approach to quantum correlations: computability versus reliability. Disponível em: $\langle$ arXiv:1301.3526v1〉, Acesso em: 11/06/2013.

49 PIANI, M.; GHARIBIAN, S.; ADESSO, G.; CALSAMIGLIA, J.; HORODECKI, P.; WINTER, A. All nonclassical correlations can be activated into distillable entanglement. Physical Review Letters, v. 106, n. 22, p. 220403-1-220403-4, 2011. 
50 VIDAL, G.; WERNER, R. F. Computable measure of entanglement. Physical Review A, v. 65, n. 3, p. 032314-1-032314-11, 2002.

51 PERES, A. Separability criterion for density matrices. Physical Review Letters, v. 77, n. 8, p. 1413-1415, 1996.

52 MONTEALEGRE, J.; PAULA, F. M.; SAGUIA, A.; SARANDY, M. One-norm geometric quantum discord under decoherence. Physical Review A, v. 87, n. 4, p. 042115-1-042115-6, 2013.

53 PAULA, F.; DEOLIVEIRA, T.; SARANDY, M. Geometric quantum discord through the schatten 1-norm. Physical Review A, v. 87, n. 6, p. 064101-1-064101-4, 2013.

54 MAZZOLA, L.; PIILO, J.; MANISCALCO, S. Sudden transition between classical and quantum decoherence. Physical Review Letters, v. 104, n. 20, p. 200401-1-200401-4, 2010.

55 MAZIERO, J.; CELERI, L. C.; SERRA, R. M.; VEDRAL, V. Classical and quantum correlations under decoherence. Physical Review A, v. 80, n. 4, p. 044102-1-044102-4, 2009.

56 AUCCAISE, R.; CELERI, L. C.; SOARES-PINTO, D.; DEAZEVEDO, E.; MAZIERO, J.; SOUZA, A.; BONAGAMBA, T.; SARTHOUR, R.; OLIVEIRA, I.; SERRA, R. M. Environmentinduced sudden transition in quantum discord dynamics. Physical Review Letters, v. 107, n. 14, p. 140403-1-140403-5, 2011.

57 MAZZOLA, L.; PIILO, J.; MANISCALCO, S. Frozen discord in non-markovian dephasing channels. International Journal Quantum Information, v. 9, n. 3, p. 981-991, 2011.

58 YOU, B.; CEN, L.-X. Necessary and sufficient conditions for the freezing phenomena of quantum discord under phase damping. Physical Review A, v. 86, n. 1, p. 012102-1-012102-5, 2012.

59 SARANDY, M. Classical correlation and quantum discord in critical systems. Physical Review A, v. 80, n. 2, p. 022108-1-022108-9, 2009.

60 PAL, A.; BOSE, I. Markovian evolution of classical and quantum correlations in transversefield xy model. European Physical Journal B, v. 85, n. 8, p. 277-1-277-11, 2012.

61 BOSE, I.; PAL, A. Quantum discord, decoherence and quantum phase transition. International Journal of Modern Physics B, v. 27, n. 1-3, p. 1345042-1-1345042-20, 2013.

62 CORNELIO, M.; JIMENEZ-FARIAS, O.; FANCHINI, F.; FREROT, I.; AGUILAR, G.; HOR-MEYLL, M.; DEOLIVEIRA, M.; WALBORN, S.; CALDEIRA, A.; SOUTO-RIBEIRO, P. Emergence of the pointer basis through the dynamics of correlations. Physical Review Letters, v. 109, n. 19, p. 190402-1-190402-5, 2012. 
63 LUO, S. Quantum discord for two-qubit systems. Physical Review A, v. 77, n. 4, p. 042303-1-042303-6, 2008.

64 AARONSON, B.; FRANCO, R. L.; ADESSO, G. Freezing of quantum correlations under nondissipative decoherence is universal. Disponível em: 〈arxiv:1304.1163v1〉, Acesso em: $11 / 06 / 2013$.

65 SORENSEN, O.; EICH, G.; LEVITT, M.; BODENHAUSEN, G.; ERNST, R. Product operator-formalism for the description of nmr pulse experiments. Progress in Nuclear Magnetic Resonance Spectroscopy, v. 16, n. 0, p. 163-192, 1983.

66 SOARES-PINTO, D.; AUCCAISE, R.; MAZIERO, J.; GAVINI-VIANA, A.; SERRA, R.; CELERI, L. On the quantumness of correlations in nuclear magnetic resonance. Philosophical Transactions of the Royal Society A, v. 370, n. 1976, p. 4821-4836, 2012.

67 MAZIERO, J.; AUCCAISE, R.; CELERI, L.; SOARES-PINTO, D.; DEAZEVEDO, E.; BONAGAMBA, T.; SARTHOUR, R.; OLIVEIRA, I.; SERRA, R. Quantum discord in nuclear magnetic resonance systems at room temperature. Brazilian Journal of Physics, v. 43, n. 1-2, p. 86-104, 2013. 